Prepared in cooperation with the U.S. Army Corps of Engineers, Chicago District

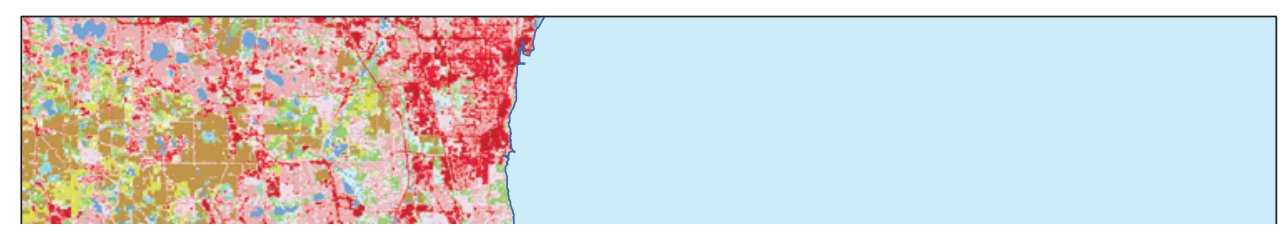

\title{
Analysis of Regional Rainfall-Runoff Parameters for the Lake Michigan Diversion Hydrological Modeling
}

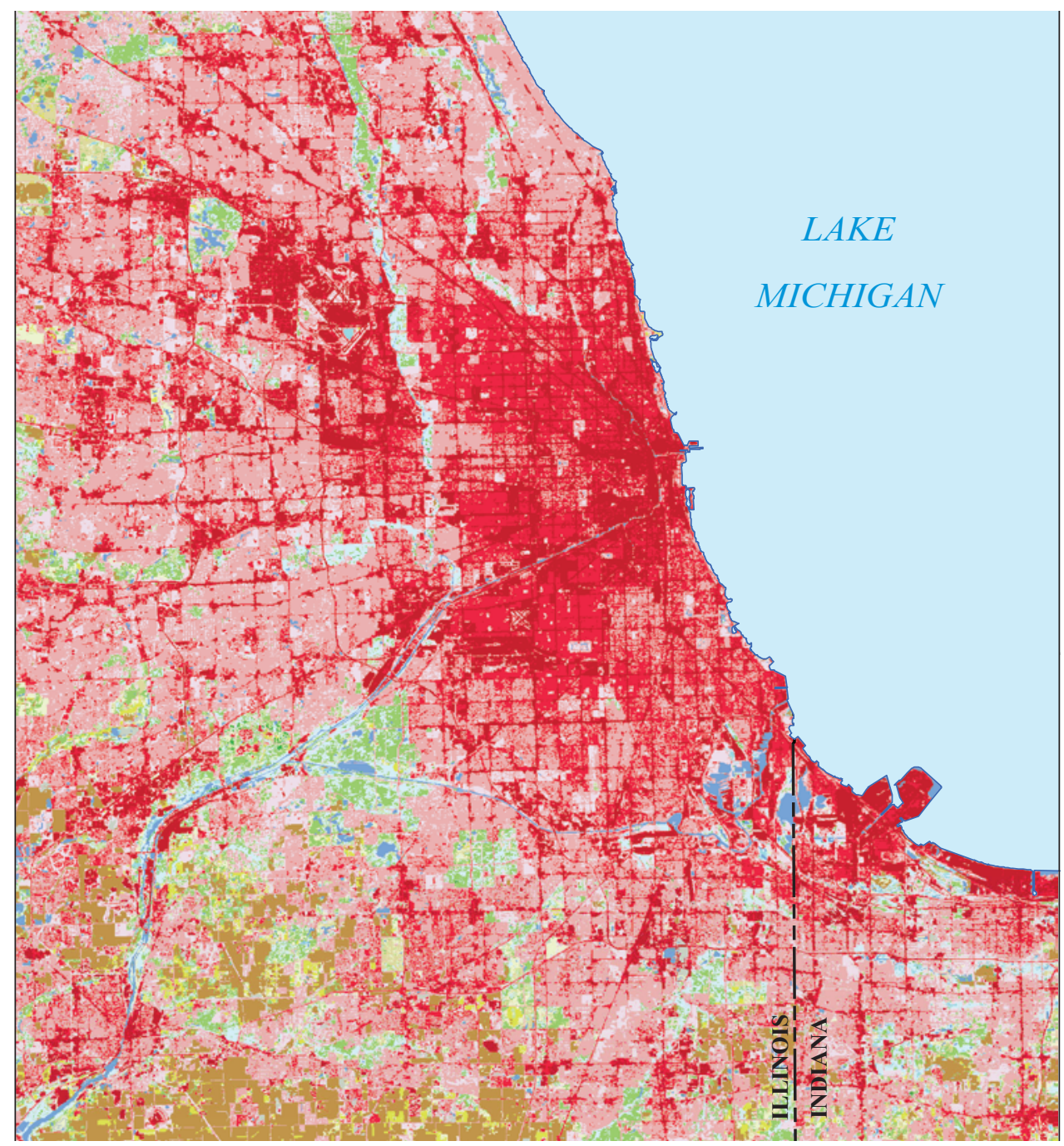

Scientific Investigations Report 2015-5053

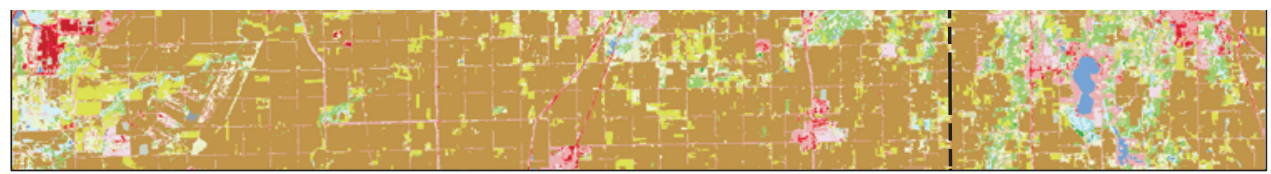

U.S. Department of the Interior

U.S. Geological Survey 
Cover: The image, also shown in figure 1, shows the National Land Cover Database, 2006. (http://www.mrlc.gov/nlcd2006.php) 


\section{Analysis of Regional Rainfall-Runoff Parameters for the Lake Michigan Diversion Hydrological Modeling}

By David T. Soong and Thomas M. Over

Prepared in cooperation with the U.S. Army Corps of Engineers, Chicago District

Scientific Investigations Report 2015-5053 


\title{
U.S. Department of the Interior SALLY JEWELL, Secretary
}

\section{U.S. Geological Survey Suzette M. Kimball, Acting Director}

\author{
U.S. Geological Survey, Reston, Virginia: 2015
}

For more information on the USGS - the Federal source for science about the Earth, its natural and living resources, natural hazards, and the environment—visit http://www.usgs.gov or call 1-888-ASK-USGS.

For an overview of USGS information products, including maps, imagery, and publications, visit http://www.usgs.gov/pubprod/.

Any use of trade, firm, or product names is for descriptive purposes only and does not imply endorsement by the U.S. Government.

Although this information product, for the most part, is in the public domain, it also may contain copyrighted materials as noted in the text. Permission to reproduce copyrighted items must be secured from the copyright owner.

Suggested citation:

Soong, D.T., and Over, T.M., 2015, Analysis of regional rainfall-runoff parameters for the Lake Michigan Diversion hydrological modeling: U.S. Geological Survey Scientific Investigations Report 2015-5053, 55 p., http://dx.doi. org/10.3133/sir20155053.

ISSN 2328-0328 (online) 


\section{Contents}

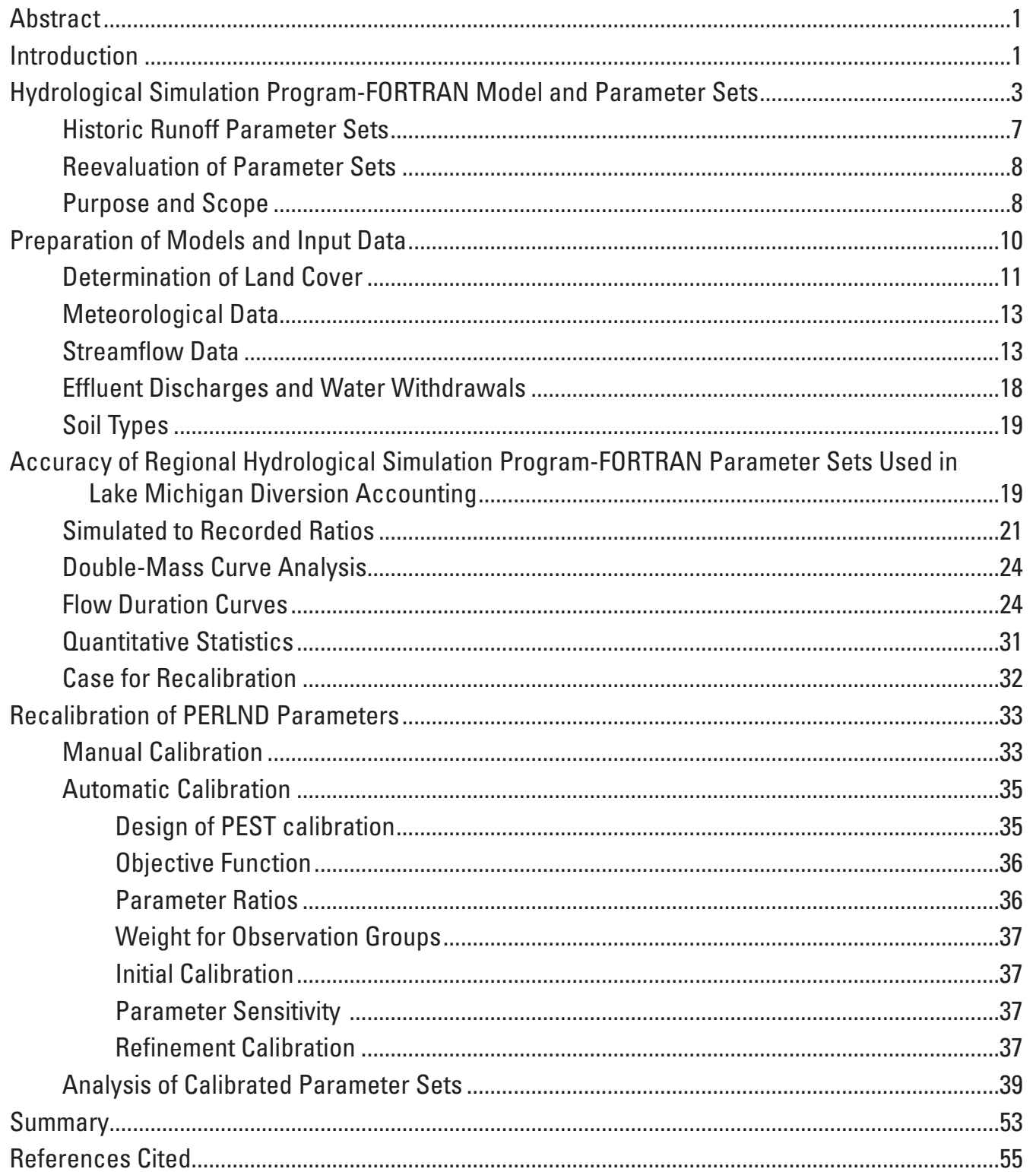

\section{Figures}

1. Map showing study area, including locations of nine watersheds selected for testing model parameters, the diverted Lake Michigan watershed, meteorological and precipitation stations, and the land-use/land-cover classes based on 2006 National Land Cover Database...

2. Diagram showing Hydrological Simulation Program-FORTRAN (HSPF) flowchart for hydrologic process for pervious land segment 
3. Graph showing normalized monthly streamflow volume and total monthly precipitation for the nine study watersheds for the period from October 1, 1995, to September 30, 2011. The red line is the average of normalized monthly streamflow volume of the nine watersheds over the study period.

4. Graph showing normalized annual streamflow volume and total monthly precipitation for the nine study watersheds for the period from October 1, 1995, to September 30, 2011. The red line is the average of normalized annual streamflow volume of the nine watersheds over the study period.

5. Graph showing flow duration curves based on mean-daily discharge between water years 1996 and 2011 for the nine study watersheds..

6. Map showing SCS hydrologic soil groups for Cook County and the nine study watersheds.

7. Graphs showing double-mass curves of observed streamflow and simulated runoff volume for the nine study watersheds using the North Branch parameter set for water years 1996 to 2011

8. Graphs showing double-mass curves of observed streamflow and simulated runoff volume for the nine study watersheds using the 1999 parameter set for water years 1996 to 2011

9. Graphs showing double-mass curves of observed streamflow and simulated runoff volume for the nine study watersheds using the 2008 parameter set for water years 1996 to 2011

10. Graphs showing flow-duration curves of observed streamflow and simulated runoff volume for the nine study watersheds using the North Branch parameter set for water years 1996 to 2011

11. Graphs showing flow-duration curves of observed streamflow and simulated runoff volume for the nine study watersheds using the 1999 parameter set for the water years 1996 to 2011 .

12. Graphs showing flow-duration curves of observed streamflow and simulated runoff volume for the nine study watersheds using the 2008 parameter set for water years 1996 to 2011

13. Graphs showing double-mass curves of observed streamflow and simulated runoff volumes for the nine study watersheds using calibrated parameter set obtained from the HSPEXP Tinley Creek watershed model for water years 1996 to 2011

14. Graphs showing double-mass curves of observed streamflow and simulated runoff volumes for the nine study watersheds using calibrated parameter set obtained from the HSPEXP Long Run watershed model for water years 1996 to 2011.

15. Graphs showing double-mass curves of observed streamflow and simulated runoff volumes for the nine study watersheds using calibrated parameter set obtained from the PEST Tinley Creek watershed model for water years 1996 to 2011.

16. Graphs showing double-mass curves of observed streamflow and simulated runoff volumes for the nine study watersheds using calibrated parameter set obtained from the PEST Long Run watershed model for water years 1996 to 2011.

17. Graphs showing double-mass curves of observed streamflow and simulated runoff volumes for the nine study watersheds using calibrated parameter set obtained from the PEST two-watershed model for water years 1996 to 2011 


\section{Tables}

1. Rainfall-runoff parameters used in the Hydrological Simulation Program-FORTRAN program and their effects on various components of the water budget.

2. Historic rainfall-runoff parameters and values for grassland in the Hydrological Simulation Program-FORTRAN program used in the diversion accounting system. Data adapted from U.S. Army Corps of Engineers, Chicago District (2004), and expanded to include Consoer Townsend EnviroDyne Engineers parameter set...............8

3. Historic rainfall-runoff parameter values for forestland in the Hydrological Simulation Program-FORTRAN program used in the diversion accounting system .........9

4. Historical rainfall-runoff parameter values for impervious land in the Hydrological Simulation Program-FORTRAN program used in the diversion accounting system. Data adapted from U.S. Army Corps of Engineers, Chicago District (2004).

5. Background information for the selected watersheds

6. Percentages of the Lake Michigan Diversion Accounting land-cover categories including forestland, grassland, and hydraulically connected impervious lands for the study watersheds and their counterpart land-cover classes according to the 2006 National Land Cover Database.

7. Matrix for conversion of National Land Cover Database land-cover classes to Lake Michigan Diversion Accounting land-cover types

8. Comparison of percentages of grassland, forestland, and hydraulically connected impervious land determined by 2005 aerial photographs and conversion of 2006 National Land Cover Database land-use categories.

9. Modeled land-cover classes determined from National Land Cover Database 1992, 2001, and 2006 datasets for nine selected watersheds.

10. The maximum discharge, mean discharge, minimum discharge, and standard deviation determined from the mean daily discharge record for the nine study watersheds, October 1, 1995, to September 30, 2011

11. Effluent discharge data in the study area during 1998 to 2012 .......................................18

12. Recommended statistical tests and ratings for evaluation of model-simulation performance

13. Ratio of simulated runoff to recorded streamflow volume for annual and total flow volumes between water years 1996 and 2011 for nine study watersheds with the six parameter sets

14. Statistics of the mean monthly runoff volume at nine study watersheds simulated by the existing parameter sets for the period from October 1, 1995, to September 30, 2011

15. Parameter values and calibration results for the manual calibration of Tinley Creek and Long Run watershed models.

16. Observation group to parameter sensitivity relations obtained from the initial Tier-3 analysis in PEST Tinley Creek and PEST Long Run watershed models.

17. Grassland and forestland parameters obtained from HSPEXP and PEST calibrations.

18. Comparison of basic flow statistics and fraction of base flow volume derived from measured daily flows and simulated daily runoff time series derived with the HSPEXP and PEST calibration parameters for the calibration period between October 1, 2000, and September 30, 2009.

19. Quantitative statistics of PBIAS, NSE, and RSR for the calibration and verification periods for parameters obtained from HSPEXP and PEST calibrations. 
20. Ratio of simulated annual runoff volume to recorded annual streamflow volume determined from HSPEXP and PEST calibrations at the nine study watersheds for water years 1996 to 2011

21. Quantitative statistics of PBIAS, NSE, RSR for the study periods, water years 1996 to 2011, for the North Branch parameter set and PEST two-watershed parameter set

22. Calibrated parameter values of grassland and forestland for the nine study watersheds with description of the sources for estimating the parameter values

\section{Conversion Factors}

Inch/Pound to International System of Units

\begin{tabular}{lcl}
\hline \multicolumn{1}{c}{ Multiply } & By & \multicolumn{1}{c}{ To obtain } \\
\hline inch (in.) & Length & \\
foot (ft) & 25.4 & millimeter $(\mathrm{mm})$ \\
mile (mi) & 0.3048 & meter $(\mathrm{m})$ \\
yard (yd) & 1.609 & kilometer $(\mathrm{km})$ \\
\hline & 0.9144 & meter $(\mathrm{m})$ \\
\hline acre & Area & \\
square mile $\left(\mathrm{mi}^{2}\right)$ & 4,047 & square meter $\left(\mathrm{m}^{2}\right)$ \\
\hline & 2.590 & square kilometer $\left(\mathrm{km}^{2}\right)$ \\
\hline cubic foot $\left(\mathrm{ft}^{3}\right)$ & Volume & \\
acre-foot $\left(\right.$ acre- $\left.\mathrm{ft}^{2}\right)$ & 0.02832 & cubic meter $\left(\mathrm{m}^{3}\right)$ \\
\hline & 1,233 & cubic meter $\left(\mathrm{m}^{3}\right)$ \\
\hline cubic foot per second $\left(\mathrm{ft}^{3} / \mathrm{s}\right)$ & Flow rate & \\
cubic foot per second $\left(\mathrm{ft}^{3} / \mathrm{s}\right)$ & 0.02832 & cubic meter $\mathrm{per} \mathrm{second}\left(\mathrm{m}^{3} / \mathrm{s}\right)$ \\
cubic foot per second $\mathrm{per}^{2}$ & 1.983 & acre-feet $/$ day \\
square mile $\left[\left(\mathrm{ft}^{3} / \mathrm{s}\right) / \mathrm{mi}^{2}\right]$ & 0.01093 & cubic meter per second per \\
\hline
\end{tabular}

Temperature in degrees Celsius $\left({ }^{\circ} \mathrm{C}\right)$ may be converted to degrees Fahrenheit $\left({ }^{\circ} \mathrm{F}\right)$ as follows: ${ }^{\circ} \mathrm{F}=\left(1.8 \mathrm{x}^{\circ} \mathrm{C}\right)+32$

Temperature in degrees Fahrenheit $\left({ }^{\circ} \mathrm{F}\right)$ may be converted to degrees Celsius $\left({ }^{\circ} \mathrm{C}\right)$ as follows: ${ }^{\circ} \mathrm{C}=\left({ }^{\circ} \mathrm{F}-32\right) / 1.8$

Vertical coordinate information is referenced to the North American Vertical Datum of 1988 (NAVD 88).

Horizontal coordinate information is referenced to the North American Datum of 1983 (NAD 83).

A water year is the 12-month period from 0ctober 1 through September 30 and is designated by the calendar year in which it ends and includes 9 of 12 months. For example, WY 2014 is from October 1, 2013, to September 30, 2014. 


\section{Acknowledgments}

Tzuoh-Ying Su, U.S. Army Corps of Engineers, Chicago District, provided valuable coordination and technical support throughout the project. Nancy Westcott, Atmospheric Science Section of the Illinois State Water Survey, Prairie Research Institute, University of Illinois at UrbanaChampaign, provided information about the 25-raingage network. Tracey Larmon of Flagg Creek Water Reclamation District provided effluent discharge data for the Hinsdale sewage treatment plant. Carey A. Johnston, U.S. Environmental Protection Agency Office of Compliance and staff at the Illinois Environmental Protection Agency assisted in the retrieval of effluent discharge data from facilities in the study area. John Doherty, developer of PEST program, kindly responded to questions regarding the approaches used in the study.

Tamara I. Ivanhenko of U.S. Geological Survey (USGS) provided initial effluent data retrieved from the Permit Compliance System (PCS) of the U.S. Environmental Protection Agency (EPA) in the study region. USGS colleagues also assisted in various components of the study: Andrew Reinhard and Rachel Egly assisted in data processing and analysis, model preparation, and figure preparations; Katherine R. Merriman-Hoehne helped update the effluent data from the PCS of the EPA and assisted in manual model calibration; and Jennifer B. Sharpe prepared the preliminary illustrations. Suggestions provided by USGS colleagues Darwin J. Ockerman and James J. Duncker greatly improved the report. 



\title{
Analysis of Regional Rainfall-Runoff Parameters for the Lake Michigan Diversion Hydrological Modeling
}

\author{
By David T. Soong and Thomas M. Over
}

\section{Abstract}

The Lake Michigan Diversion Accounting (LMDA) system has been developed by the U.S. Army Corps of Engineers, Chicago District (USACE-Chicago) and the State of Illinois as a part of the interstate Great Lakes water regulatory program. The diverted Lake Michigan watershed is a 673-square-mile watershed that is comprised of the Chicago River and Calumet River watersheds. They originally drained into Lake Michigan, but now flow to the Mississippi River watershed via three canals constructed in the Chicago area in the early twentieth century. Approximately 393 square miles of the diverted watershed is ungaged, and the runoff from the ungaged portion of the diverted watershed has been estimated by the USACE-Chicago using the Hydrological Simulation Program-FORTRAN (HSPF) program. The accuracy of simulated runoff depends on the accuracy of the parameter set used in the HSPF program. Nine parameter sets comprised of the North Branch, Little Calumet, Des Plaines, Hickory Creek, CSSC, NIPC, 1999, CTE, and 2008 have been developed at different time periods and used by the USACE-Chicago. In this study, the U.S. Geological Survey and the USACEChicago collaboratively analyzed the parameter sets using nine gaged watersheds in or adjacent to the diverted watershed to assess the predictive accuracies of selected parameter sets. Six of the parameter sets, comprising North Branch, Hickory Creek, NIPC, 1999, CTE, and 2008, were applied to the nine gaged watersheds for evaluating their simulation accuracy from water years 1996 to 2011. The nine gaged watersheds were modeled by using the three LMDA land-cover types (grass, forest, and hydraulically connected imperviousness) based on the 2006 National Land Cover Database, and the latest meteorological and precipitation data consistent with the current (2014) LMDA modeling framework.

Results indicate that the North Branch and Hickory Creek parameter sets, which belong to the original calibration group, attained an overall "satisfactory" rating on monthly runoff volumes based on the three performance statistics selected, but the annual and over-the-period runoff volumes were generally underestimated. Parameter sets CTE and 2008 attained a similar satisfactory rating on monthly runoff volumes but the annual and over-the-period runoff volumes were overestimated in general. Although the percent bias was improved, the CTE and 2008 parameter sets also had increased residuals in monthly runoff volumes and decreased quality of the model fit to the measured streamflows relative to the North Branch and Hickory Creek parameter sets. The NIPC and 1999 parameter sets, on the other hand, had larger percent bias and residuals in monthly runoff volumes, and underestimated the annual and over-the-period runoff volumes.

Recalibration of the HSPF parameters to the updated inputs and land covers was completed on two representative watershed models selected from the nine by using a manual method (HSPEXP) and an automatic method (PEST). The objective of the recalibration was to develop a regional parameter set that improves the accuracy in runoff volume prediction for the nine study watersheds. Knowledge about flow and watershed characteristics plays a vital role for validating the calibration in both manual and automatic methods. The best performing parameter set was determined by the automatic calibration method on a two-watershed model. Applying this newly determined parameter set to the nine watersheds for runoff volume simulation resulted in "very good" ratings in five watersheds, an improvement as compared to "very good" ratings achieved for three watersheds by the North Branch parameter set.

\section{Introduction}

Illinois' Lake Michigan Diversion is made up of three components, domestic water supply, direct diversion, and storm water runoff (Illinois Department of Natural Resources, Office of Water Resources, http://www.dnr.illinois.gov/ WaterResources/Pages/LakeMichiganWaterAllocation.aspx, accessed March 23, 2015). The diverted Lake Michigan watershed (figure 1, hereafter diverted watershed) is a 673-squaremile watershed that is comprised of the Chicago River and Calumet River watersheds. Flows from the two rivers which originally drained into Lake Michigan now are diverted to the Mississippi River watershed via three canals constructed in the Chicago area in the early twentieth century. In response to a 1967 Supreme Court Decree amended in 1980, a Lake 


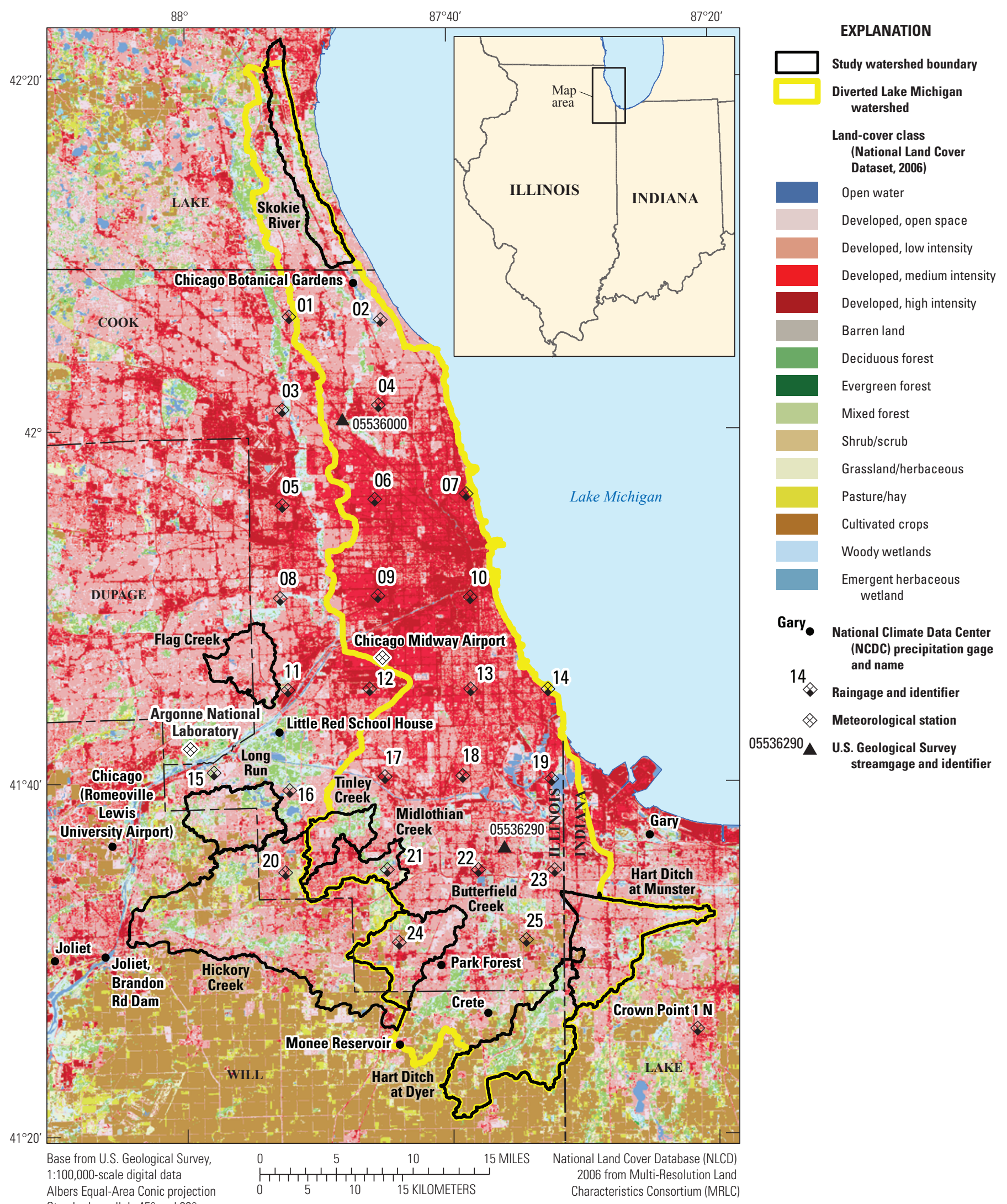

Albers Equal-Area Conic projection

central meridian $-89^{\circ}$

Figure 1. Study area, including locations of nine watersheds selected for testing model parameters, the diverted Lake Michigan watershed, meteorological and precipitation stations, and the land-use/land-cover classes based on 2006 National Land Cover Database (Fry and others, 2011). 
Michigan Diversion Accounting (LMDA) system has been developed by the U.S. Army Corps of Engineers, Chicago District (USACE-Chicago) and the State of Illinois as a part of the interstate Great Lakes water regulatory program. The 1986 Water Resources Development Act (WRDA) stipulates that the USACE is responsible for monitoring the flow measurement and computation of annual diversion accounting for the State of Illinois' Lake Michigan diversion. (T.Y. Su, written commun., March 24, 2015). In the current LMDA system, the total runoff volume from the diverted watershed is comprised of the streamflow portion of the discharges (effluent removed) measured at two U.S. Geological Survey (USGS) streamflow gages located at the mid portion of the two rivers, the North Branch Chicago River at Niles (05536000, 92 square miles) and Little Calumet River at South Holland (05536290, 188 square miles) plus the runoff estimated for the ungaged portion of the diverted watershed (T.Y. Su, written commun., March $31,2015)$. Runoff from the ungaged portion of the diverted watershed (393 square miles) is estimated by the Hydrological Simulation Program-FORTRAN (HSPF; Bicknell and others, 2000). Depending on the amount of precipitation, the annual total runoff volume from the diverted watershed amounts to approximately 30 percent of the annual total diversion volumes.

Runoff has been simulated by using the same rainfallrunoff parameter set in all HSPF models covering the ungaged portion of the diverted watershed (that is, a regional parameter set approach), together with respective measured meteorological data including measured precipitation, air temperature, dew point temperature, wind speed, cloud cover, solar radiation, and computed potential evapotranspiration. The detailed descriptions of the background, authorities, and accounting procedures of the LMDA system are presented in the diversion accounting report for water year (WY, a water year is the 12-month period from October 1 through September 30) 2011 by the USACE-Chicago District (U.S. Army Corps of Engineers, 2014) and the review report by the Seventh LMDA Technical Committee (U.S. Army Corps of Engineers, 2014). The USGS, in cooperation with the USACE-Chicago conducted this collaborative study to assess the accuracy of regional rainfall-runoff parameter sets in simulated runoff volumes from gaged watersheds in and adjacent to the diverted Lake Michigan watershed.

\section{Hydrological Simulation Program- FORTRAN Model and Parameter Sets}

The HSPF model (Bicknell and others, 2000) is a continuous, semi-lumped parameter model (Singh, 1995). The HSPF model can quantify runoff and water-quality constituent and the effects of various land uses and stormwater-management practices on runoff, and address water-quality impairments associated with combined point and nonpoint sources through continuous simulation of physically-based processes in conceptual pathways of the hydrological cycle in a watershed. The HSPF is public-domain software supported by the U.S. Environmental Protection Agency (EPA) and USGS. The HSPF rainfall-runoff processes and associated parameters are briefly introduced in figure 2 and table 1 . A schematic showing the conceptual pathway of HSPF for the rainfall and water mass moving through the pervious land segment (PERLND) is shown in figure 2. Detailed explanations about the modeling philosophy and parameter descriptions and their functions are present in the HSPF user's manual (Bicknell and others, 2000). The meteorological and precipitation time series are inputs. Precipitation was subject to interception, transpiration, and surface detention; some of the remaining water becomes direct runoff on land surface and the rest infiltrates into the ground, which then moves through zones including interflow storage, upper zone storage, lower zone storage, and active groundwater storage. Water in the various storage zones is subject to retention and evapotranspiration losses; eventually, some of the infiltrated water might flow to streams as base flow (groundwater outflows) or could be lost to deep groundwater aquifers (inactive groundwater). Base flow remains active before, during, and after the storm events, but direct surface runoff and interflow occur shortly after a storm (the sum is referred to as "quick flow"). The sum of base flow and quick flow is the simulated total runoff which is the modeled output for comparison with the measured streamflow. For an impervious land segment (IMPLND), the infiltration is assumed to be zero and there is no groundwater component. On an annual basis, a conceptual water balance model is expressed by Donigian (2002) as follows.

precipitation-actual evapotranspiration-deep percolationchanges in soil moisture storage $=$ total runoff

Some items in the water balance model are not measurable and have to be approximated by modeling, and various flow components are needed to describe the physical processes involved.

The HSPF software uses an array of empirical equations to compute the flux and changes in storage in a continuous manner. By adjusting key parameters used in these empirical equations to match the measured streamflow of a real watershed, an HSPF watershed model is calibrated and could be used to simulate outflows in other input or management scenarios. Table 1 is a list of parameters, their descriptions and effects on flow components included in the PERLND and IMPLND segments of the HSPF model. The list is summarized from the HSPF user's manual (Bicknell and others, 2000), BASINS Technical Note No. 6 (U.S. Environmental Protection Agency, 2000), and literature such as Duncker and Melching (1998) and Price (1996).

A HSPF watershed model is represented with designated land covers as separate PERLNDs and IMPLNDs, each with its own hydrological parameter values to simulate the runoffs. In the LMDA system, three types of land cover are prescribed: 


\section{Lake Michigan Diversion Accounting Land Cover Change Estimation}

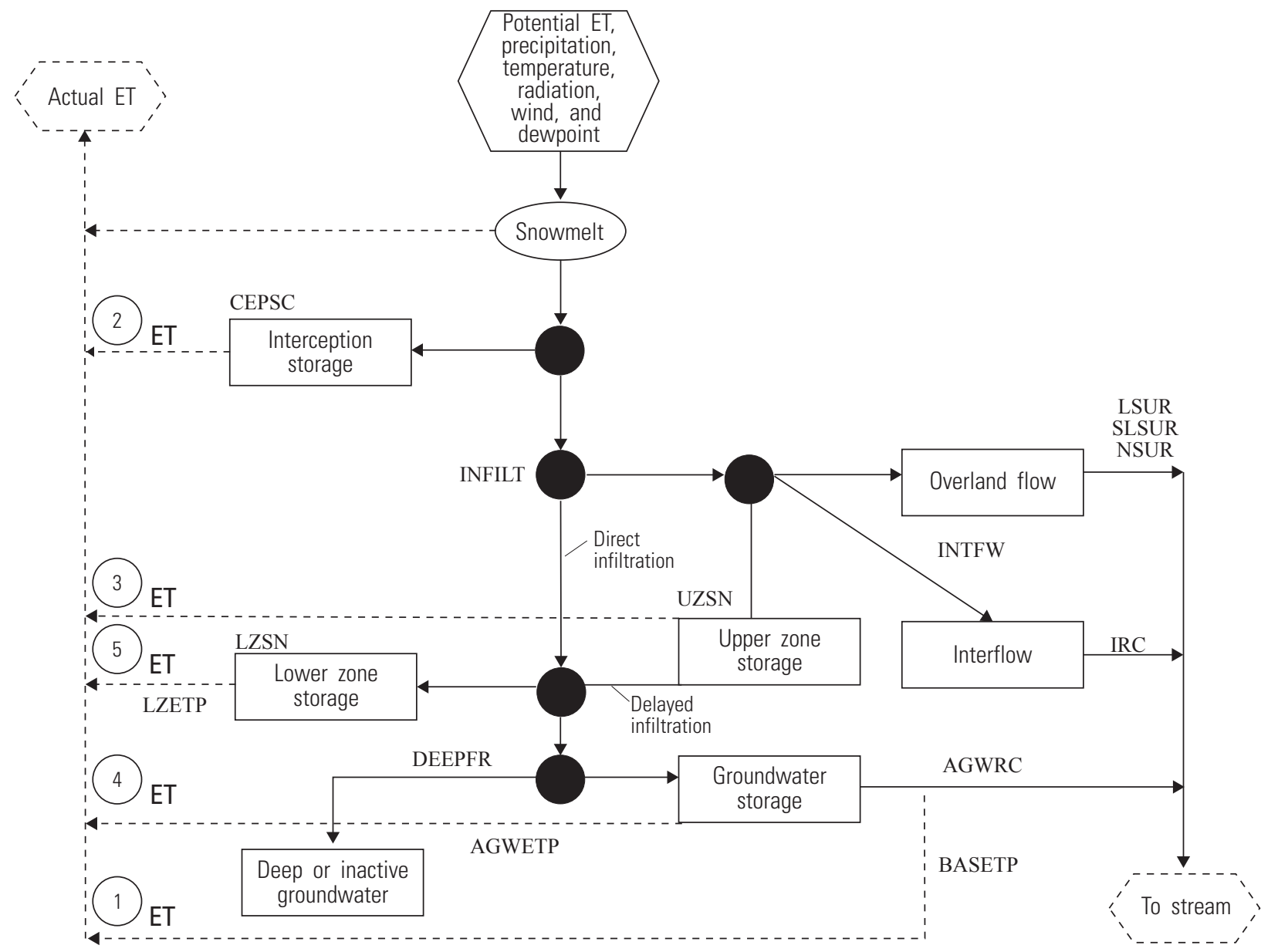

EXPLANATION

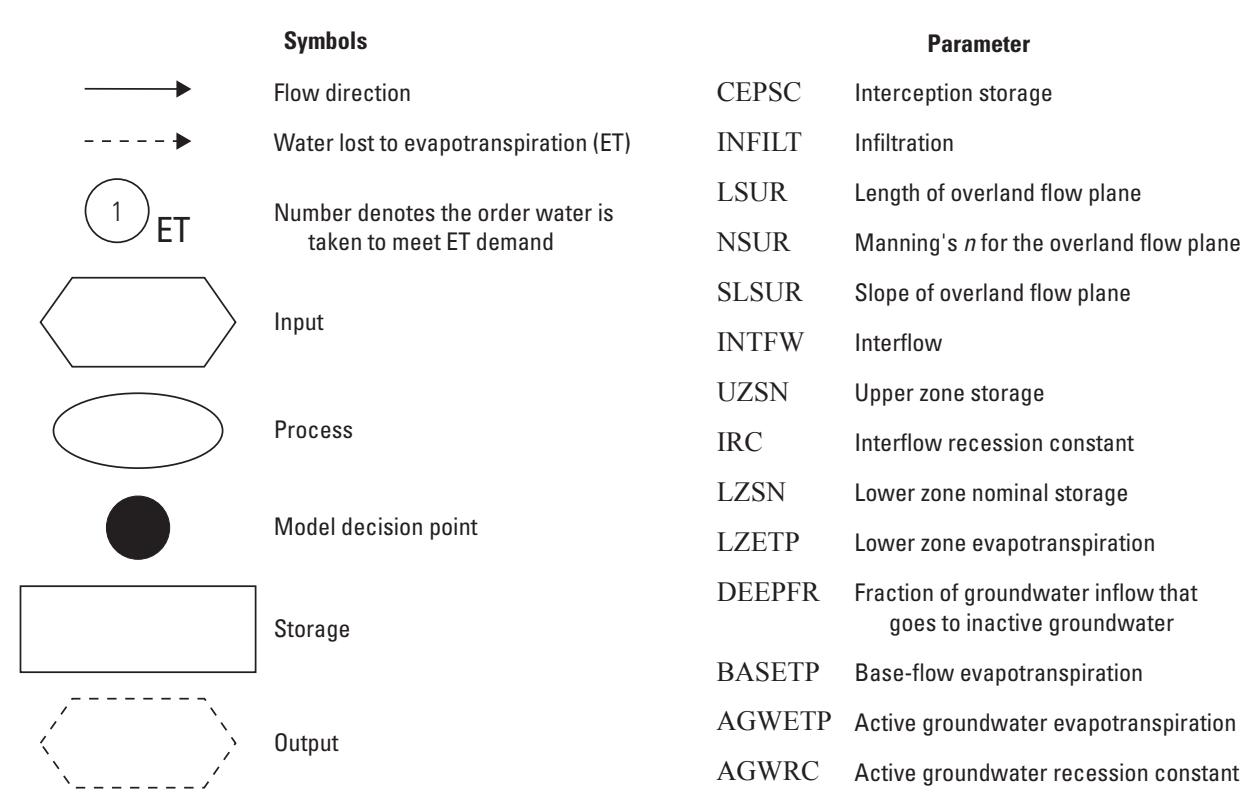

Figure 2. Hydrological Simulation Program-FORTRAN (HSPF) flowchart for hydrologic process for pervious land segment (adapted from Bicknell and others, 2000). 
Table 1. Rainfall-runoff parameters used in the Hydrological Simulation Program-FORTRAN program and their effects on various components of the water budget.

[ET, evapotranspiration; in/hr, inches per hour; $\mathrm{ft} / \mathrm{ft}$, foot per foot; $1 /$ in, inverse of one inch; ${ }^{\circ} \mathrm{F}$, degrees Fahrenheit]

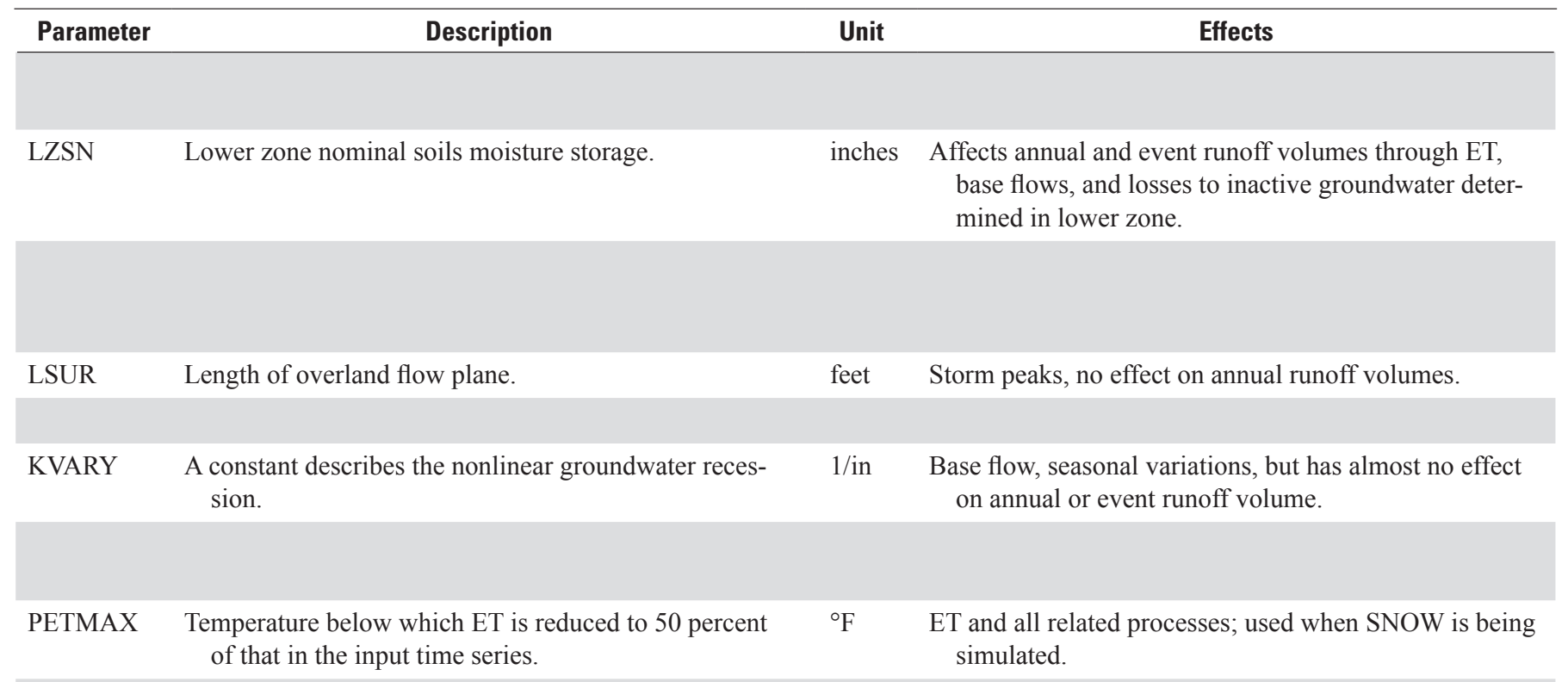

INFEXP

\begin{tabular}{|c|c|c|c|}
\hline INFEXP & $\begin{array}{l}\text { Exponent in infiltration equation that determines how } \\
\text { much a deviation from nominal lower zone storage } \\
\text { affects the infiltration rate. }\end{array}$ & none & Those affected by INFILT. \\
\hline DEEPFR & $\begin{array}{l}\text { Fraction of infiltrating water lost to inactive groundwa- } \\
\text { ter (deep percolation). }\end{array}$ & none & $\begin{array}{l}\text { Primarily the portion of base flow between storms but } \\
\text { also event runoff volumes as groundwater discharge } \\
\text { continues. }\end{array}$ \\
\hline
\end{tabular}

AGWETP Fraction of PERLND subjects to direct evaporation $\begin{aligned} & \text { none } \\ & \text { from groundwater storage. }\end{aligned} \quad \begin{aligned} & \text { Base flow volume (as ET is exerted from the storage } \\ & \text { portion of active groundwater); annual runoff volume } \\ & \text { in the context of base flow generation. }\end{aligned}$

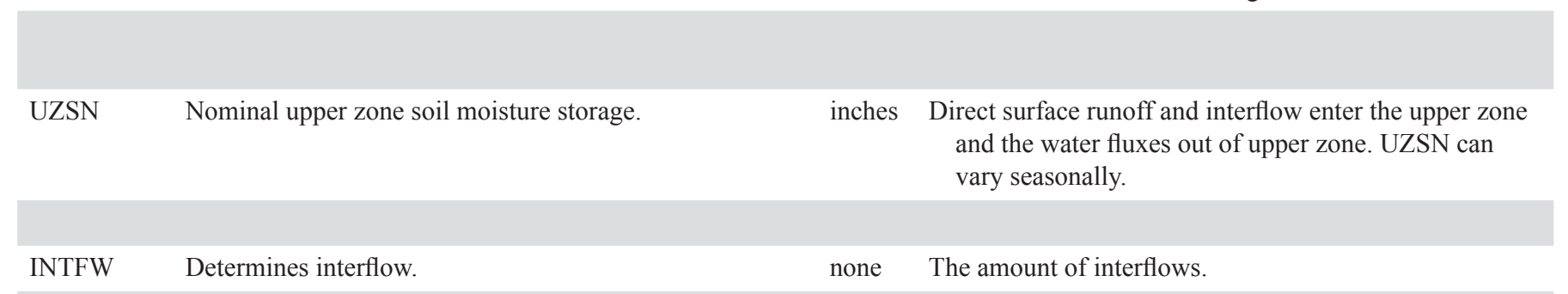

LZETP Parameter determines lower zone ET. $\quad \begin{gathered}\text { none } \\ \begin{array}{c}\text { Annual runoff and some storm events through seasonal } \\ \text { dormancy of vegetation that draws water from lower } \\ \text { zone. }\end{array}\end{gathered}$




\section{Lake Michigan Diversion Accounting Land Cover Change Estimation}

grassland, forestland, and hydraulically connected impervious land. Grassland and forestland represent the PERLND segments where water movement is simulated by using SNOW and PWATER modules. The hydraulically connected impervious land represents the IMPLND segment and water movement is simulated by using SNOW and IWATER modules. The simulated total runoff from a watershed model is the sum of simulated runoff from each type of land covers used in describing the watershed. Simulated runoff volume from each type of land cover depends on the meteorological inputs and its parameter values and is independent of the simulations by other types of land covers. In HSPF, spatial patterns of the PERLND and IMPLND segments are not considered. Simulated runoff from all PERLND and IMPLND segments appears at the outlet of the watershed. If a watershed model is segmented further into subbasins to meet the study needs, simulated runoff from each subbasin can be routed with hydrologic routing if a reach module (RCHRES) is included. Linking RCHRES in a network representing the watershed system enables the routed runoff to be specified at the outlet of the watershed or other designated locations in the watershed; however, if RCHRES is not considered (which is true in LMDA HSPF modeling), then runoffs simulated by PERLND and IMPLND segments in each subbasin outflow to the designated outlets instantaneously.

The quality of the meteorological and precipitation data, the representativeness of the land covers (types and acreages), the physical processes that are captured by the model, and the parameterization are factors that can affect the accuracy of runoff simulations. The regional HSPF parameter approach means that all watersheds modeled with HSPF in the LMDA system are described with respective compositions of grassland, forestland, and hydraulically connected impervious land but the parameter values representing the grassland, forestland, and hydraulically connected impervious land. Only meteorological and precipitation inputs are varied for each watershed according to location. The original regional parameter set was determined from calibrating 14 watersheds in and near the LMDA area in the 1960s and 1970s (Hydrocomp, 1977a, b, c, d and 1979; USACE-Chicago, 2004). There have been several updates to parameter values and some changes may have resulted from the quality and types of data used as well as the watersheds selected in the calibration process (USACE-Chicago, 2009). These updates include a 1993 assessment of the runoff parameter values after the precipitation assignments from 25-raingage network replaced the original13-raingage network (Peppler, 1991). Also, land cover was redelineated from aerial photographs (RUST Environment and Infrastructure, 1993a). Since WY 1996, meteorological inputs have been modified by (1) using direct solar radiation measured at Argonne National Laboratory, (2) incorporating the National Weather Service (NWS) 3-hour meteorological data recorded at O'Hare Airport for snowmelt computation, and (3) switching air temperature data for subareas that previously referenced to the University of Chicago data to either the O'Hare Airport, Midway Airport, or Park Forest temperature gage, depending on proximity (USACE-Chicago, 2009). The parameter set used between WYs 1997 and 2000 was evolved from the calibrated "original" HSPF model, which probably resulted from a hydrologic recalibration conducted by Hey and others (1980). The Fifth Technical Review Committee (USACE-Chicago, 2004) concluded that this parameter set provided acceptable results at Water Reclamation Plants (WRPs); however, some parameter values were outside the range of previously calibrated values, and evaluating the accuracy of the rainfall-runoff simulations by comparing flows at the WRPs was not sufficient. The parameter set that has been in use since 2000 was developed by Consoer Townsend Envirodyne Engineers (CTE), now AECOM, based on a water budget analysis at WRPs and the Chicago and Sanitary Ship Canal (CSSC) waterway system (T.Y. Su, USACE-Chicago, written commun., April 6, 2006). For identification purposes, the parameter set determined by Hey and others (1980) is hereafter referred to as "1999" and the parameter set determined by CTE is hereafter referred to as "CTE."

The regional HSPF parameter approach and the original calibration of HSPF met the Supreme Court requirement of using the "best current engineering practice and scientific knowledge" according to the Fifth Technical Review Committee (USACE-Chicago, 2004, p ii); however, because of lack of documentation on the transfer, the Fifth Technical Review Committee recommended additional checks of simulated flows to confirm the accuracy of the HSPF model. An additional interest in parameter accuracy is the representativeness of runoff simulated from forestland segments. Grass and impervious lands are the primary land covers in the interior part of the diverted watershed but for the ungaged Calumet River and Lower Des Plaines River, which are located in the perimeters of the diverted watershed, have greater amounts of forestland (T.Y. Su, oral commun. September 20, 2012).

In 2008, the USGS and USACE-Chicago assessed the accuracy of CTE and 1999 parameter sets by evaluating the simulated runoff volumes from the gaged Tinley Creek and Midlothian Creek watersheds (USACE-Chicago, 2009). Both watersheds are located in the boundary of the diverted watershed (fig. 1), drain into the Calumet River system, and have greater than 10 percent forestland acreages. The 2008 analysis used meteorological and precipitation network data consistent with the LMDA model input system, and the land-cover features were delineated from a 2005 USGS digital orthophotography colored aerial photograph (http://seamless.usgs. gov/, accessed March 2007; now http://geoinfo.msl.mt.gov/ Home/data/aerial_photographs_of_Montana/USGS_Digital_Orthophoto_Quarter_Quadrangles_Partners). Based on the simulated runoff volume to recorded streamflow volume (S/R) ratios, between WYs 1996 and 2005, the runoff volumes simulated with the 1999 parameter set underestimated the observed annual streamflow volumes in both watersheds. Both the 1999 and CTE parameter sets underestimated the observed annual streamflow volumes in the Tinley Creek watershed 
(USACE-Chicago, 2009). Underestimation in simulated runoff was determined to be the result of underestimated runoff simulated from forestland, and subsequently the forestland parameters were recalibrated while keeping the grassland parameters unaltered from the CTE parameter set.

The 2008 recalibration used Tinley Creek watershed as the index watershed and the convergence criteria of the HSPEXP expert system (Lumb and others, 1994) for evaluating the quality of calibration. The results indicated that the 2008 parameter set satisfactorily improved the simulation accuracy at Tinley Creek but slightly increased the $\mathrm{S} / \mathrm{R}$ ratios at Midlothian Creek (moved further away from unity than those simulated with the CTE parameter set). Because the simulation of runoff from forestland is independent of that from the grassland, adjusting the grassland and forestland parameters at the same time might be the preferred method of calibration. Simulation with additional gaged watersheds could be useful to validate the regional performance. An attempt to validate the parameters with the Flag Creek watershed was not successful because the Flag Creek watershed has little forestland coverage.

\section{Historic Runoff Parameter Sets}

Historic parameter sets and their values for the grassland and forestland are listed in tables 2 and 3; parameters for the hydraulically connected impervious land are given in table 4 . Among the parameter sets, North Branch, Little Calumet, Des Plaines, and Hickory Creek are the parameter sets from the original calibration watersheds; CSSC are the original parameters of the Chicago Sanitary and Ship Canal (CSSC); and NIPC are the parameters by RUST Environment and Infrastructure $(1993 \mathrm{a}, \mathrm{b})$ that were applied in the diversion accounting models by the Northeastern Illinois Planning Commission (NIPC). The 1999, CTE, and 2008 parameter sets have been explained previously in the "HSPF Model and Parameter Sets" section.

The 1999 parameter set differed from the NIPC parameter set in LZSN and LSUR for the forestland, and reductions in LSUR, SLSUR, and RETSC parameters in the impervious land segment. The CTE parameter set differed from the 1999 parameter set in LZSN and INFILT for the grassland and RETSC in impervious land. The 2008 parameter set was developed from the CTE but recalibrated for forestland parameters only. The ranges of these previously calibrated values possibly could serve as the upper and lower limits (bounds) of individual parameters for the LMDA HSPF model, and the changes between parameter sets could reveal the relative importance of the parameters to the accuracy of LMDA simulations. It is desirable that an individual parameter value resides within its realistic bounds because perhaps then the predictability of the final parameter set is not biased when undergoing significantly different hydrological conditions from those used in the calibration. The NIPC, 1999,
CTE, and 2008 parameter sets all have individual parameter values outside the ranges in earlier calibration datasets (tables 2 and 3). These parameters (CEPSC, UZSN, LZSN, LZETP, INFILT, INTFW, LSUR, and KVARY for grassland; UZSN, LZSN, INTFW, and KVARY for forestland) affect different flow components of the discharge hydrographs. The reasonableness of these ranges can be assessed only if we know the objective function and termination criteria used at the time of the calibration. For a comparison, the "typical" ranges reported in BASINS Technical Note No. 6 (U.S. Environmental Protection Agency, 2000) are also included in tables 2 and 3. Note that the values and ranges documented in BASINS Technical Note No. 6 are for typical pervious land without differentiating the types of land cover. It can be reasoned that the values for the same parameter in grassland and forestland should follow a consistent physical explanation; however, this is not consistently established in the previous calibrations. The performances of these parameter sets in the new data environment cannot be inferred by whether the parameter values were outside the reasonable ranges or not, but need be assessed through model testing.

Parameters including FOREST, PETMAX, PETMIN, INFEXP, INFILD, and BASETP are not presented in tables 2 and 3 . These parameter definitions and the values used in LMDA are discussed briefly here. These parameter values were obtained from user control input (UCI) example files provided by USACE-Chicago (T.Y. Su, written commun. April 2006). The FOREST parameter specifies the fraction of the land in the forestland segment that can transpire when there is snow (for example, conifers). Currently, FOREST is set to 0.3 for forestland and 0.2 for grassland segments. Information regarding how these values were determined for the LMDA system was not determined during the study. It is possible that forestland areas were small compared to the grassland areas and were absorbed into the grassland for the ungaged portion of the diverted watershed; therefore, this parameter was assigned with higher values. This logic, however, should be modified if the forestland is specifically modeled. Note that the FOREST parameter for forestland was adjusted from 0.3 to 0.2 in the 2008 calibration. PETMAX and PETMIN are the air temperatures at which plant transpiration is reduced to 50 percent or to 0 , respectively. Current values for PETMAX and PETMIN are 50 degrees Fahrenheit $\left({ }^{\circ} \mathrm{F}\right)$ and $45^{\circ} \mathrm{F}$ for both grassland and forestland. Using the air temperature record from Midway Airport, a $50^{\circ} \mathrm{F}$ value for PETMAX, in general defines a period from October to the end of April; a 45 ${ }^{\circ} \mathrm{F}$ value for PETMIN defines a period from mid-November to mid-April; and a $35^{\circ} \mathrm{F}$ value for PETMIN defines a period from mid-December to mid-February. The following three parameters have not been changed: INFEXP is the exponent in the infiltration equation, and INFILD is the ratio between the maximum and mean infiltration capacities over the PERLND. The values used in the LMDA system are the HSPF model default value of 2.0 as in the HSPF manual (Bicknell and others, 2000). BASETP is the fraction of remaining potential 


\section{Lake Michigan Diversion Accounting Land Cover Change Estimation}

evapotranspiration (ET) lost to riparian vegetation as base flow enters the streambed. The HSPF model default value used is 0.0 .

\section{Reevaluation of Parameter Sets}

The objectives of the study were to (1) evaluate the performance of previously developed regional parameter sets, and (2) develop a parameter set, if necessary, that demonstrates better regional performance. Evaluating HSPF simulated runoff volumes by using watersheds in or adjacent to the diverted Lake Michigan watershed is a viable approach to assess the accuracy of regional parameter sets and fits with the methodology used for the development of the original parameter sets. An understanding of the performance of existing parameter sets under the new input data environment and modifications to the parameters can form a basis for further improvement of model simulations.

\section{Purpose and Scope}

This report evaluates the accuracy of six LMDA HSPF parameter sets applied to nine selected watersheds in and adjacent to the diverted Lake Michigan watershed. Also, regional parameters representing grassland and forestland were recalibrated by manual and automatic methods and the accuracy of the resulting regional parameter set was evaluated.

The premises of HSPF models were (1) use a meteorological and precipitation data system consistent with the current LMDA modeling practices and (2) derive land covers used in the LMDA-HSPF models from the National Land Cover Database 2006 (NLCD 2006, Fry and others, 2011). The accuracy of existing parameter sets was assessed with measured USGS streamflow data from WY 1996 to WY 2011. The recalibration adopted manual and automatic techniques and focused on the PERLND (grassland and forestland) parameters. SNOW and IMPLND parameters were not modified in this study.

Table 2. Historic rainfall-runoff parameters and values for grassland in the Hydrological Simulation Program-FORTRAN program used in the diversion accounting system. Data adapted from U.S. Army Corps of Engineers, Chicago District (2004), and expanded to include Consoer Townsend EnviroDyne Engineers parameter set.

[CSSC, Chicago Sanitary and Ship Canal; NIPC, Northeastern Illinois Planning Commission; CTE, Consoer Townsend Envirodyne Engineers; TN6, BASINS Technical Note 6, typical ranges. Parameter values that are outside of previously calibrated ranges in NIPC, 1999, and CTE are listed in bold]

\begin{tabular}{lccccccccc}
\hline $\begin{array}{l}\text { Parameter } \\
\text { name }\end{array}$ & North Branch & Little Calumet & Des Plaines & Hickory Creek & CSSC & NIPC & $\mathbf{1 9 9 9}$ & CTE & TN6 \\
\hline CEPSC & 0.12 & $0.1-0.2$ & $0.12-0.15$ & 0.15 & $0.1-0.12$ & $\mathbf{0 . 2 5}$ & $\mathbf{0 . 2 5}$ & 0.1 & $0.03-0.20$ \\
UZSN & 1.1 & $0.75-0.8$ & $0.75-2.2$ & 1.5 & $0.75-1.1$ & $\mathbf{1 . 8}$ & $\mathbf{1 . 8}$ & $\mathbf{0 . 5}$ & $0.10-1.0$ \\
LZSN & 7.5 & 8.5 & $7.5-8.0$ & 8 & $7.5-8.5$ & $\mathbf{9 . 5}$ & $\mathbf{9 . 5}$ & $\mathbf{8 . 5}$ & $3.0-8.0$ \\
LZETP & 0.25 & $0.1-0.25$ & $0.25-0.35$ & 0.25 & $0.1-0.25$ & $\mathbf{0 . 3 8}$ & $\mathbf{0 . 3 8}$ & $\mathbf{0 . 3 8}$ & $0.2-0.7$ \\
AGWETP & 0.08 & $0.02-0.05$ & $0.05-0.30$ & 0.05 & $0.00-0.08$ & 0.05 & 0.05 & 0.05 & $0.00-0.05$ \\
INFILT & 0.015 & $0.02-0.022$ & $0.015-0.045$ & $0.02-0.03$ & $0.015-0.02$ & 0.015 & $\mathbf{0 . 0 1 5}$ & $\mathbf{0 . 1}$ & $0.01-0.10$ \\
DEEPFR & 0.08 & $0.05-0.10$ & $0.05-0.30$ & 0.05 & $0.00-0.08$ & 0.05 & 0.05 & 0.05 & $0.0-0.20$ \\
INTFW & 3.5 & $2.7-3.2$ & $2.5-5.0$ & 3.5 & $3.2-3.5$ & $\mathbf{1 5}$ & $\mathbf{1 5}$ & $\mathbf{1 0}$ & $1.0-3.0$ \\
LSUR & 250 & 400 & $250-500$ & 400 & $250-400$ & $\mathbf{5 0}$ & $\mathbf{5 0}$ & $\mathbf{5 0}$ & $200-500$ \\
SLSUR & 0.01 & 0.002 & $0.01-0.05$ & 0.05 & $0.002-0.01$ & 0.01 & 0.01 & 0.01 & $0.01-0.15$ \\
NSUR & 0.25 & 0.35 & $0.2-0.35$ & 0.35 & $0.25-0.35$ & 0.2 & 0.2 & 0.2 & $0.15-0.35$ \\
IRC & 0.5 & 0.5 & $0.5-0.6$ & 0.5 & 0.5 & 0.5 & 0.5 & 0.5 & $0.5-0.7$ \\
KVARY & 1 & 1.5 & $1.0-1.5$ & 1 & $1.0-1.5$ & $\mathbf{1 . 7}$ & $\mathbf{1 . 7}$ & $\mathbf{1 . 7}$ & $0.0-3.0$ \\
AGWRC & 0.98 & 0.99 & $0.97-0.99$ & 0.97 & $0.98-0.99$ & 0.98 & 0.98 & 0.98 & $0.92-0.99$ \\
\hline
\end{tabular}


Table 3. Historic rainfall-runoff parameter values for forestland in the Hydrological Simulation Program-FORTRAN program used in the diversion accounting system. Data adapted from U.S. Army Corps of Engineers, Chicago District (2004) and expanded to include Consoer Townsend EnviroDyne Engineers and 2008 parameter set.

[CSSC, Chicago Sanitary and Ship Canal; NIPC, Northeastern Illinois Planning Commission; CTE, Consoer Townsend Envirodyne Engineers; TN6, BASINS Technical Note 6, typical ranges. Parameter values that are outside of previously calibrated ranges in NIPC, 1999, and CTE are listed in bold]

\begin{tabular}{lccccccccc}
\hline $\begin{array}{c}\text { Parameter } \\
\text { name }\end{array}$ & North Branch & Little Calumet & Des Plaines & Hickory Creek & NIPC & 1999 & CTE & 2008 & TN6 \\
\hline CEPSC & 0.2 & $0.25-0.4$ & $0.18-0.20$ & 0.2 & 0.2 & 0.2 & 0.2 & 0.2 & $0.03-0.20$ \\
UZSN & 6 & 6 & $5.0-6.0$ & 6 & $\mathbf{3}$ & $\mathbf{3}$ & $\mathbf{3}$ & $\mathbf{1}$ & $0.10-1.0$ \\
LZSN & 7.5 & 8 & $7.5-8.0$ & 8 & $\mathbf{1 0}$ & $\mathbf{9 . 5}$ & $\mathbf{9 . 5}$ & 7.5 & $3.0-8.0$ \\
LZETP & 0.9 & $0.8-0.9$ & $0.85-0.90$ & 0.9 & 0.9 & 0.9 & 0.9 & 0.6 & $0.2-0.7$ \\
AGWETP & 0.15 & $0.10-0.26$ & $0.05-0.15$ & 0.05 & 0.15 & 0.15 & 0.15 & 0.05 & $0.00-0.05$ \\
INFILT & 0.007 & $0.01-0.025$ & $0.005-0.015$ & 0.005 & 0.01 & 0.01 & 0.01 & 0.005 & $0.01-0.10$ \\
DEEPFR & 0.15 & $0.15-0.20$ & $0.05-0.20$ & 0.05 & 0.05 & 0.05 & 0.05 & 0.05 & $0.0-0.20$ \\
INTFW & 3.5 & $2.5-5.0$ & $3.0-5.0$ & 3.5 & $\mathbf{7 . 5}$ & $\mathbf{7 . 5}$ & $\mathbf{7 . 5}$ & 5 & $1.0-3.0$ \\
LSUR & 1,000 & 1,000 & $100-1,000$ & 1,000 & 300 & 400 & 400 & 400 & $200-500$ \\
SLSUR & 0.001 & 0.002 & $0.00-0.01$ & 0 & 0.01 & 0.01 & 0.01 & 0.01 & $0.01-0.15$ \\
NSUR & 0.35 & 0.35 & $0.25-0.35$ & 0.35 & 0.25 & 0.25 & 0.25 & 0.25 & $0.15-0.35$ \\
IRC & 0.5 & 0.5 & $0.5-0.6$ & 0.5 & 0.5 & 0.5 & 0.5 & 0.5 & $0.5--0.7$ \\
KVARY & 1 & 1.5 & $1.0-1.5$ & 1 & $\mathbf{1 . 7}$ & $\mathbf{1 . 7}$ & $\mathbf{1 . 7}$ & 1.5 & $0.0-3.0$ \\
AGWRC & 0.99 & 0.99 & $0.97-0.99$ & 0.97 & 0.98 & 0.98 & 0.98 & 0.95 & $0.92-0.99$ \\
\hline
\end{tabular}

Table 4. Historical rainfall-runoff parameter values for impervious land in the Hydrological Simulation Program-FORTRAN program used in the diversion accounting system. Data adapted from U.S. Army Corps of Engineers, Chicago District (2004).

[NIPC, Northeastern Illinois Planning Commission; CTE, Consoer Townsend Envirodyne Engineers; TN6, BASINS Technical Note 6, typical ranges; $\mathrm{ft} / \mathrm{ft}$, foot per foot. Parameter values that are outside of previously calibrated ranges in NIPC, 1999, and CTE are listed in bold].

\begin{tabular}{llcllllll}
\hline $\begin{array}{c}\text { Parameter } \\
\text { name }\end{array}$ & Unit & $\begin{array}{c}\text { North } \\
\text { Branch }\end{array}$ & Hickory & NIPC & $\mathbf{1 9 9 9}$ & CTE & $\mathbf{2 0 0 8}$ & TN6 \\
\hline LSUR & feet & 100 & 100 & 100 & 50 & 50 & 50 & $50-150$ \\
SLSUR & $\mathrm{ft} / \mathrm{ft}$ & 0.015 & 0.015 & 0.015 & 0.01 & 0.01 & 0.01 & $0.01-0.05$ \\
NSUR & none & $\mathbf{0 . 2}$ & $\mathbf{0 . 2}$ & $\mathbf{0 . 2}$ & $\mathbf{0 . 2}$ & $\mathbf{0 . 2}$ & $\mathbf{0 . 2}$ & $0.03-0.10$ \\
RETSC & inches & $\mathbf{0 . 3}$ & $\mathbf{0 . 3}$ & $\mathbf{0 . 3}$ & $\mathbf{0 . 2 5}$ & 0.1 & 0.1 & $0.03-0.10$ \\
\hline
\end{tabular}




\section{Preparation of Models and Input Data}

Nine gaged watersheds including Flag Creek near Willow Spring, IL (05533000), Skokie River near Highland Park, IL (05535070), Butterfield Creek near Flossmoor, IL (05536255), Midlothian Creek at Oak Park, IL (05536340), Tinley Creek near Palos Park, IL (05536500), Long Run near Lemont, IL (05537500), Hickory Creek at Joliet, IL (05539000), Hart Ditch at Dyer, IN (streamflow gage 05536179), and Hart Ditch at Munster, IN (05536190) representing various landuse compositions and watershed sizes, and in or adjacent to the diverted Lake Michigan watershed, were selected (fig. 1). The basic information about each watershed is summarized in table 5. Among the information, the "mean watershed slope" is similar to the HSPF runoff parameter SLSUR discussed in table 1 . The slight variations in mean watershed slope among these watersheds serves as an initial indication of their hydrological similarity. The mean watershed slopes, determined from BSLOPGM (http://water.usgs.gov/osw/streamstats/ bcdefinitions 1.html) as defined in SSURGO database (http:// soildatamart.nrcs.usda.gov, accessed September, 2013). Flood control reservoirs have been built in the Chicago metropolitan area since the 1960s (Resource Coordination Policy Committee, 1998). An "accumulative area above dams/area above gage" column is included to indicate the existence of reservoirs in the selected watersheds. The ratio can be greater than 1 if there are multiple reservoirs above the gage because the area above each dam is counted independently. Flood control reservoirs - depending on the sizes, locations, and operations can alter the temporal distribution of streamflows and therefore the evaluation of parameter accuracy, because the effects of reservoirs are not addressed in the present modeling (no RCHRES). Reservoirs are classified under "open water" and then converted as impervious surfaces in the present modeling work. Among the selected watersheds, Midlothian Creek had several flood-protection related projects constructed during the 1970s and 1980s (Arlan Juhl, Illinois Department of Natural Resources, Office of Water Resources, written commun., October 2006).

Drainage boundaries of the study watersheds were obtained from the Illinois StreamStats (http://water.usgs.gov/ osw/streamstats/illinois.html). The drainage boundaries of Hart Ditch at Dyer and at Munster, Indiana, were determined by compiling watershed shape files obtained from the Indiana StreamStats (http://water.usgs.gov/osw/streamstats/indiana. html). The retrieved watershed boundaries might require modifications if they were subject to local drainage alterations. The National Watershed Boundary Dataset (http://nhd.usgs. gov/wbd.html) and the boundaries of the special contributing area (SCA) serviced by the combined sewer system in Cook County, Illinois (shape files provided by USACE-Chicago District, written commun., June 2011) were reviewed for changes due to drainage works, sewer systems, and flood diversions. As a result, a small part of the Flag Creek watershed is serviced by SCA; hence, the Flag Creek watershed boundary has been modified.

Table 5. Background information for the selected watersheds.

[ft/ft, foot per foot; IL, Illinois; IN, Indiana]

\begin{tabular}{clllclcr}
\hline $\begin{array}{c}\text { Station } \\
\text { number }\end{array}$ & \multicolumn{1}{c}{ Station name } & County & $\begin{array}{c}\text { Area } \\
\text { (square miles) }\end{array}$ & $\begin{array}{c}\text { Mean } \\
\text { watershed } \\
\text { slope } \\
\text { (ft/ft) }\end{array}$ & $\begin{array}{c}\text { Accumulative } \\
\text { area above dams/ } \\
\text { areas above gage }\end{array}$ & $\begin{array}{c}\text { Availability of daily } \\
\text { streamflow records }\end{array}$ \\
\hline 05536340 & Midlothian Creek at Oak Forest, IL & Cook & 13.5 & 0.01068 & 1.207 & $10 / 1 / 1950$ to present. \\
05536500 & Tinley Creek near Palos Park, IL & Cook & 11.2 & 0.01325 & 0.025 & $7 / 11 / 1951$ to present. \\
05533000 & Flag Creek near Willow Springs, IL & Cook & 16.5 & 0.01513 & 0.0 & $7 / 26 / 1951$ to present. \\
05535070 & Skokie River near Highland Park, IL & Lake & 21.1 & 0.00895 & 0.0 & $8 / 21 / 1967$ to present. \\
05539000 & Hickory Creek at Joliet, IL & Will & 107.0 & 0.01343 & 0.101 & $10 / 1 / 1944$ to present. \\
05536179 & Hart Ditch at Dyer & Lake (IN) & 37.6 & 0.01375 & 0.0 & $9 / 19 / 1989$ to present. \\
05536190 & Hart Ditch at Munster, IN & Lake (IN) & 70.7 & 0.01028 & 0.0 & $10 / 1 / 1942$ to present. \\
05536255 & Butterfield Creek at Flossmoor, IL & Cook & 23.5 & 0.00884 & 0.122 & $5 / 17 / 1948$ to present. \\
05537500 & Long Run near Lemont, IL & Cook & 20.9 & 0.01745 & 0.127 & $7 / 1 / 1951$ to present. \\
\hline
\end{tabular}




\section{Determination of Land Cover}

Land covers for the study watersheds were determined on the basis of National Land Cover Database 2006 (NLCD 2006, Fry and others, 2011). The NLCD uses a 16 land-use classification scheme to describe land uses/land covers; in general, the study watersheds and LMDA watersheds have 15 of the 16 classes. The 15 land-use classifications then were converted to the grassland, forestland, and hydraulically connected impervious land categories for each watershed. The 2006 NLCD land-use classifications in the nine study watersheds, and the final grassland, forestland, and hydraulically connected land, in percentages, are shown in table 6. Conversion from NLCD land classifications to the LMDA land-cover categories is accomplished through a conversion matrix (table 7) developed in this study. Weights in table 7 are determined by calibrating with the 2008 results for Tinley Creek, Midlothian Creek, and Flag Creek that were based on the 2005 aerial photographs (http://seamless.usgs.gov/), and table 8 shows the comparison of two results at these three watersheds.

Table 6. Percentages of the Lake Michigan Diversion Accounting land-cover categories including forestland, grassland, and hydraulically connected impervious lands for the study watersheds and their counterpart land-cover classes according to the 2006 National Land Cover Database.

[NLCD, National Land Cover Database; LMDA, Lake Michigan Diversion Accounting]

\begin{tabular}{|c|c|c|c|c|c|c|c|c|c|}
\hline & \multicolumn{9}{|c|}{ Watershed and station number } \\
\hline \multirow[t]{2}{*}{ Total acreage } & 8,076 & 7,197 & 9,196 & 13,380 & 68,794 & 23,639 & 44,447 & 14,801 & 13,513 \\
\hline & \multicolumn{9}{|c|}{ NLCD land-cover classes (percent) } \\
\hline $\begin{array}{l}\text { Developed open } \\
\text { space }\end{array}$ & 4.25 & 7.20 & 14.68 & 31.29 & 9.51 & 5.02 & 9.98 & 12.30 & 17.90 \\
\hline $\begin{array}{l}\text { Developed low } \\
\text { intensity }\end{array}$ & 49.39 & 41.30 & 66.80 & 31.64 & 32.89 & 12.37 & 31.09 & 46.11 & 39.45 \\
\hline $\begin{array}{l}\text { Developed medium } \\
\text { intensity }\end{array}$ & 28.91 & 19.44 & 13.88 & 14.99 & 11.79 & 2.06 & 6.78 & 14.45 & 4.99 \\
\hline Deciduous forest & 3.65 & 11.93 & 0.60 & 7.53 & 5.49 & 15.40 & 9.63 & 3.72 & 8.72 \\
\hline Evergreen forest & 0.01 & 0.09 & 0.00 & 0.00 & 0.05 & 0.08 & 0.04 & 0.02 & 0.01 \\
\hline Mixed forest & 0.67 & 1.33 & 0.00 & 0.11 & 2.22 & 1.77 & 1.09 & 0.85 & 3.24 \\
\hline Shrub/scrub & 0.29 & 1.54 & 0.00 & 0.04 & 1.71 & 0.59 & 0.77 & 0.87 & 0.33 \\
\hline Grassland/herbaceous & 3.48 & 1.38 & 0.05 & 0.55 & 4.61 & 10.39 & 6.52 & 3.74 & 4.04 \\
\hline Pasture/hay & 0.08 & 0.04 & 0.00 & 0.00 & 3.75 & 8.52 & 4.80 & 1.14 & 2.25 \\
\hline Cultivated crops & 0.47 & 0.89 & 0.05 & 1.06 & 19.77 & 36.23 & 19.86 & 11.06 & 10.50 \\
\hline Forestland & 10.10 & 24.90 & 2.00 & 13.10 & 12.80 & 22.40 & 17.00 & 7.40 & 16.90 \\
\hline
\end{tabular}




\section{Lake Michigan Diversion Accounting Land Cover Change Estimation}

Table 7. Matrix for conversion of National Land Cover Database land-cover classes to Lake Michigan Diversion Accounting land-cover types.

[NLCD, National Land Cover Database]

\begin{tabular}{clcll}
\hline $\begin{array}{c}\text { NLCD } \\
\text { class number }\end{array}$ & \multicolumn{1}{c}{ NLCD class definition } & Impervious & Grass & Forest \\
\hline 11 & Open water & 1 & 0 & 0 \\
21 & Developed, open space & 0.19 & 0.81 & 0 \\
22 & Developed, low intensity & 0.37 & 0.615 & 0.015 \\
23 & Developed, medium intensity & 0.45 & 0.51 & 0.04 \\
24 & Developed, high intensity & 0.95 & 0.05 & 0 \\
31 & Barren land (rock/sand/clay) & 0.75 & 0.25 & 0 \\
41 & Deciduous forest & 0 & 0.15 & 0.85 \\
42 & Evergreen forest & 0 & 0.1 & 0.9 \\
43 & Mixed forest & 0 & 0.2 & 0.8 \\
52 & Scrub/shrub & 0 & 0.5 & 0.5 \\
71 & Grassland/herbaceous & 0 & 0.9 & 0.1 \\
81 & Pasture/hay & 0 & 1 & 0 \\
82 & Cultivated crops & 0 & 1 & 0 \\
90 & Woody wetlands & 0 & 0 & 1 \\
95 & Emergent herbaceous wetlands & 0 & 0 & 1 \\
\hline
\end{tabular}

Table 8. Comparison of percentages of grassland, forestland, and hydraulically connected impervious land determined by 2005 aerial photographs and conversion of 2006 National Land Cover Database land-use categories.

[NLCD, National Land Cover Database]

\begin{tabular}{lccc}
\hline \multicolumn{1}{c}{ Source } & $\begin{array}{c}\text { Grass } \\
\text { (percent) }\end{array}$ & $\begin{array}{c}\text { Forest } \\
\text { (percent) }\end{array}$ & $\begin{array}{c}\text { Imperviousness } \\
\text { (percent) }\end{array}$ \\
\hline Tinley Creek (aerial photograph) & 0.46 & 0.24 & 0.3 \\
Tinley Creek (2006 NLCD) & 0.46 & 0.25 & 0.29 \\
Midlothian Creek (aerial photograph) & 0.54 & 0.11 & 0.35 \\
Midlothian Creek (2006 NLCD) & 0.53 & 0.1 & 0.37 \\
Flag Creek (aerial photograph) & 0.59 & 0.02 & 0.39 \\
Flag Creek (2006 NLCD) & 0.6 & 0.02 & 0.38 \\
\hline
\end{tabular}


Besides the acreages of each land cover for model use, changes in the land-cover areas in the study period could have hydrological effects on streamflows if the changes were substantial. Such information is reviewed by comparing the land-cover acreages determined by applying the same methodology to the retrofitted 1992 and 2001 versions of NLCD datasets (http://www.mrlc.gov/index.php); the 2011 data were not available before the study was conducted. The resulting percentages of forestland, grassland, and hydraulically connected impervious lands in each watershed are presented in table 9. The results indicated that the largest increase in impervious land percentages was from 19.6 to 23.2 percent in Hickory Creek watershed, followed by 27 to 29.9 percent in the Butterfield Creek watershed. The increase in percent impervious area in Hart Ditch, Long Run, and Midlothian Creek watersheds also is more than 1 percent. The increases in impervious lands were compensated with decreases in grassland, forestland, or both. The effects on the accuracy of simulation by using the 2006 NLCD land-use data alone for the entire study period is examined in the "Accuracy of Regional HSPF Parameter" section.

\section{Meteorological Data}

Meteorological and precipitation stations used in the study are shown in figure 1. Data for the study period were provided by USACE-Chicago (T.Y. Su, USACE-Chicago, written commun., June 2012). Hourly meteorological data include air temperature, cloud cover, dewpoint temperature, computed potential ET, and wind speed at O'Hare Airport; air temperature at Midway Airport; and solar radiation at Argonne National Laboratory. The Illinois State Water Survey operates and maintains the 25-raingage precipitation network (Westcott, 2006) and publishes hourly precipitation depth. Coordinates of the 25 precipitation gages were provided by Westcott (written commun., June 2012). Several precipitation gages previously have been relocated (Westcott, 2013), including a few used in this study. Relocations of gages used in the study were not appreciable, were mostly near their original sites, and occurred before 2011; therefore, the 2012 coordinates were used in the analysis. The hourly precipitation amounts were partitioned on the basis of the Thiessen method (Chow, 1972) and assigned to each study watershed and its subbasins. The meteorologic data were assigned according to their proximity.

Parts of the Skokie River, Hickory Creek, Hart Ditch at Dyer, and Hart Ditch at Munster watersheds are located outside the 25-raingage precipitation network. Precipitation data from the National Climatic Data Center (NCDC) (http://www. ncdc.noaa.gov/cdo-web/, accessed June 2012) stations in the vicinity of these watersheds that have concurrent time periods were retrieved (fig. 1). Most of the NCDC data are daily stations except Crete (IL112011), which is an hourly station. After filling missing daily data with data from a nearby station, daily records are disaggregated to hourly by referencing to nearby hourly stations and using the "Disaggregate" utility in the WDMUtil program (Hummel and others, 2001). Station data that were disaggregated included Chicago Botanical Garden (station number USC00111497; "station number" is omitted hereafter), disaggregated by using ISWS raingage No. 2; Joliet Brandon Road Dam (IL114530), disaggregated by using triangular distribution; Little Red School House (IL115110), disaggregated by using ISWS raingages No. 11 and No. 16; Monee Reservoir (IL115763), disaggregated by using NWS Crete station; and Park Forest (IL116616), disaggregated by using Crete and ISWS raingage 24. Two remote stations do not have nearby hourly stations and the daily values of these stations were disaggregated by using the "triangular distribution" utility in the WDMUtil program. These stations are Romeoville Lewis University AP (IL117457) and Crown Point IN (IN121940). For Hickory Creek simulations, the Romeoville Lewis University Airport station starts from 1997. Switching precipitation coverage from Romeoville Lewis University Airport to Joliet Brandon Road Dam station did not result in changes in the annual S/R ratios; therefore, the disaggregated precipitation data at Joliet Brandon Road Dam station have been used for Hickory Creek simulation and the simulation starts from WY 1996.

\section{Streamflow Data}

Streamflow data are available at the National Water Information System (NWIS, http://waterdata.usgs.gov/i1/nwis/sw/). For the nine study watersheds, unit values (sub-daily interval) and mean daily records are available. Because the length of daily records spans the calibration and verification periods, daily records were used for the study.

Daily streamflow time series and its derivatives are useful for describing the hydrological characteristics of a watershed; such information is also useful in the rainfall-runoff calibration and verification (for example, the streamflow volume in response to the precipitation received). The watershed yield characterizes a watershed, as described in the conceptual water balance model (eq. 2 in the "Background" section). If the study watersheds are hydrologically similar, the streamflow to precipitation responses should also be similar. Plots of the total monthly precipitation and normalized monthly streamflow volumes of the nine study watersheds for the study period are shown in figure 3 . The monthly streamflow volume of each watershed is normalized by the corresponding drainage area for comparison purposes. The Flag Creek and Hart Ditch at Munster watersheds consistently have higher magnitudes of normalized monthly streamflow volumes, whereas Hart Ditch at Dyer and Butterfield Creek generally have lower normalized monthly streamflow volumes than the remaining study watersheds. The higher normalized monthly streamflow volumes in Flag Creek and Hart Ditch at Munster could be due to the existence of wastewater effluent discharges, which will be explained later in the "Effluent Discharge and Water Withdrawals" section. The precipitation and streamflow volumes have clear monthly distributions (fig. 3). The red line in 
Table 9. Modeled land-cover classes determined from National Land Cover Database 1992, 2001, and 2006 datasets for nine selected watersheds.

\begin{tabular}{|c|c|c|c|c|c|c|c|c|c|}
\hline \multirow[b]{2}{*}{ Watershed } & \multicolumn{3}{|c|}{1992 NLCD $^{1}$} & \multicolumn{3}{|c|}{2001 NLCD } & \multicolumn{3}{|c|}{2006 NLCD } \\
\hline & $\begin{array}{l}\text { Hydraulically } \\
\text { connected } \\
\text { impervious land }\end{array}$ & Grassland & Forestland & $\begin{array}{l}\text { Hydraulically } \\
\text { connected } \\
\text { impervious land }\end{array}$ & Grassland & Forestland & $\begin{array}{l}\text { Hydraulically } \\
\text { connected } \\
\text { impervious land }\end{array}$ & Grassland & Forestland \\
\hline Midlothian Creek & $35.60 \%$ & $53.80 \%$ & $10.50 \%$ & $35.80 \%$ & $54.60 \%$ & $9.70 \%$ & $36.60 \%$ & $53.30 \%$ & $10.10 \%$ \\
\hline Tinley Creek & $28.60 \%$ & $46.40 \%$ & $25.00 \%$ & $28.80 \%$ & $48.80 \%$ & $22.50 \%$ & $28.80 \%$ & $46.30 \%$ & $24.90 \%$ \\
\hline Flag Creek & $37.50 \%$ & $60.40 \%$ & $2.10 \%$ & $37.50 \%$ & $60.40 \%$ & $2.10 \%$ & $37.60 \%$ & $60.40 \%$ & $2.00 \%$ \\
\hline Skokie Creek & $30.90 \%$ & $55.40 \%$ & $13.80 \%$ & $30.70 \%$ & $57.10 \%$ & $12.20 \%$ & $31.40 \%$ & $55.50 \%$ & $13.10 \%$ \\
\hline Hickory Creek & $19.60 \%$ & $66.70 \%$ & $13.70 \%$ & $19.60 \%$ & $66.50 \%$ & $13.90 \%$ & $23.20 \%$ & $64.10 \%$ & $12.80 \%$ \\
\hline Hart Ditch-Dyer & $6.90 \%$ & $70.70 \%$ & $22.40 \%$ & $7.10 \%$ & $73.00 \%$ & $19.90 \%$ & $7.70 \%$ & $69.90 \%$ & $22.50 \%$ \\
\hline Hart Ditch-Munster & $18.30 \%$ & $64.00 \%$ & $17.60 \%$ & $18.50 \%$ & $66.50 \%$ & $15.00 \%$ & $19.60 \%$ & $63.40 \%$ & $17.00 \%$ \\
\hline Butterfield Creek & $27.00 \%$ & $64.60 \%$ & $8.40 \%$ & $27.00 \%$ & $64.60 \%$ & $8.40 \%$ & $29.90 \%$ & $62.70 \%$ & $7.40 \%$ \\
\hline Long Run & $22.10 \%$ & $60.80 \%$ & $17.10 \%$ & $22.30 \%$ & $61.90 \%$ & $15.80 \%$ & $23.30 \%$ & $59.80 \%$ & $16.80 \%$ \\
\hline
\end{tabular}


figure 3, obtained by taking the average of the nine normalized monthly streamflow volumes during the study period, shows this distribution pattern. The streamflow in October generally is the lowest for the area. The precipitation between November and March was low but streamflow gradually increased, most likely due to a decrease in ET. Snow pack and snowmelt are primary sources of streamflow in the winter months. April and May had the highest precipitation as well as the highest mean monthly streamflow in the study watersheds. Although the magnitudes of mean monthly precipitation remained at about the same level, streamflow began receding in June and reached the lowest point in October.

The maximum discharge, mean discharge, minimum discharge, and standard deviation (table 10) are products of basic statistics that describe the observed streamflow time series. If the simulated runoff time series is reasonably correct,

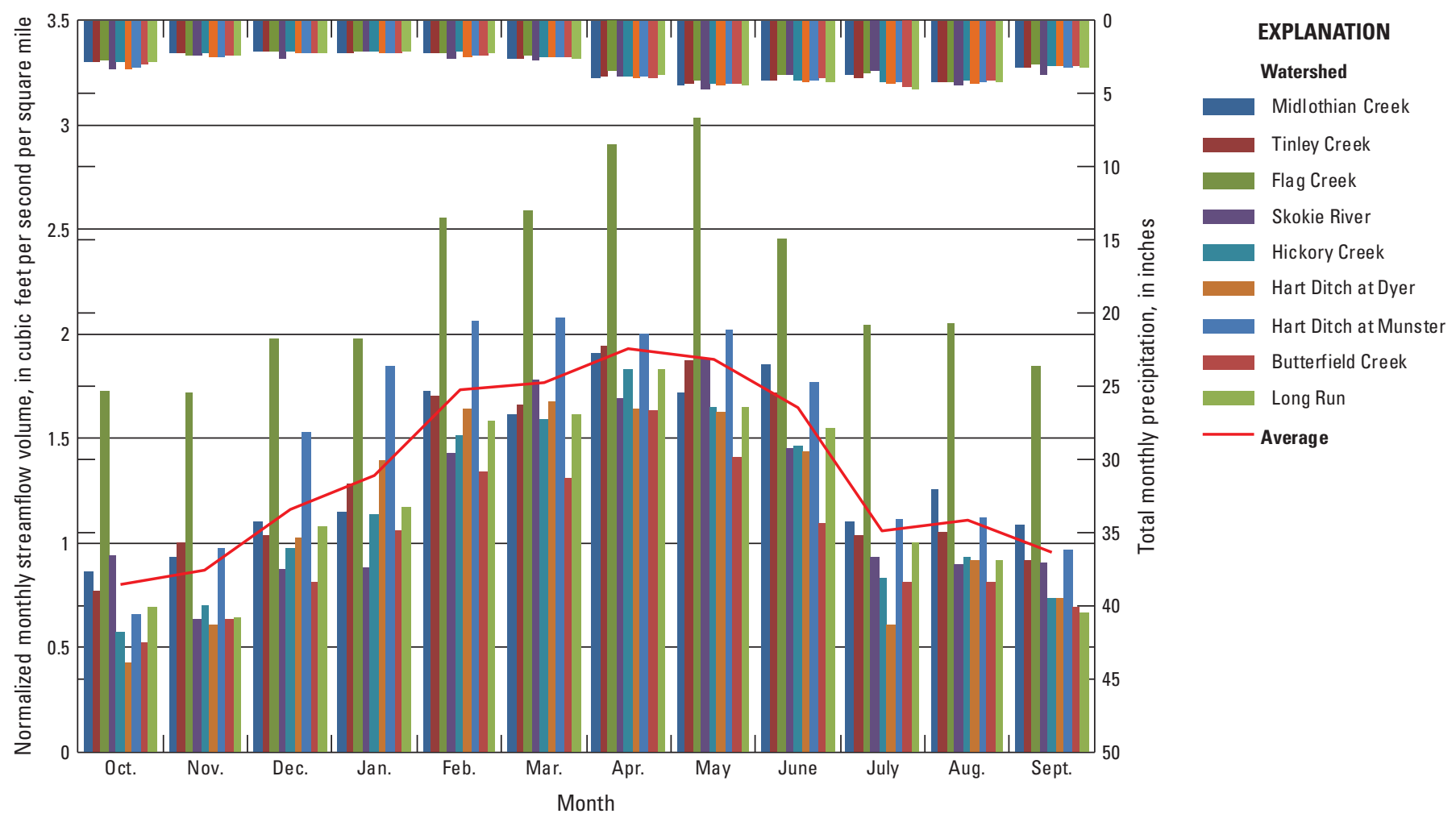

Figure 3. Normalized monthly streamflow volume (in cubic feet per second per square mile) and total monthly precipitation (in inches) for the nine study watersheds for the period from October 1, 1995, to September 30, 2011. The red line is the average of normalized monthly streamflow volume of the nine watersheds over the study period.

Table 10. The maximum discharge, mean discharge, minimum discharge, and standard deviation determined from the mean daily discharge record for the nine study watersheds, October 1, 1995, to September 30, 2011.

$\left[\mathrm{ft}^{3} / \mathrm{s}\right.$, cubic feet per second]

\begin{tabular}{|c|c|c|c|c|c|c|c|c|c|}
\hline & \multicolumn{9}{|c|}{ Watershed } \\
\hline $\begin{array}{l}\text { Mean discharge, } \\
\text { in } \mathrm{ft}^{3} / \mathrm{s}\end{array}$ & 17 & 15 & 32 & 25 & 124 & 42 & 105 & 23 & 25 \\
\hline Standard deviation & 30.8 & 39.3 & 47.7 & 52.5 & 272.8 & 104.2 & 224.1 & 64.6 & 63 \\
\hline
\end{tabular}


it should produce similar statistics. Also, the comparison of the maximum daily streamflows among the nine study watersheds indicates that the Midlothian Creek watershed has the lowest maximum streamflow magnitude; therefore, the operations of flood-protection reservoirs in the watershed have most likely suppressed its peaks.

Annual patterns of total precipitation and normalized streamflow volume for each of the nine watersheds are presented in figure 4 . The red line in figure 4 shows the trend of normalized annual streamflow volume of the nine watersheds from WYs 1996 to WY 2011. The trend of annual streamflow volume is obtained by averaging the normalized annual streamflow volume from the nine watersheds. Based on the annual total precipitation amounts, WYs 2002 to 2005 were dry and WYs 2007 to 2011 were wet. For model calibration, we selected the period from WYs 2001 to 2009 for testing the parameters because it included dry, average, and wet years; and the periods of WYs 1996 to 2000 and WYs 2010 to 2011 for model verifications. There are appreciable differences in the normalized annual streamflow volume among the nine watersheds (fig. 4). The plots of normalized annual streamflow volume of the nine watersheds indicate that their differences were smaller in wet years than in drier years. Observing these differences and identifying whether the differences reflect the nature of watersheds or external causes will help the calibration and validation processes discussed in the "Recalibration of PERLND Parameters" section. Flag Creek and Hart Ditch at Munster again have higher normalized annual streamflow volume and Butterfield Creek has lower normalized annual streamflow volume than the rest of the watersheds. The watersheds that showed alternate lower annual streamflow volume throughout the study period include Hart Ditch at Dyer, Skokie River, and Long Run.

A flow duration curve (FDC) provides visual and a systematic means to describe the variability of flows in the specified time period at a site. The FDCs of normalized mean daily discharges (normalized by drainage area hence representing unit daily yield) for WYs 1996 to 2011 for each of the nine watersheds are shown in figure 5. For infrequent storm events (that is, storm events with high peaks or with small exceedance probabilities), the unit daily yield of the nine watersheds is similar except for Midlothian Creek, where storm peaks could be affected by operations of flood-protection reservoirs (see discussion for table 10). Conversely, in the low flow range

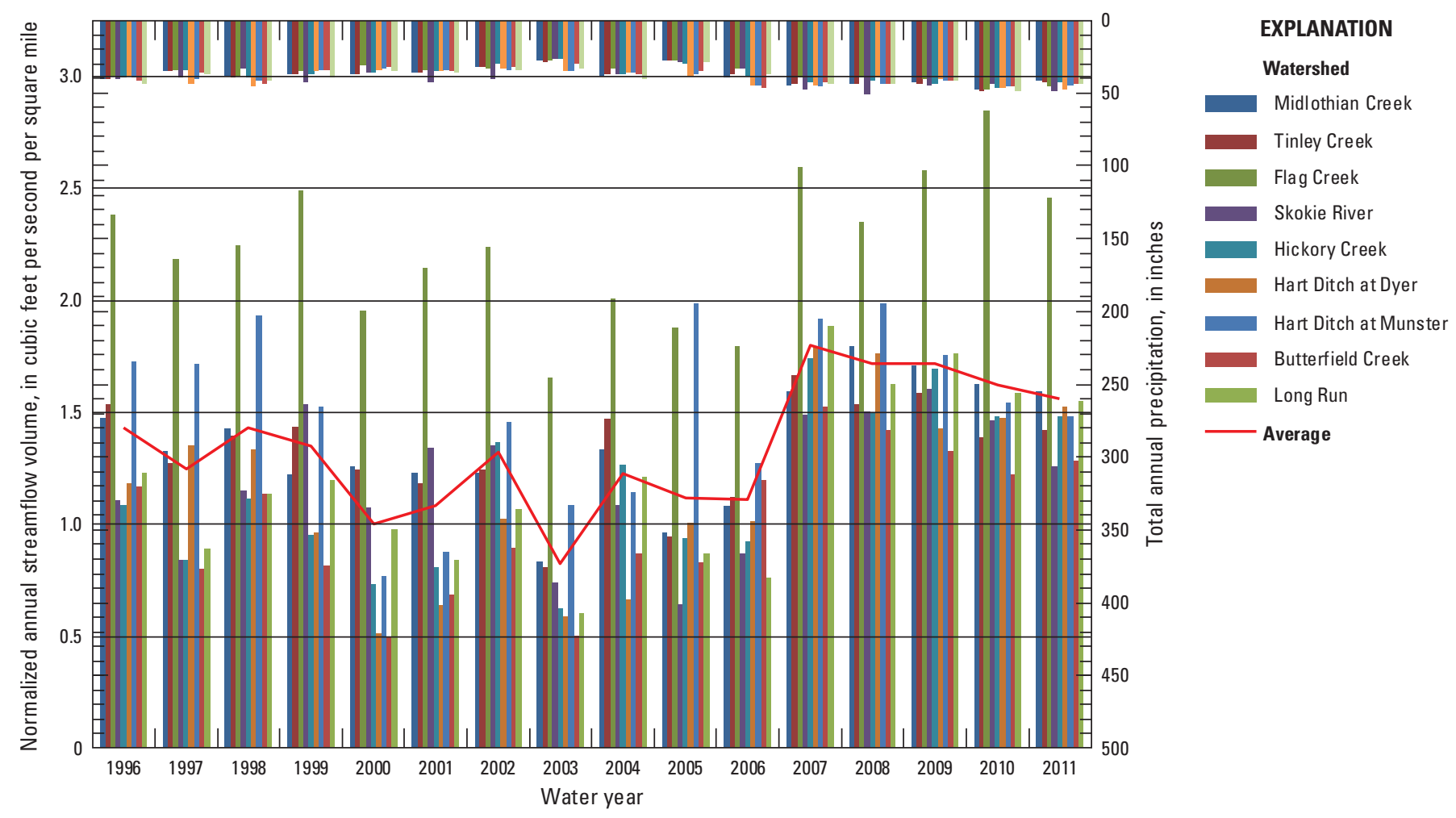

Figure 4. Normalized annual streamflow volume (in cubic feet per second per square mile) and total monthly precipitation (in inches) for the nine study watersheds for the period from October 1, 1995, to September 30, 2011. The red line is the average of normalized annual streamflow volume of the nine watersheds over the study period. 
(that is, exceedance probability close to 1), Flag Creek has higher magnitudes than other watersheds, followed by Hart Ditch at Munster, Hickory Creek, and Hart Ditch at Dyer. The higher low-flow magnitudes are likely augmented by wastewater treatment effluent discharge. In the low-flow range, Butterfield Creek has lower magnitudes than the other watersheds. The mean of daily discharge of each watershed (table 10) corresponds to a normalized daily discharge of approximately 1.2 cubic feet per second per square mile $\left(\mathrm{ft}^{3} / \mathrm{s} / \mathrm{mi}^{2}\right)$. This mean value corresponds to exceedance probabilities between 0.2 and 0.25 , approximately, as is shown in figure 5 .

The measured streamflow is the sum of quick flow and base flow although neither of the latter two components is measureable. Base flow time series can be extracted from daily streamflow time series by using base flow separation techniques such as HYSEP (http://water.usgs.gov/software/ HYSEP/, accessed August 2012); however, base flow is a simulated time series of the watershed model. Therefore, the fraction of base flow in the total streamflow volume during a specified time period can be compared to base flow obtained from the simulation, and the base flow time series is useful for analyzing low-flow and groundwater recession rates.
In HSPF, the process parameter AGWRC controls the basic groundwater recession rate when KVARY is set to zero and groundwater does not receive inflow (Bicknell and others, 2000). Using the master-depletion curve method (Chow, 1972), Gutierrez-Magness (2005) determined the relation between number of days (k coefficient) and AGWRC. For example, when $\mathrm{AGWRC}=0.99$ or 0.97 (the maximum and minimum AGWRC values in tables 2 and 3), the corresponding recession days are 95 and 33 days, respectively, computed as $k=-\ln (A G W R C)^{-1}$. The recession days of the study watersheds were examined graphically from isolated rainfallrunoff events in the study period by counting the days between the inflection point and the day when base flow magnitude stopped decreasing. For an event between April 24 and May 15,2007 , the receding days for the nine watersheds ranged from 16 to 19 days, which corresponds to AGWRC values between 0.939 and 0.949; for an event between August 24 and September 12, 1999, the receding days ranged between 14 and 18 days, and the corresponding AGWRC values ranged between 0.931 and 0.946 .

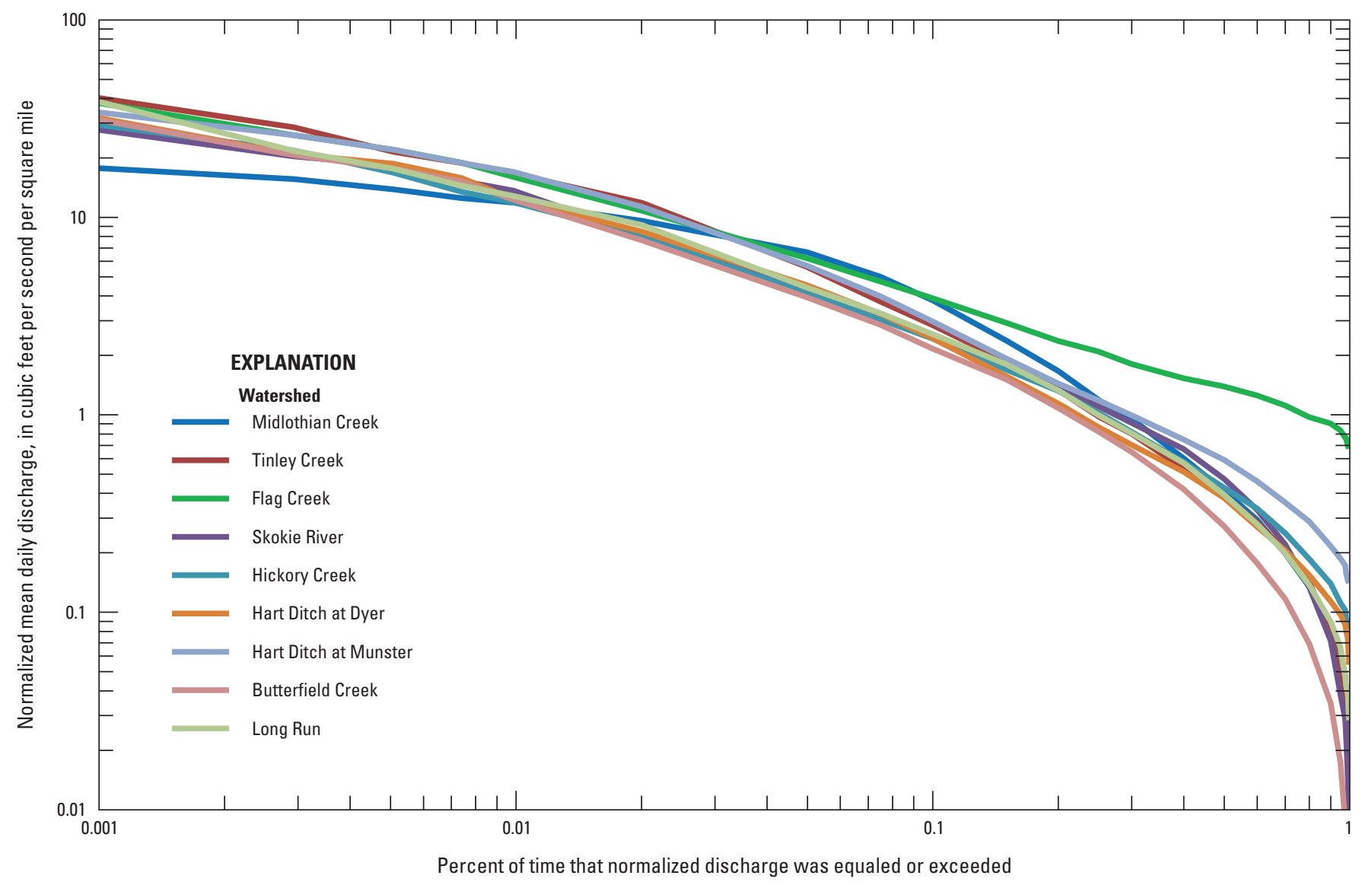

Figure 5. Flow duration curves based on mean-daily discharge between water years 1996 and 2011 for the nine study watersheds. 


\section{Effluent Discharges and Water Withdrawals}

Effluent discharges can come from sewer systems, wastewater treatment plants (WWTPs), or industrial plants that draw from surface-water or groundwater sources, and may have different paths to the surface-water system. Determining the role of effluents in the measured streamflow is challenging because the magnitudes are not readily available and the influencing factors can only be assessed by judgment. In the cases of effluent discharges from WWTPs and sewer overflows, or factory and industrial discharges whose sources are tap waters or operational water pumped from shallow or deep groundwater aquifers, the amounts need to be added to the simulated runoff time series. Water removed from a surface-water system and discharged back as effluent to the same surfacewater system at locations upstream from the gage does not add discharge to the observations; however, the withdrawal amount does need to be subtracted from the simulated runoff time series if effluent is returned at locations downstream from the gage. Further, some discharged water may have losses to infiltration or evaporation or others between local storage facilities and receiving streams.

This study retrieved historical effluent discharge data from various sources and treated the data as point sources with the magnitudes added to the simulated runoff time series in the corresponding watershed models. Thirty-four facilities located in the Butterfield Creek, Flag Creek, Hart Ditch at Dyer, Hart Ditch at Munster, and Long Run watersheds were identified through the EPA's Permit Compliance System (PCS). The effluent data were retrieved from three separate databases: data from 1998 to 2007 were obtained from http: www.epa.gov/ enviro/facts/pcs-icis/customized.html, data from 2007 to 2010 were obtained from http://cfpub.epa.gov/dmr/, and data from 2007 to 2012 were obtained from http://www.epa-echo.gov/ echo/compliance_report_water.html. After verifying the data, the three datasets were consolidated to form the time series from 1998 to 2012. Attempts to recover effluent data for 1995 to 1997 were not successful. In this analysis, effluent magnitudes for 1995 to 1997 were estimated by using the corresponding mean monthly values determined from 1998 to 2012.

A list of the effluent discharges included in the study is shown in table 11. Effluent stations with magnitude less than 0.1 million gallons per day (MGD) were omitted. Flag Creek has the largest effluent discharges, followed by Hickory Creek, Hart Ditch at Dyer, and Hart Ditch at Munster. The greater effluent discharges in Flag Creek and Hart Ditch at Munster possibly have caused higher water yield per unit area and base flow to streamflow ratios, and affected the shape of FDCs in the low-flow regime (see "Flow Duration Curves" section).

The Flagg Creek Water Reclamation District serves 10 communities with an area of approximately 24 square miles, covering areas outside of the Flag Creek watershed boundary (Tracey Larmon, Flagg Creek Water Reclamation, oral commun., October 3, 2012). The Hinsdale sewage treatment plant is about 2 miles upstream from the Flag Creek streamflow gage. Effluent discharge data from the Hinsdale sewage treatment plant were obtained (Tracey Larmon, Flagg Creek Water Reclamation District, written commun., October 3, 2012) and were the basis for estimating wastewater treatment facility effluent data for Flag Creek. Information for identifying the source of other effluent discharges was not directly available. Butterfield Creek is within the service area of Thorn Creek Basin Sanitary District (TCBSD). Drainage patterns in the watershed are complicated with sewer inflow often

Table 11. Effluent discharge data in the study area during 1998 to 2012.

[NPDES, National Pollutant Discharge Elimination System; MGD, million gallons per day; no., number]

\begin{tabular}{llc}
\hline \multicolumn{1}{c}{$\begin{array}{c}\text { Watershed name and subbasin } \\
\text { number where effluent discharges to }\end{array}$} & NPDES permit number & $\begin{array}{c}\text { Mean of monthly effluent } \\
\text { (MGD) }\end{array}$ \\
\hline Flag Creek, no. 3 & IL0022586 & 12.18 \\
Hickory Creek, no. 5 & IL0055981 & 0.68 \\
Hickory Creek, no. 6 & IL0024201 & 1.72 \\
Hickory Creek, no. 8 & IL0020559 & 1.84 \\
Hickory Creek, no. 12 & IL0066613, IL0045403, \\
Hickory Creek, no. 15 & IL0020532, IL0072192 & 3.44 \\
Hart Ditch at Dyer, no. 2 & IL0024422 & 0.18 \\
Hart Ditch at Munster, no. 16 & IL0031798 & 0.37 \\
& ING080050, ING340034, \\
Hart Ditch at Munster, no. 21 & ING340038, ING080089, & 9.56 \\
Hart Ditch at Munster, no. 36 & IN0024457 & \\
\hline
\end{tabular}

${ }^{1}$ Values in this column are the average of mean monthly effluent discharge from January 1998 to December 2012. 
overwhelming the treatment capacity of TCBSD (written commun., T.Y. Su, USACE-Chicago, June 4, 2014). The excess flow comes from leakage of sewer pipe (infiltration) and illegal sump pump connections (inflow). Inflow and infiltration seemed to be abnormally high in the Butterfield Creek watershed, and thus TCBSD initiated an inflow/infiltration limit program (T.Y. Su, USACE-Chicago, written commun., June 4, 2014). Once the storm runoff enters the sanitary-sewer system, treated or untreated water discharges to Thorn Creek, bypassing the USGS streamflow gage on Butterfield Creek (station number 05536255, not shown in the map).

Permitted water users (for example, a golf course) withdraw water directly from a stream for irrigation purposes and these withdrawals can affect streamflow volumes, especially during low-flow periods. A golf course is located in the lower reach of the Flag Creek watershed. The estimated average daily mean water use for a dry year could amount to 0.06 MGD/day and about 0.04 MGD/day for an average year, based on a 6,720-yard course with 40 yards width, and 4 courses (Patrick Mills, USGS, oral commun., May 31, 2013). Compared to the magnitude of effluent discharges in Flag Creek, such withdrawal amounts are not distinguishable in measured discharges, and therefore are not accounted for in the model simulations. There are also several golf courses along Butterfield Creek and their withdrawal amounts were not estimated because no withdrawal records could be located (Mills, oral commun., May 31, 2013).

\section{Soil Types}

Soil type is an important component in formulating hydrological studies. The Soil Conservation Service (SCS) hydrologic soil groups, which are determined by the minimum rate of infiltration obtained in bare soil after prolonged wetting (Natural Resources Conservation Service, 2007), are a set of physical data useful for estimating the initial values of INFILT. The dominant soil groups for the overall areas covering the diverted watershed and the nine study watersheds are C and D (fig. 6), determined from the SSURGO database (http://soildatamart.nrcs.usda.gov, accessed September, 2013). Soils in groups $\mathrm{C}$ and $\mathrm{D}$ have low to very low infiltration rates and therefore high runoff potentials. The soil groups for the nine study watersheds are primarily in $\mathrm{C}$ and $\mathrm{C} / \mathrm{D}$ but for the diverted watershed (fig. 1) the predominant soil group is D. Groups that are classified as "C/D" in figure 6 are soils that are classified as group $\mathrm{D}$ because there is a drainage problem created by high water tables. However, once the soils are effectively drained, they are placed in group C. The INFILT values corresponding to the SCS soil groups are in BASINS Technical Note No. 6 (U.S. Environmental Protection Agency,
2000). Among the INFILT values listed in tables 2 and 3, the value of 0.015 (The 1999 parameter set, table 2) belongs to soil group D, but a value of 0.10 (CTE parameter set, table 2) would belong to soil group $\mathrm{B}$ or $\mathrm{C}$, which represents "moderate" or "moderate to high" runoff potentials.

\section{Accuracy of Regional Hydrological Simulation Program-FORTRAN Parameter Sets Used in Lake Michigan Diversion Accounting}

Six of the nine LMDA parameter sets were evaluated for their accuracy in the simulated runoff volumes. The six parameter sets are North Branch and Hickory Creek parameter sets, which represent the original calibration parameter sets; and NIPC, 1999, CTE, and 2008 parameter sets, which represent calibration parameter sets with known modifications. The Little Calumet, Des Plaines, and CSSC parameter sets reported multiple parameters as ranges in values and therefore were not feasible for the study. Each of the six parameter sets was applied to each of the nine HSPF watershed models, which generate flow component time series that can be used for accuracy analysis. For documenting purpose, parameter values of each parameter set are listed in tables 2, 3, and 4. However, the following parameters are not mentioned in these tables and are reported here. The FOREST parameters are 0.2 and 0.3 for grassland and forestland, respectively, for all parameter sets except for the 2008 parameter set, which is 0.2 for forestland; PETMAX and PETMIN were $50^{\circ} \mathrm{F}$ and $45^{\circ} \mathrm{F}$, respectively, and a 0.76 factor was applied to wind input for the forestland.

The LMDA has used the $\mathrm{S} / \mathrm{R}$ ratio to describe the accuracy of simulated annual runoff volumes. In addition to annual S/R ratios, this study also used statistical and graphical techniques in the evaluation for identifying and explaining the discrepancies between simulated runoff and observed streamflow volumes. To evaluate the regional performance of a parameter set, simulation results of the nine watersheds are presented together. For statistical evaluations, the study used percent bias (PBIAS), Nash-Sutcliffe efficiency (NSE), and ratio of the root mean square error to the standard deviation of measured data (RSR), which was recommended by Moriasi and others (2007). The PBIAS is a measure of bias related to the $\mathrm{S} / \mathrm{R}$ ratio as $1-\mathrm{S} / \mathrm{R}$ ratio=PBIAS. Moriasi and others (2007) also suggested using a performance system for rating the accuracy of model calibrations (table 12). Graphical evaluations used in the study include flow duration curves and doublemass curve (DMC). 


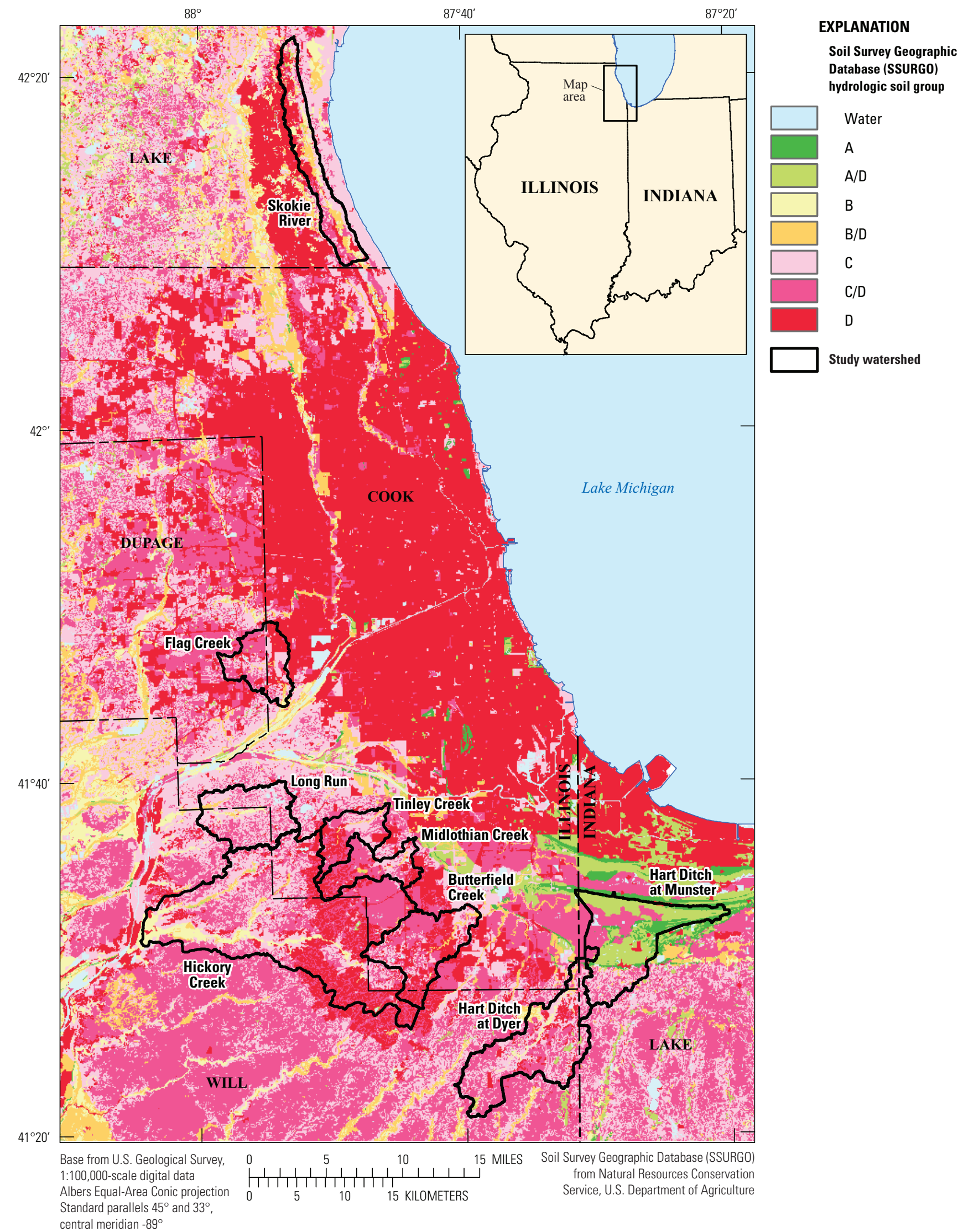

Figure 6. Soil Conservation Service hydrologic soil groups for Cook County and the nine study watersheds 
Table 12. Recommended statistical tests and ratings for evaluation of model-simulation performance.

[Modified from Moriasi and others (2007). RSR, root mean square error to the standard deviation of measured data, in ratio; NSE, Nash-Sutcliffe efficiency; PBIAS, deviation of simulated from observed data, in ratio; $\leq$, less than or equal to; $<$, less than; \pm , plus or minus]

\begin{tabular}{lccc}
\hline Performance rating & RSR & NSE & PBIAS \\
\hline Very good & $0.00 \leq \mathrm{RSR} \leq 0.50$ & $0.75<\mathrm{NSE} \leq 1.00$ & PBIAS $< \pm 0.10$ \\
Good & $0.50<\mathrm{RSR} \leq 0.60$ & $0.65<\mathrm{NSE} \leq 0.75$ & $\pm 0.10 \leq \mathrm{PBIAS}< \pm 0.15$ \\
Satistactory & $0.60<\mathrm{RSR} \leq 0.70$ & $0.50<\mathrm{NSE} \leq 0.65$ & $\pm 0.15 \leq \mathrm{PBIAS}< \pm 0.25$ \\
Unsatisfactory & $0.70<\mathrm{RSR}$ & $\mathrm{NSE} \leq 0.50$ & $\pm 0.25<\mathrm{PBIAS}$ \\
\hline
\end{tabular}

\section{Simulated to Recorded Ratios}

The simulated runoff time series from a modeled watershed is the sum of direct runoff, interflow, and groundwater outflow time series at the outlet of the watershed. The annual and overall $\mathrm{S} / \mathrm{R}$ ratios and the range of annual $\mathrm{S} / \mathrm{R}$ ratios from WY 1996 to WY 2011 for the six parameter sets and nine watersheds are given in table 13 . An overall $\mathrm{S} / \mathrm{R}$ ratio, computed from the total volumes of the study period, is also included in table 13 for a simple assessment of the $\mathrm{S} / \mathrm{R}$ ratio results.

Based on the overall quality of the resulting annual S/R ratios, the three land-cover acreages determined from the 2006 NLCD dataset are reasonably correct. The S/R ratios in annual and overall values in general score in the "fair" to "very good" ranks, but unsatisfactory underestimates occurred in the two Hart Ditch watersheds, and overestimates occurred in the Butterfield Creek, Skokie, and Long Run watersheds. The performance in terms of annual and overall $\mathrm{S} / \mathrm{R}$ ratios is summarized as follows.

1. Similar results were generated from the North Branch and Hickory Creek parameter sets, the NIPC and 1999 parameter sets, and the CTE and 2008 parameter sets; therefore, these parameter sets can be paired in three parameter groups. The 1999 group generated the lowest $\mathrm{S} / \mathrm{R}$ ratios and the North Branch and 2008 groups generated "very good" results in different watersheds.

2. All parameter sets resulted in overestimation for Butterfield Creek. Overestimation also occurred for Flag Creek but to a smaller degree. It appeared the effluent discharge time series used in the simulations are reasonable; however, besides effluent discharges, unaccounted water withdrawals in Flag and Butterfield Creeks and complex infiltration and inflow losses in Butterfield Creek could alter the natural streamflow patterns in the two watersheds.

3. The accuracy in simulated runoffs produced from specific land-cover categories could be a source of the discrepancies. For example, the Flag Creek watershed has the lowest amount of forestland areas ( 2 percent) fol- lowed by Butterfield Creek (7.4 percent). The percentage of land covers in each watershed is shown in table 6 . The annual and overall S/R ratios computed for Tinley Creek, Hart Ditch at Dyer, and the Hart Ditch at Munster have underestimation patterns for all parameters except the 2008 parameter set (table 13). These three watersheds have the highest forestland percentages among the nine study watersheds, which are 24.9, 22.4, and 17 percent, respectively (table 6). Long Run also has comparable forestland coverage (16.9 percent) but its grassland percentage is less than that of Hart Ditch at Munster (59.8 percent compared to 63.4 percent); therefore, the $S / R$ ratios for Long Run are higher.

4. The patterns of annual bias (1-annual $\mathrm{S} / \mathrm{R}$ ratio) from watershed to watershed can be examined by plotting the bias time series. Examining such plots does not indicate that the annual bias corresponds consistently to the annual precipitation amount of a certain year, but could be associated with precipitation of the previous year (soil moisture conditions); therefore, the discrepancies are parameter related.

5. The North Branch parameter generated "very good" overall S/R ratios for Midlothian Creek, Hickory Creek, and Long Run watersheds, and "satisfactory" overall S/R ratios for all watersheds except Butterfield Creek. The CTE and 2008 parameter sets generated "very good" overall S/R ratios for Midlothian Creek, Tinley Creek, Hart Ditch at Dyer and Munster, and Long Run watersheds, and "satisfactory" results at all watersheds except Butterfield Creek. The difference between North Branch and CTE or 2008 is that North Branch tends to slightly underestimate the $\mathrm{S} / \mathrm{R}$ ratios and CTE or 2008 tend to slightly overestimate the $\mathrm{S} / \mathrm{R}$ ratios.

As indicated in tables 2 and 3, the 1999 parameter set differed from the NIPC parameter set in LZSN and LSUR for the forestland, and most parameters in the impervious land segment. The CTE parameter set differed from the 1999 parameter set in LZSN and INFILT for the grassland and RETSC in 
Table 13. Ratio of simulated runoff to recorded streamflow volume (S/R ratio) for annual and total flow volumes between water years 1996 and 2011 for nine study watersheds with the six parameter sets.

[NIPC, Northeastern Illinois Planning Commission; CTE, Consoer Townsend Envirodyne Engineers]

\begin{tabular}{|c|c|c|c|c|c|c|c|c|c|c|c|c|c|c|c|c|c|c|}
\hline Parameter set & 1996 & 1997 & 1998 & 1999 & 2000 & 2001 & 2002 & 2003 & 2004 & 2005 & 2006 & 2007 & 2008 & 2009 & 2010 & 2011 & Overall & Range \\
\hline \multicolumn{19}{|c|}{ Midlothian Creek watershed } \\
\hline North Branch & 1.00 & 1.04 & 0.96 & 1.02 & 0.93 & 0.96 & 0.89 & 0.86 & 0.99 & 1.04 & 1.13 & 1.12 & 0.96 & 1.03 & 1.12 & 0.94 & 1.00 & $(0.86-1.13)$ \\
\hline Hickory & 0.96 & 1.03 & 0.94 & 1.00 & 0.90 & 0.95 & 0.88 & 0.84 & 0.97 & 1.03 & 1.10 & 1.11 & 0.94 & 1.02 & 1.11 & 0.93 & 0.99 & $(0.843-1.11)$ \\
\hline NIPC & 0.92 & 0.99 & 0.89 & 0.95 & 0.83 & 0.89 & 0.82 & 0.79 & 0.90 & 0.97 & 1.00 & 1.07 & 0.88 & 0.99 & 1.05 & 0.87 & 0.93 & $(0.79-1.07)$ \\
\hline 1999 & 0.92 & 0.99 & 0.89 & 0.95 & 0.83 & 0.89 & 0.82 & 0.79 & 0.90 & 0.97 & 1.00 & 1.07 & 0.88 & 0.99 & 1.05 & 0.87 & 0.93 & $(0.785-1.066)$ \\
\hline CTE & 1.06 & 1.10 & 1.04 & 1.12 & 1.03 & 1.07 & 0.96 & 0.93 & 1.10 & 1.10 & 1.24 & 1.20 & 1.02 & 1.10 & 1.21 & 1.01 & 1.08 & $(0.93-1.237)$ \\
\hline 2008 & 1.09 & 1.10 & 1.04 & 1.11 & 1.03 & 1.06 & 0.95 & 0.93 & 1.10 & 1.08 & 1.24 & 1.20 & 1.02 & 1.09 & 1.21 & 1.01 & 1.08 & $(0.927-1.239)$ \\
\hline \multicolumn{19}{|c|}{ Tinley Creek watershed } \\
\hline North Branch & 0.78 & 0.95 & 0.85 & 0.77 & 0.75 & 0.80 & 0.71 & 0.72 & 0.72 & 0.89 & 0.82 & 0.86 & 0.94 & 1.05 & 1.15 & 0.94 & 0.86 & $(0.71-1.15)$ \\
\hline Hickory & 0.76 & 0.94 & 0.84 & 0.76 & 0.73 & 0.79 & 0.71 & 0.71 & 0.71 & 0.89 & 0.79 & 0.86 & 0.93 & 1.05 & 1.14 & 0.93 & 0.85 & $(0.706-1.143)$ \\
\hline NIPC & 0.74 & 0.92 & 0.79 & 0.72 & 0.67 & 0.75 & 0.66 & 0.65 & 0.66 & 0.84 & 0.72 & 0.84 & 0.89 & 1.03 & 1.09 & 0.87 & 0.81 & $(0.65-1.09)$ \\
\hline 1999 & 0.74 & 0.92 & 0.80 & 0.72 & 0.67 & 0.75 & 0.66 & 0.65 & 0.66 & 0.84 & 0.72 & 0.84 & 0.89 & 1.03 & 1.09 & 0.87 & 0.81 & $(0.654-1.091)$ \\
\hline CTE & 0.87 & 1.04 & 0.99 & 0.89 & 0.87 & 0.96 & 0.84 & 0.81 & 0.86 & 1.02 & 0.96 & 1.00 & 1.09 & 1.18 & 1.31 & 1.06 & 0.99 & $(0.814-1.308)$ \\
\hline 2008 & 0.95 & 1.04 & 0.98 & 0.87 & 0.87 & 0.94 & 0.82 & 0.81 & 0.86 & 0.99 & 0.96 & 1.00 & 1.10 & 1.16 & 1.32 & 1.06 & 0.99 & $(0.81-1.316)$ \\
\hline \multicolumn{19}{|c|}{ Flag Creek watershed } \\
\hline North Branch & 1.15 & 1.23 & 1.23 & 1.06 & 1.06 & 1.13 & 1.11 & 1.14 & 1.17 & 1.18 & 1.19 & 1.13 & 1.22 & 1.17 & 1.12 & 1.26 & 1.16 & $(1.06-1.26)$ \\
\hline Hickory & 1.12 & 1.22 & 1.22 & 1.06 & 1.05 & 1.12 & 1.10 & 1.13 & 1.15 & 1.17 & 1.17 & 1.12 & 1.20 & 1.16 & 1.11 & 1.25 & 1.15 & $(1.049-1.247)$ \\
\hline NIPC & 1.08 & 1.18 & 1.17 & 1.03 & 1.01 & 1.08 & 1.06 & 1.09 & 1.10 & 1.13 & 1.12 & 1.08 & 1.15 & 1.14 & 1.08 & 1.20 & 1.11 & $(1.01-1.2)$ \\
\hline 1999 & 1.08 & 1.18 & 1.17 & 1.03 & 1.01 & 1.08 & 1.06 & 1.09 & 1.10 & 1.13 & 1.12 & 1.08 & 1.15 & 1.14 & 1.08 & 1.20 & 1.11 & $(1.011-1.203)$ \\
\hline CTE & 1.17 & 1.24 & 1.28 & 1.09 & 1.12 & 1.18 & 1.14 & 1.18 & 1.21 & 1.19 & 1.22 & 1.15 & 1.24 & 1.20 & 1.17 & 1.29 & 1.19 & $(1.09-1.291)$ \\
\hline 2008 & 1.19 & 1.24 & 1.28 & 1.09 & 1.12 & 1.18 & 1.14 & 1.18 & 1.21 & 1.19 & 1.22 & 1.15 & 1.24 & 1.20 & 1.17 & 1.29 & 1.19 & $(1.09-1.291)$ \\
\hline \multicolumn{19}{|c|}{ Skokie River watershed } \\
\hline North Branch & 1.23 & 1.70 & 0.92 & 0.92 & 0.91 & 0.99 & 1.09 & 0.93 & 1.10 & 1.32 & 0.96 & 1.24 & 1.35 & 1.12 & 0.98 & 1.38 & 1.13 & $(0.91-1.7)$ \\
\hline Hickory & 1.19 & 1.68 & 0.91 & 0.90 & 0.89 & 0.97 & 1.07 & 0.93 & 1.08 & 1.30 & 0.93 & 1.22 & 1.33 & 1.11 & 0.97 & 1.34 & 1.11 & $(0.886-1.683)$ \\
\hline NIPC & 1.14 & 1.61 & 0.86 & 0.84 & 0.81 & 0.91 & 1.01 & 0.87 & 1.00 & 1.19 & 0.83 & 1.15 & 1.28 & 1.07 & 0.91 & 1.25 & 1.04 & $(0.81-1.61)$ \\
\hline 1999 & 1.14 & 1.61 & 0.86 & 0.84 & 0.81 & 0.91 & 1.01 & 0.87 & 1.00 & 1.19 & 0.83 & 1.15 & 1.28 & 1.07 & 0.91 & 1.25 & 1.04 & $(0.806-1.612)$ \\
\hline CTE & 1.31 & 1.83 & 1.01 & 1.00 & 1.04 & 1.10 & 1.18 & 1.06 & 1.21 & 1.39 & 1.05 & 1.34 & 1.47 & 1.21 & 1.08 & 1.48 & 1.23 & $(0.998-1.826)$ \\
\hline 2008 & 1.36 & 1.83 & 1.00 & 1.00 & 1.03 & 1.10 & 1.18 & 1.04 & 1.21 & 1.38 & 1.04 & 1.35 & 1.47 & 1.20 & 1.08 & 1.49 & 1.23 & $(0.995-1.826)$ \\
\hline \multicolumn{19}{|c|}{ Hickory Creek watershed } \\
\hline North Branch & 1.29 & 1.47 & 1.13 & 1.19 & 1.26 & 1.20 & 0.68 & 0.91 & 0.92 & 1.02 & 1.16 & 0.90 & 1.01 & 1.00 & 1.08 & 0.97 & 1.05 & $(0.68-1.47)$ \\
\hline Hickory & 1.24 & 1.44 & 1.10 & 1.18 & 1.23 & 1.19 & 0.67 & 0.89 & 0.89 & 1.01 & 1.13 & 0.89 & 0.98 & 0.99 & 1.06 & 0.94 & 1.03 & $(0.67-1.443)$ \\
\hline NIPC & 1.18 & 1.36 & 1.01 & 1.09 & 1.11 & 1.08 & 0.61 & 0.81 & 0.80 & 0.92 & 0.99 & 0.84 & 0.90 & 0.95 & 0.99 & 0.87 & 0.95 & $(0.61-1.36)$ \\
\hline 1999 & 1.18 & 1.36 & 1.01 & 1.09 & 1.11 & 1.08 & 0.61 & 0.81 & 0.80 & 0.92 & 0.99 & 0.84 & 0.90 & 0.96 & 0.99 & 0.87 & 0.95 & $(0.605-1.356)$ \\
\hline CTE & 1.39 & 1.57 & 1.28 & 1.35 & 1.46 & 1.38 & 0.76 & 0.99 & 1.05 & 1.10 & 1.31 & 0.99 & 1.10 & 1.10 & 1.19 & 1.07 & 1.16 & $(0.762-1.571)$ \\
\hline 2008 & 1.44 & 1.58 & 1.27 & 1.34 & 1.45 & 1.38 & 0.76 & 0.99 & 1.05 & 1.09 & 1.31 & 0.99 & 1.10 & 1.09 & 1.20 & 1.07 & 1.16 & $(0.755-1.575)$ \\
\hline
\end{tabular}


Table 13. Ratio of simulated runoff to recorded streamflow volume (S/R ratio) for annual and total flow volumes between water years 1996 and 2011 for nine study watersheds with the six parameter sets.-Continued

[S, simulated annual runoff volume; R, recorded annual streamflow volume; NIPC, Northeastern Illinois Planning Commission; CTE, Consoer Townsend Envirodyne Engineers]

\begin{tabular}{|c|c|c|c|c|c|c|c|c|c|c|c|c|c|c|c|c|c|c|}
\hline Parameter set & 1996 & 1997 & 1998 & 1999 & 2000 & 2001 & 2002 & 2003 & 2004 & 2005 & 2006 & 2007 & 2008 & 2009 & 2010 & 2011 & Overall & Range \\
\hline \multicolumn{19}{|c|}{ Hart Ditch at Dyer watershed } \\
\hline North Branch & 0.81 & 0.93 & 0.94 & 0.81 & 0.88 & 1.16 & 0.73 & 0.93 & 1.01 & 0.80 & 0.88 & 0.72 & 0.50 & 0.67 & 0.80 & 0.84 & 0.80 & $(0.5-1.16)$ \\
\hline Hickory & 0.75 & 0.91 & 0.92 & 0.80 & 0.85 & 1.13 & 0.72 & 0.86 & 0.96 & 0.76 & 0.85 & 0.71 & 0.47 & 0.66 & 0.79 & 0.82 & 0.78 & $(0.472-1.127)$ \\
\hline NIPC & 0.69 & 0.87 & 0.86 & 0.73 & 0.67 & 1.04 & 0.62 & 0.67 & 0.82 & 0.66 & 0.72 & 0.67 & 0.41 & 0.63 & 0.72 & 0.75 & 0.70 & $(0.41-1.04)$ \\
\hline 1999 & 0.69 & 0.88 & 0.86 & 0.73 & 0.67 & 1.04 & 0.63 & 0.67 & 0.82 & 0.66 & 0.72 & 0.67 & 0.41 & 0.64 & 0.72 & 0.75 & 0.71 & $(0.414-1.039)$ \\
\hline CTE & 0.92 & 1.06 & 1.08 & 0.95 & 1.15 & 1.46 & 0.90 & 1.14 & 1.29 & 0.98 & 1.15 & 0.82 & 0.61 & 0.83 & 0.96 & 0.99 & 0.97 & $(0.608-1.464)$ \\
\hline 2008 & 1.01 & 1.08 & 1.08 & 0.93 & 1.13 & 1.46 & 0.88 & 1.14 & 1.28 & 0.97 & 1.14 & 0.82 & 0.62 & 0.82 & 0.96 & 0.98 & 0.97 & $(0.619-1.46)$ \\
\hline \multicolumn{19}{|c|}{ Hart Ditch at Munster watershed } \\
\hline North Branch & 0.76 & 0.85 & 0.70 & 0.64 & 1.01 & 1.08 & 0.77 & 0.79 & 0.95 & 0.57 & 1.05 & 0.89 & 0.80 & 0.84 & 0.99 & 1.00 & 0.83 & $(0.57-1.08)$ \\
\hline Hickory & 0.72 & 0.84 & 0.68 & 0.63 & 0.98 & 1.06 & 0.76 & 0.76 & 0.92 & 0.56 & 1.03 & 0.89 & 0.77 & 0.83 & 0.97 & 0.98 & 0.82 & $(0.558-1.062)$ \\
\hline NIPC & 0.68 & 0.81 & 0.64 & 0.59 & 0.87 & 0.99 & 0.70 & 0.67 & 0.84 & 0.52 & 0.93 & 0.85 & 0.72 & 0.80 & 0.91 & 0.92 & 0.76 & $(0.52-0.99)$ \\
\hline 1999 & 0.68 & 0.81 & 0.64 & 0.59 & 0.87 & 0.99 & 0.70 & 0.67 & 0.84 & 0.52 & 0.93 & 0.85 & 0.72 & 0.80 & 0.91 & 0.92 & 0.76 & $(0.516-0.988)$ \\
\hline CTE & 0.82 & 0.94 & 0.77 & 0.72 & 1.16 & 1.26 & 0.86 & 0.89 & 1.08 & 0.64 & 1.23 & 0.97 & 0.88 & 0.94 & 1.11 & 1.12 & 0.93 & $(0.64-1.258)$ \\
\hline 2008 & 0.87 & 0.94 & 0.77 & 0.71 & 1.15 & 1.26 & 0.85 & 0.90 & 1.08 & 0.63 & 1.22 & 0.97 & 0.89 & 0.92 & 1.11 & 1.12 & 0.93 & $(0.634-1.255)$ \\
\hline \multicolumn{19}{|c|}{ Butterfield Creek watershed } \\
\hline North Branch & 1.33 & 1.61 & 1.38 & 1.35 & 1.62 & 1.45 & 1.16 & 1.50 & 1.41 & 1.34 & 1.31 & 1.04 & 1.19 & 1.17 & 1.27 & 1.18 & 1.29 & $(1.04-1.62)$ \\
\hline Hickory & 1.27 & 1.58 & 1.34 & 1.34 & 1.58 & 1.42 & 1.14 & 1.46 & 1.36 & 1.33 & 1.28 & 1.03 & 1.16 & 1.16 & 1.24 & 1.15 & 1.26 & $(1.034-1.583)$ \\
\hline NIPC & 1.20 & 1.50 & 1.24 & 1.25 & 1.42 & 1.29 & 1.04 & 1.31 & 1.23 & 1.22 & 1.16 & 0.99 & 1.08 & 1.11 & 1.15 & 1.07 & 1.17 & $(0.99-1.5)$ \\
\hline 1999 & 1.20 & 1.50 & 1.24 & 1.25 & 1.42 & 1.29 & 1.04 & 1.31 & 1.23 & 1.22 & 1.16 & 0.99 & 1.08 & 1.11 & 1.15 & 1.07 & 1.17 & $(0.986-1.495)$ \\
\hline CTE & 1.40 & 1.72 & 1.50 & 1.48 & 1.81 & 1.63 & 1.25 & 1.61 & 1.56 & 1.42 & 1.46 & 1.10 & 1.25 & 1.27 & 1.40 & 1.28 & 1.40 & $(1.097-1.81)$ \\
\hline 2008 & 1.42 & 1.72 & 1.50 & 1.47 & 1.81 & 1.63 & 1.24 & 1.61 & 1.56 & 1.41 & 1.46 & 1.10 & 1.25 & 1.26 & 1.40 & 1.28 & 1.40 & $(1.095-1.81)$ \\
\hline \multicolumn{19}{|c|}{ Long Run watershed } \\
\hline North Branch & 1.15 & 1.46 & 1.08 & 0.94 & 0.84 & 1.08 & 0.90 & 1.12 & 0.97 & 0.98 & 1.09 & 0.74 & 0.88 & 0.84 & 0.97 & 0.86 & 0.96 & $(0.74-1.46)$ \\
\hline Hickory & 1.10 & 1.45 & 1.06 & 0.93 & 0.82 & 1.06 & 0.89 & 1.08 & 0.94 & 0.99 & 1.05 & 0.73 & 0.86 & 0.84 & 0.95 & 0.83 & 0.94 & $(0.731-1.446)$ \\
\hline NIPC & 1.06 & 1.38 & 0.98 & 0.88 & 0.73 & 0.94 & 0.82 & 0.96 & 0.86 & 0.92 & 0.92 & 0.69 & 0.79 & 0.81 & 0.89 & 0.77 & 0.87 & $(0.69-1.38)$ \\
\hline 1999 & 1.06 & 1.38 & 0.98 & 0.88 & 0.73 & 0.94 & 0.82 & 0.96 & 0.86 & 0.92 & 0.92 & 0.69 & 0.79 & 0.81 & 0.89 & 0.77 & 0.88 & $(0.688-1.38)$ \\
\hline CTE & 1.26 & 1.58 & 1.24 & 1.06 & 1.00 & 1.28 & 1.04 & 1.31 & 1.12 & 1.08 & 1.27 & 0.84 & 0.99 & 0.95 & 1.09 & 0.96 & 1.09 & $(0.837-1.576)$ \\
\hline 2008 & 1.33 & 1.58 & 1.23 & 1.05 & 0.99 & 1.27 & 1.02 & 1.31 & 1.13 & 1.05 & 1.26 & 0.84 & 0.99 & 0.93 & 1.10 & 0.96 & 1.09 & $(0.835-1.579)$ \\
\hline
\end{tabular}




\section{Lake Michigan Diversion Accounting Land Cover Change Estimation}

impervious land. The 2008 parameter set was developed based on CTE with recalibrated forestland parameters. Although the analysis pointed to the parameter values as the source of the discrepancies, other factors such as watershed changes or errors in measured meteorological or streamflow time series could also be the causes of simulation inaccuracy. The DMC and FDC analyses graphically illustrate the fit of simulated runoffs and the DMC also can be used to examine if other factors played a role in the accuracy of simulations. In the following discussions, the DMCs were developed with monthly observed mean streamflow and simulated runoff volumes, and FDCs were developed with daily mean streamflow and simulated runoff volumes. Unlike FDCs, time can be traced in the DMCs and therefore relevant changes could be gathered for identifying the causes of discrepancies.

\section{Double-Mass Curve Analysis}

In hydrological and meteorological studies, the DMC analysis has been used to determine the need for corrections to the data due to changes in data collection procedures or other local conditions (Chow, 1972). A DMC is the plot of accumulative streamflow against the accumulative precipitation for a specified time unit in the study period. Chaille and Yen (2000) applied DMC analysis to investigate historical watershed changes reflected in streamflow records representing an urbanizing area. If the trend in precipitation and streamflow yields does not change during the study period, then the DMC developed from the two records should follow a straight line. Attributes of urban developments, such as changes in land uses (as acreages in forestland, grassland, or impervious surfaces shown in table 9), storm water management (detention basins, flood mitigation controls, and others), or channel regulation work can introduce changes in the slopes of the measured DMC. Unless these changes are described in the models, the model simulation would not reflect the changes because the acreages of various land-cover types generally are fixed in model simulations. A change in the slope of the DMC will appear when the precipitation to runoff relation is altered. Some of the changes can be temporary (referred to as "slope change" in the following text), but some are permanent (referred to as "slope break" in the following text).

Monthly DMCs were developed for measured streamflow and simulated runoff volumes. The measured DMCs are for examining the consistency between streamflows and precipitation, and the simulated DMCs were compared to the measured DMCs for evaluating the accuracy of parameters because the slope of simulated DMC would not change unless those watershed changes were introduced to the models during the simulations. The DMCs for the study period developed for the nine watersheds based on the North Branch, 1999, and 2008 parameter sets are shown in figures 7,8 , and 9. These DMCs didn't show obvious slope breaks but there were piecewise slope changes of various degrees in almost all measured
DMCs (fig. 7). In figures 7, 8, and 9 the small slope changes in measured DMCs were matched by the simulated DMCs, which indicated there were no systematic problems and it is acceptable to use a fixed land-cover composition to model the rainfall-runoff mechanisms for the study period.

The North Branch parameter set underestimated streamflows at Tinley Creek, Hart Ditch at Dyer, and Hart Ditch at Munster; matched streamflows well at Midlothian Creek, Hickory Creek, and Long Run; and overestimated streamflows at Flag Creek and Butterfield Creek. This pattern agrees with the overall S/R ratios shown in table 13. The 1999 parameter set simulated the lowest runoff volumes in all watersheds. These results were achieved through parameter modifications including some minor changes in the IMPLND segment. The reduction in predicted volumes resulted in better simulation results for Skokie River and, to a lesser extent, in Flag Creek and Long Run. The 2008 parameter set increased the simulated runoff volumes from forestlands and improved the simulation results for Tinley Creek and Hart Ditch at Munster, but overestimated runoff volumes for the other watersheds. Simulations with the 2008 parameter set produced small slope changes in the observed DMCs. Overall, when a different parameter set was applied, there were simultaneous improvements on matches of DMCs and small slope changes at multiple watersheds, indicating that parameter values could be the primary cause of the simulation inaccuracy and it is possible that recalibrating a regional parameter set can improve the prediction at multiple watersheds.

\section{Flow Duration Curves}

Analysis of FDCs can reveal how well the model reproduces the measured daily flows in the specified time period as well as the adequacy of simulation throughout the entire range of flow conditions (Van Liew and others, 2007). The FDCs used in the study are based on mean daily discharge data for the study period. Note that the model development did not emphasize the flow routing component; therefore, the FDCs in the study primarily are used for (1) assessing the general fit of flow magnitudes in the entire time series of the study period, and (2) identifying how to specify FDCs in the calibration. The FDCs developed from North Branch, 1999, and 2008 parameter sets for the nine study watersheds are shown in figures 10, 11, and 12. Overall, the North Branch and 1999 parameter sets underestimated flow magnitudes for the majority of the FDC frequencies (figs. 7 and 8). The underestimation is most prominent for high frequency quartiles (that is, low flows). The exception is the FDCs generated for Flag Creek by both parameter sets. The 2008 parameters improved the underestimations at most occurrence frequencies for Midlothian Creek, Tinley Creek, Skokie River, Hart Ditch at Dyer and Munster, and Long Run, but resulted in overestimations for Flag Creek, Butterfield Creek, and Hickory Creek, although the degree of overestimation varies. 

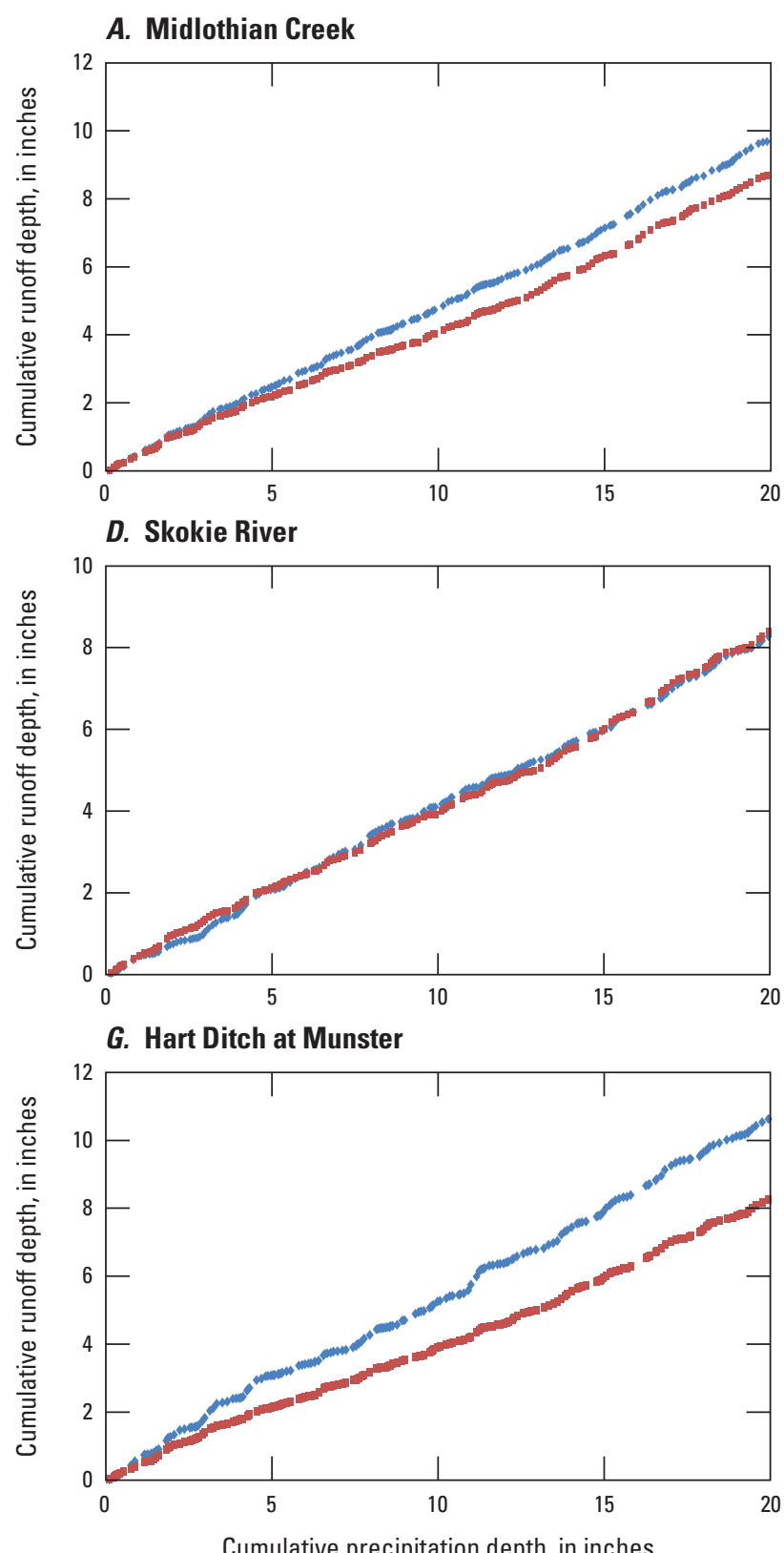

Cumulative precipitation depth, in inches

Figure 7. Double-mass curves of observed streamflow and simulated runoff volume for the nine study watersheds using the North Branch parameter set for water years 1996 to 2011.
B. Tinley Creek

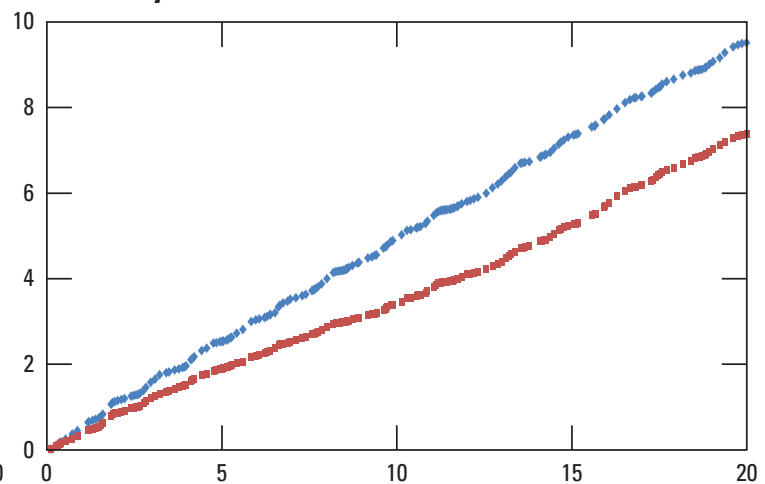

\section{Flag Creek}

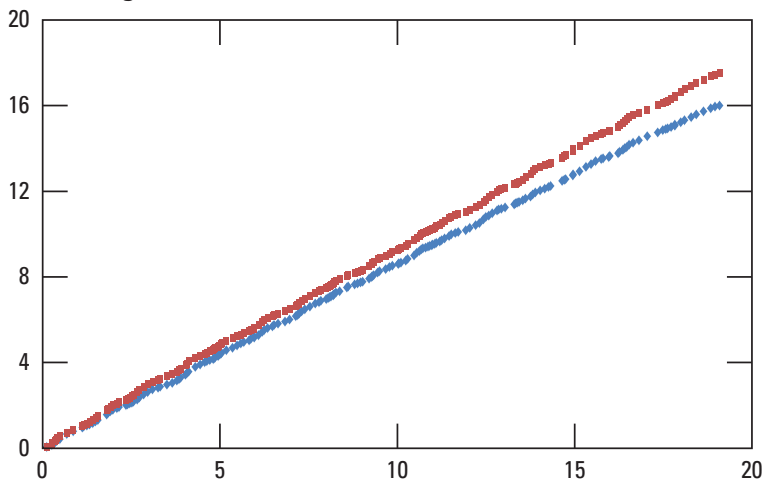

E. Hickory Creek

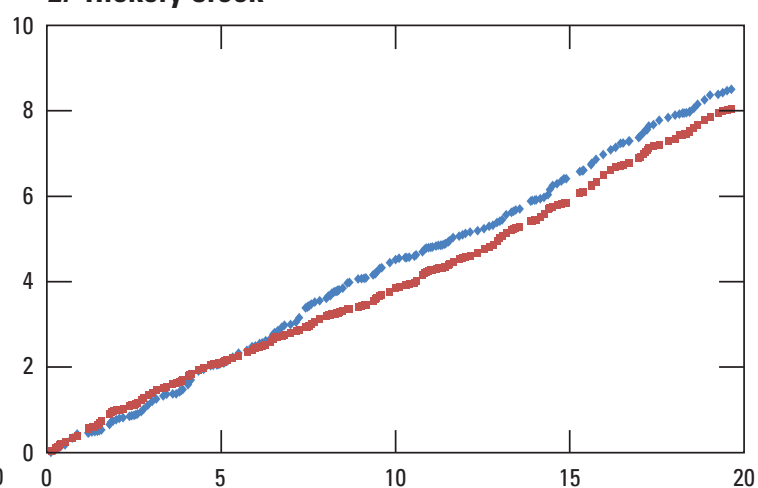

H. Butterfield Creek

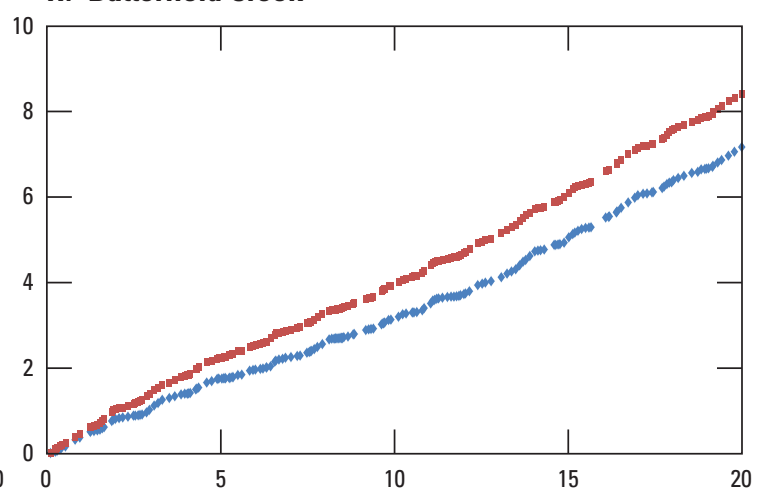

Cumulative precipitation depth, in inches
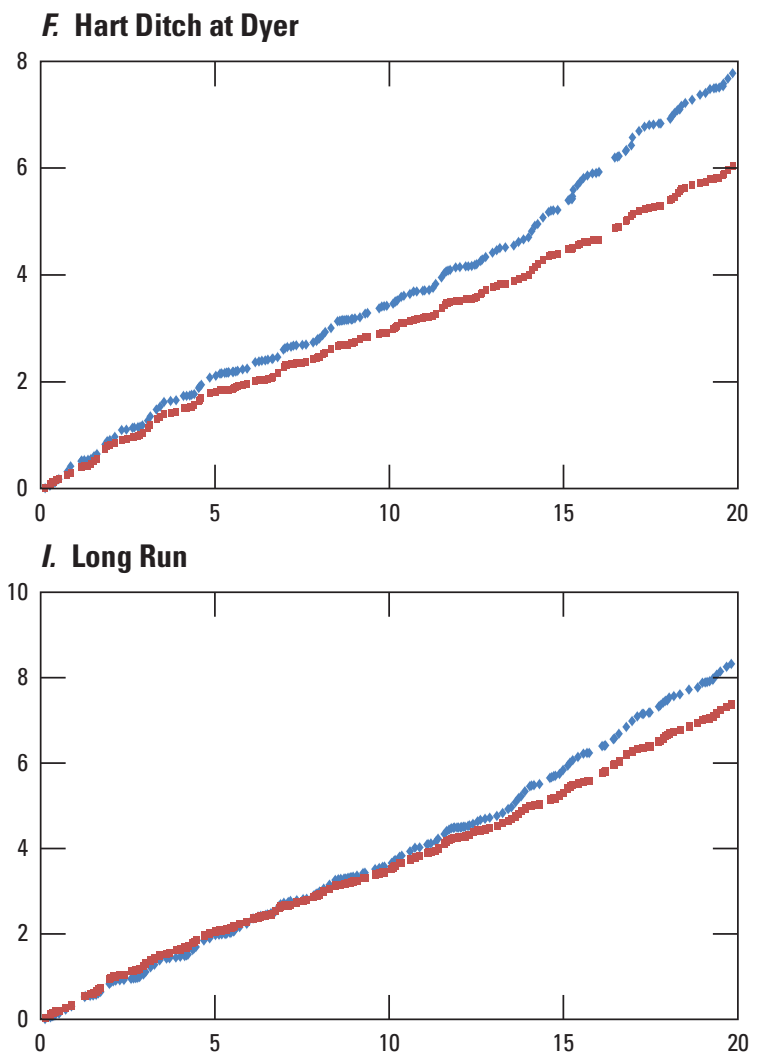

Cumulative precipitation depth, in inches

\section{EXPLANATION}

- Observed flow

- Simulated total runoff (SIMO) 

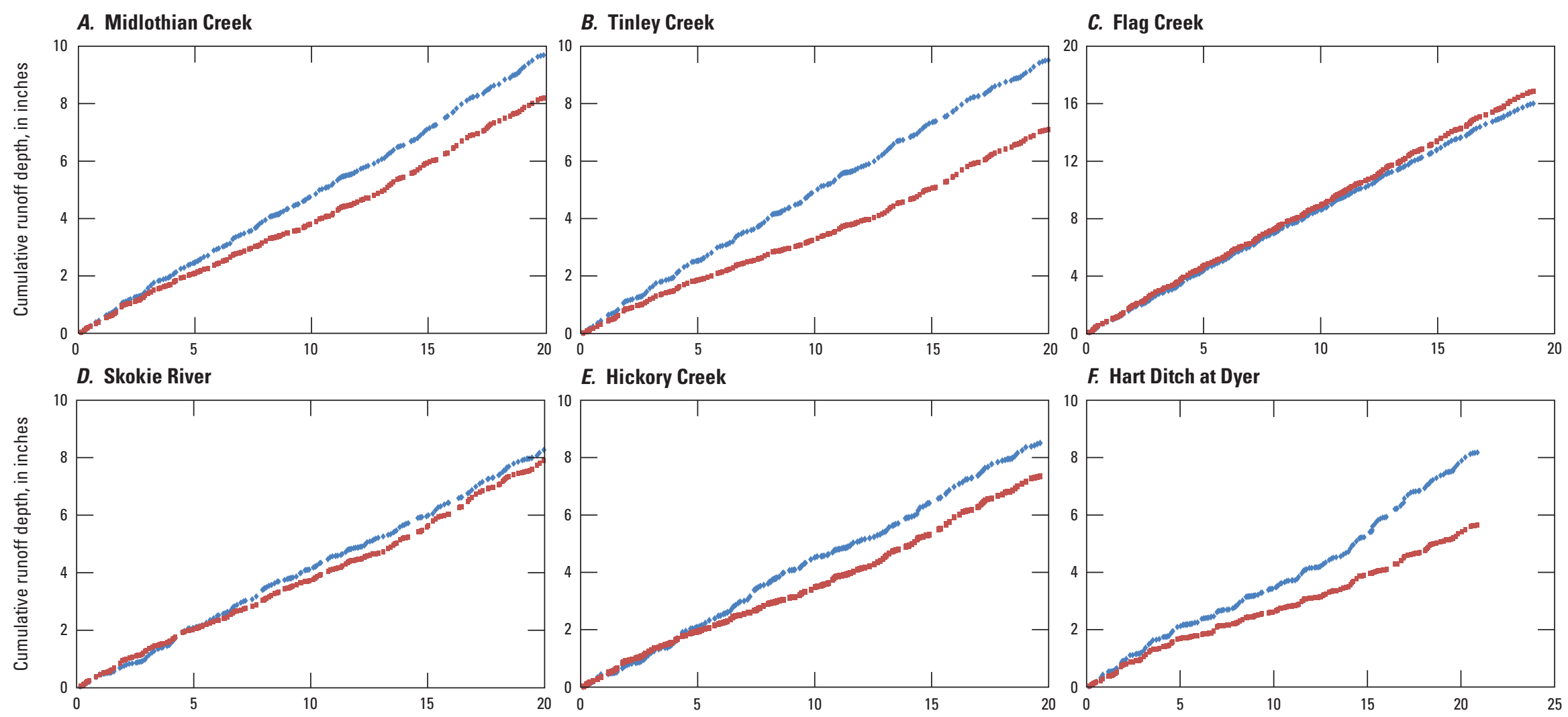

E. Hickory Creek
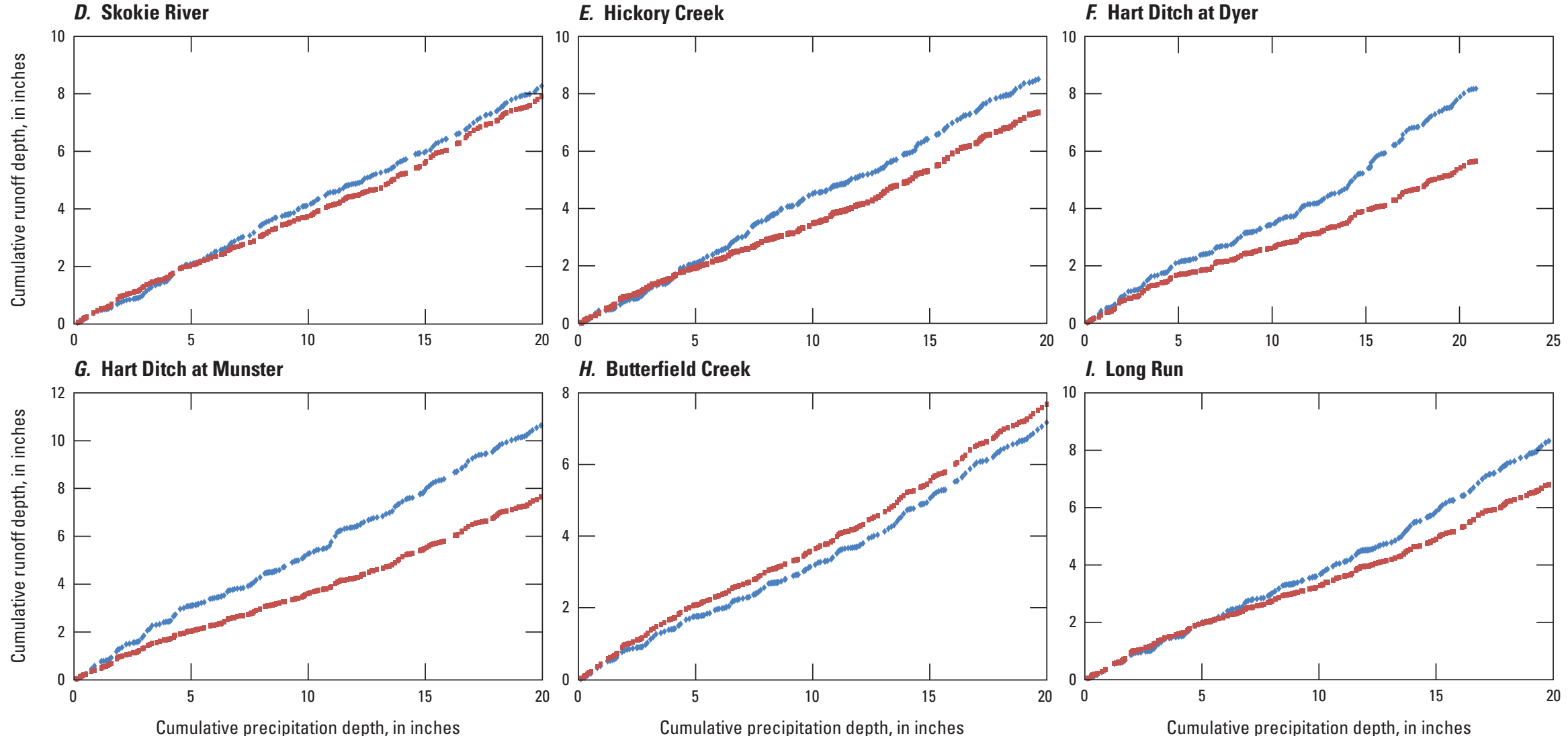

H. Butterfield Creek

I. Long Run
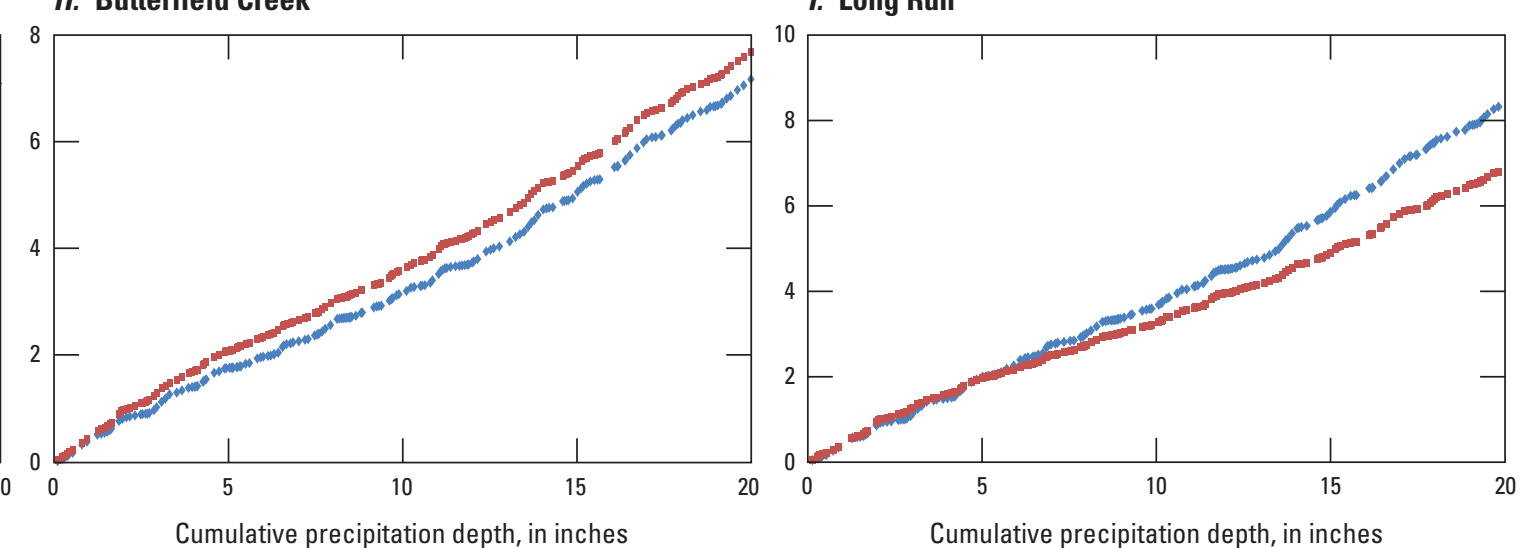

EXPLANATION

Figure 8. Double-mass curves of observed streamflow and simulated runoff volume for the nine study watersheds using the 1999 parameter set for water years 1996 to 2011. 
A. Midlothian Creek
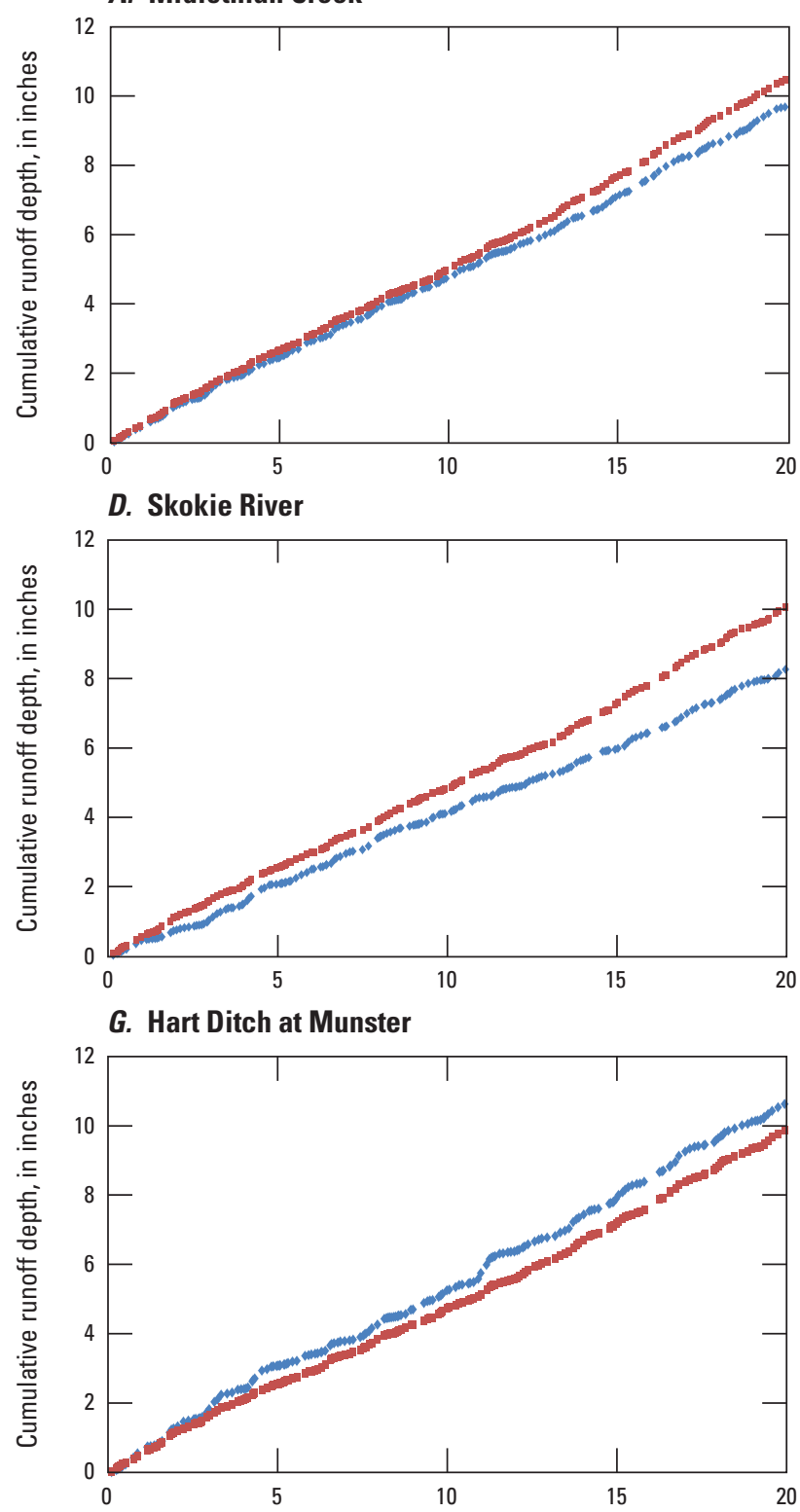

Cumulative precipitation depth, in inches
B. Tinley Creek

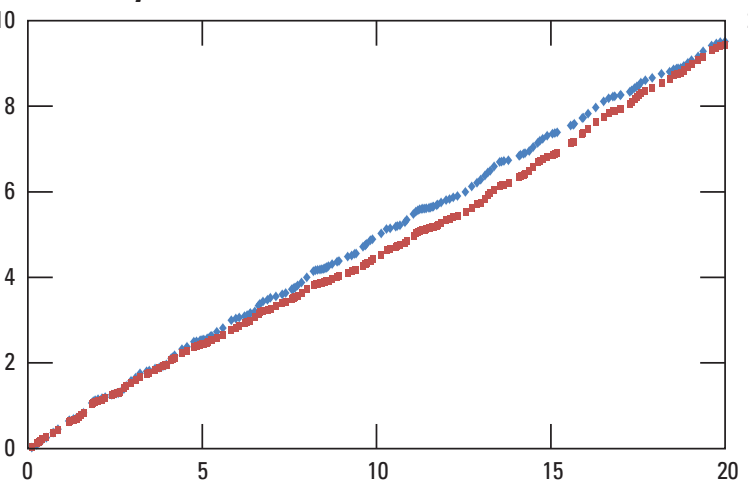

E. Hickory Creek

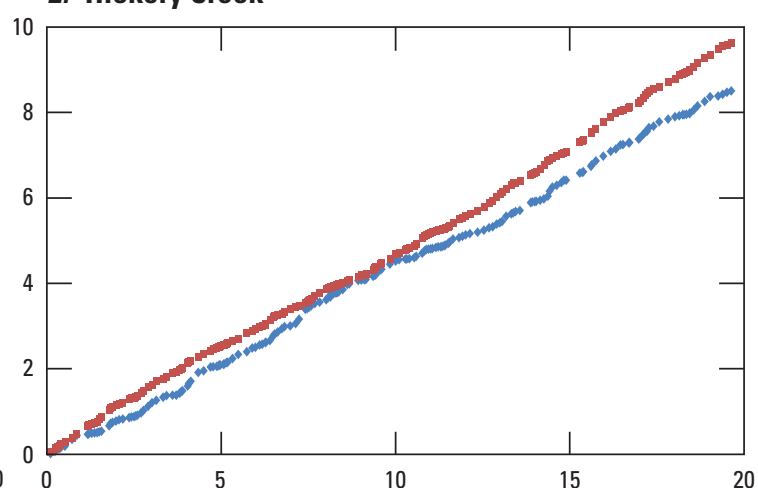

H. Butterfield Creek

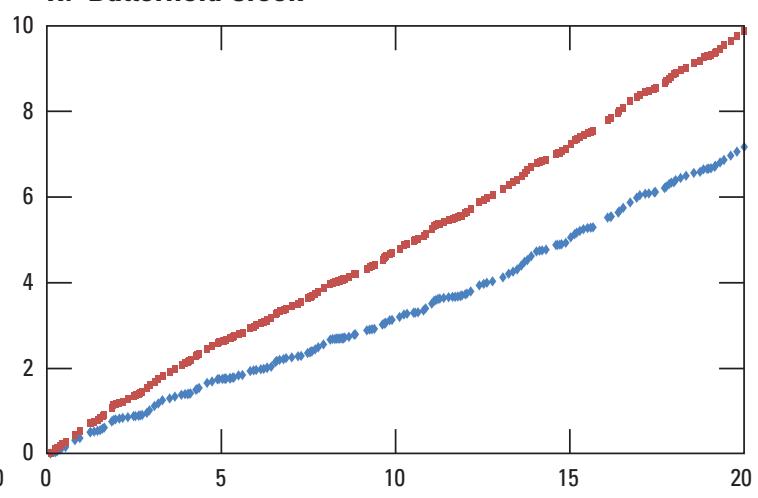

Cumulative precipitation depth, in inches
C. Flag Creek

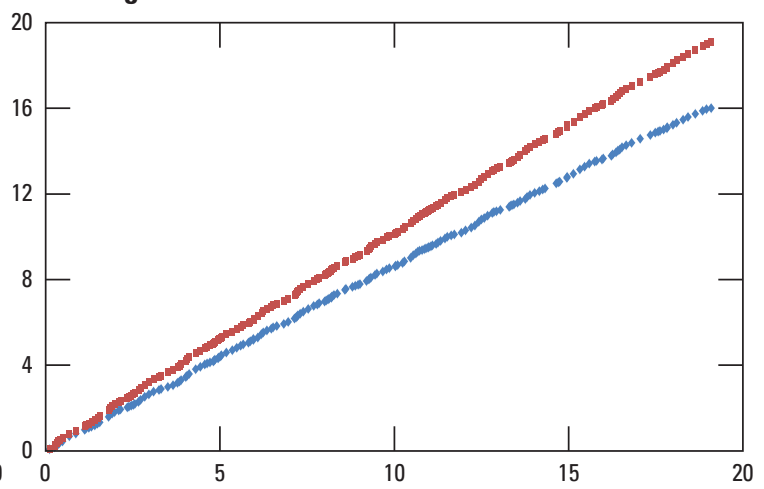

F. Hart Ditch at Dyer

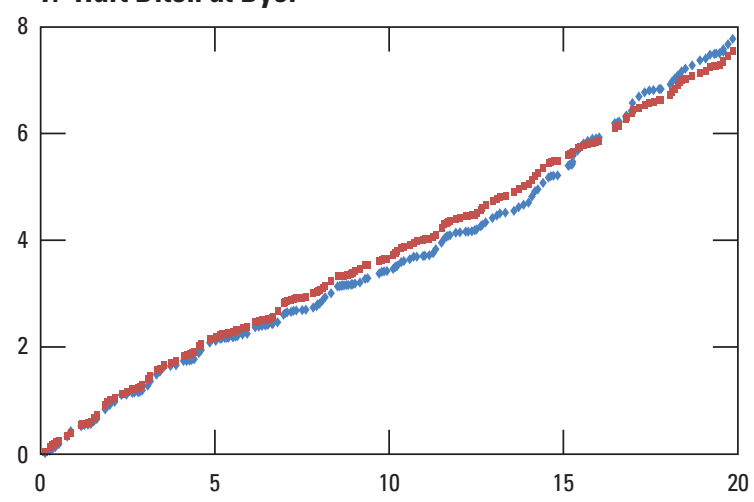

I. Long Run

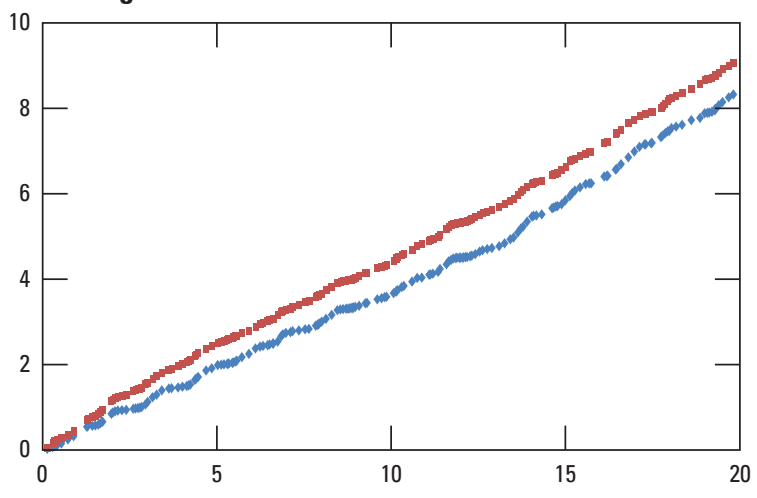

Cumulative precipitation depth, in inches

\section{EXPLANATION}

Figure 9. Double-mass curves of observed streamflow and simulated runoff volume for the nine study

- Observed flow

- Simulated total runoff (SIMO) 


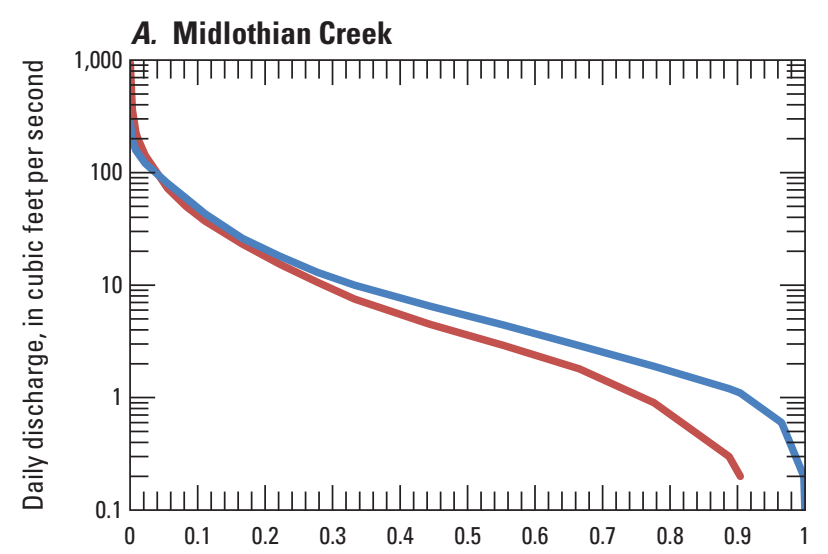

\section{B. Tinley Creek}

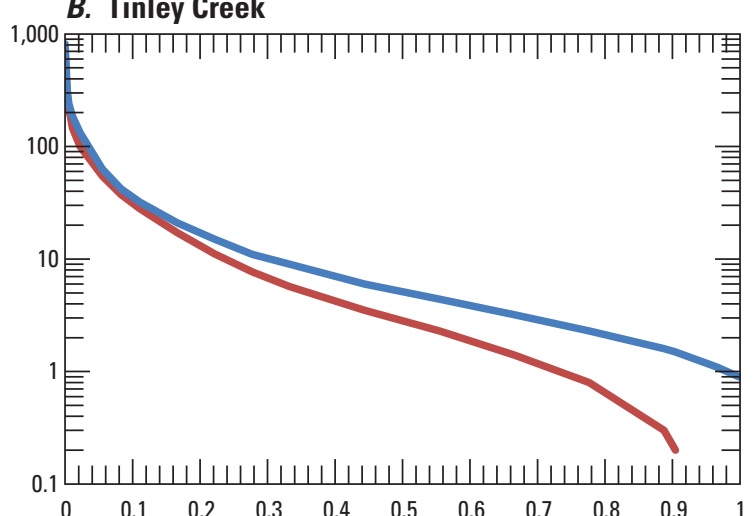

D. Skokie River

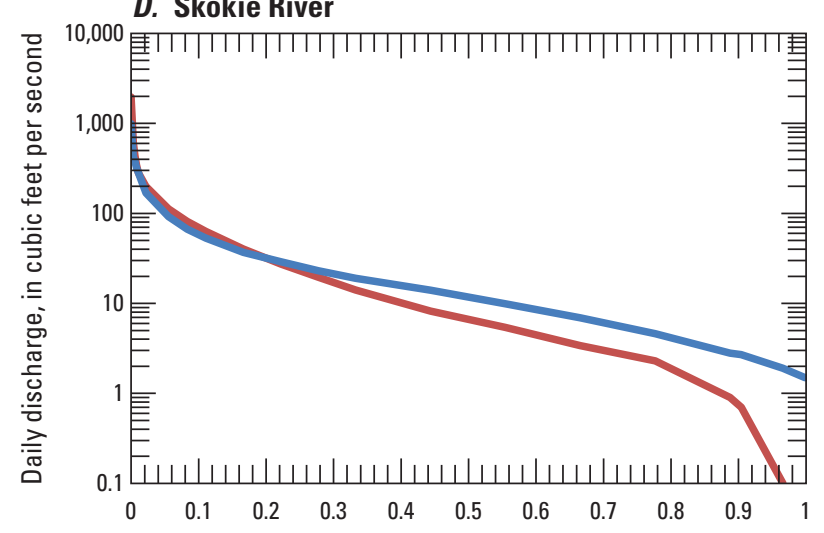

G. Hart Ditch at Munster

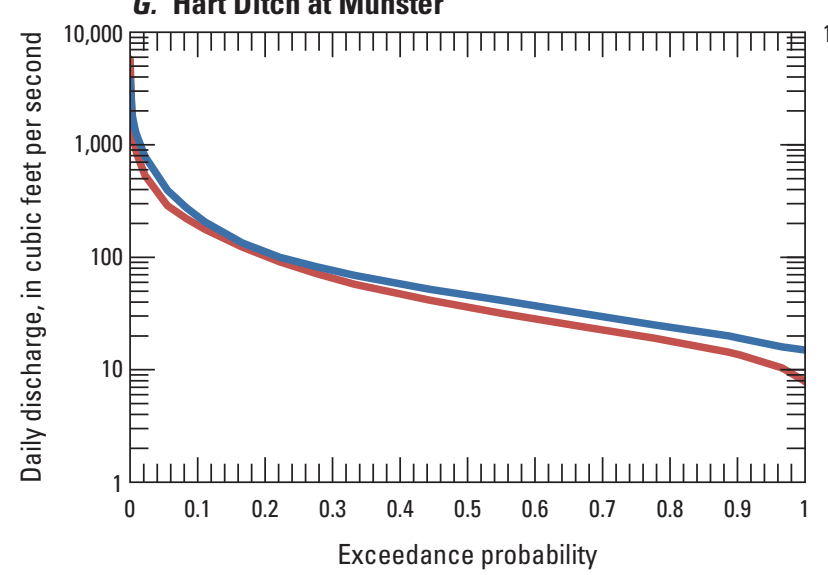

\section{E. Hickory Creek}

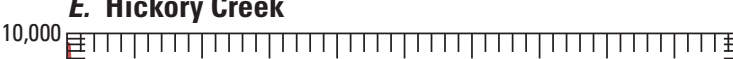

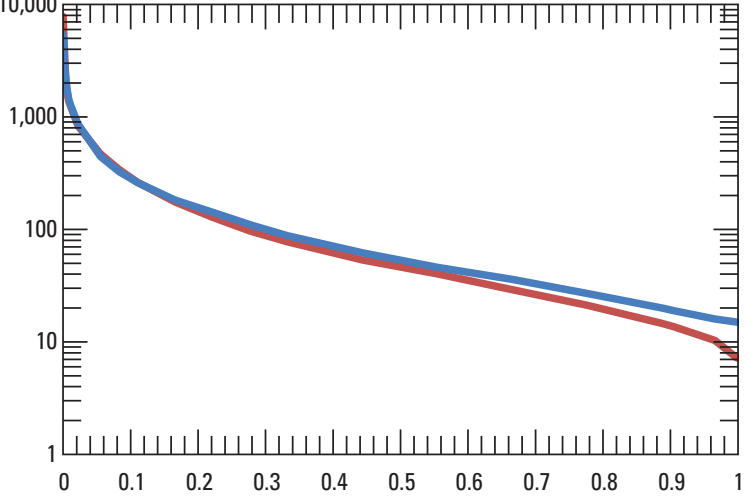

\section{H. Butterfield Creek}

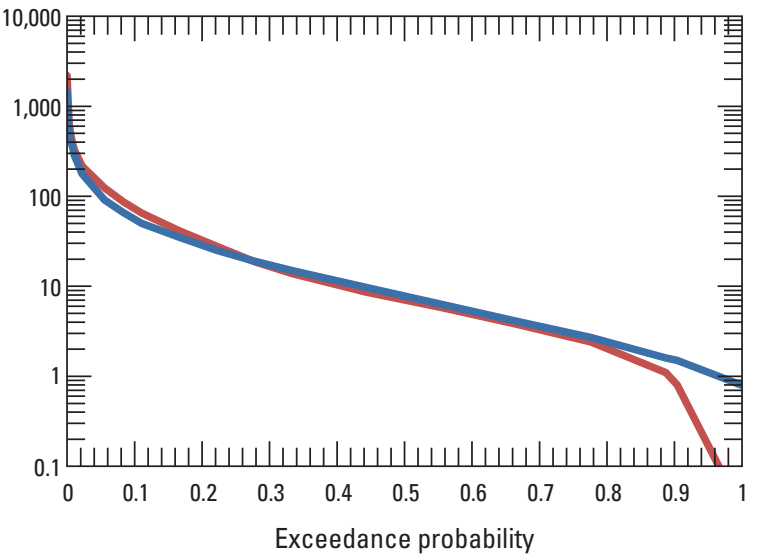

C. Flag Creek

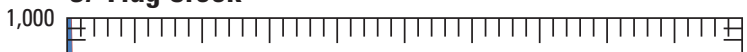

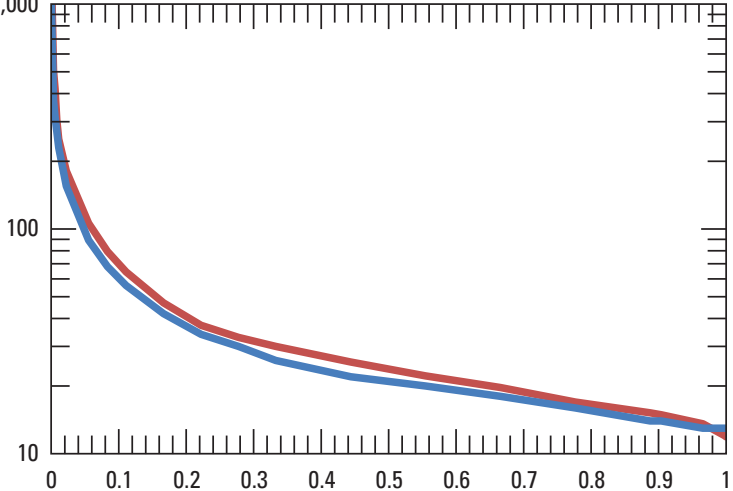

F. Hart Ditch at Dyer

10,000

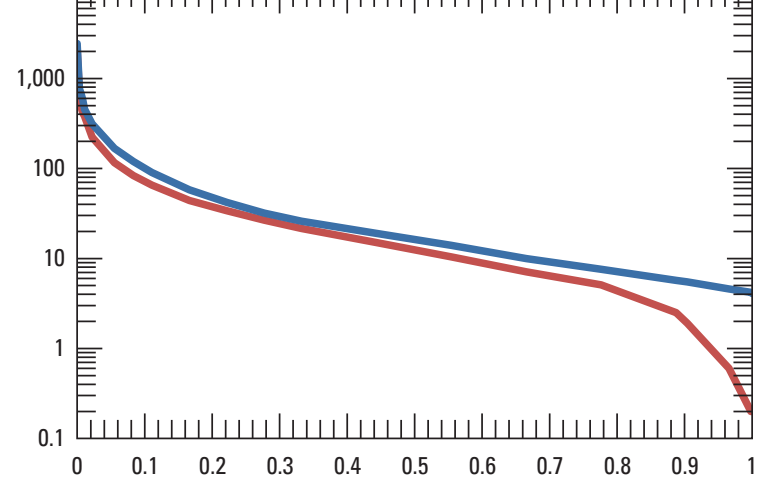

I. Long Run

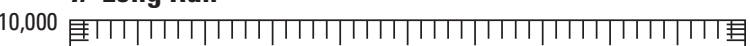

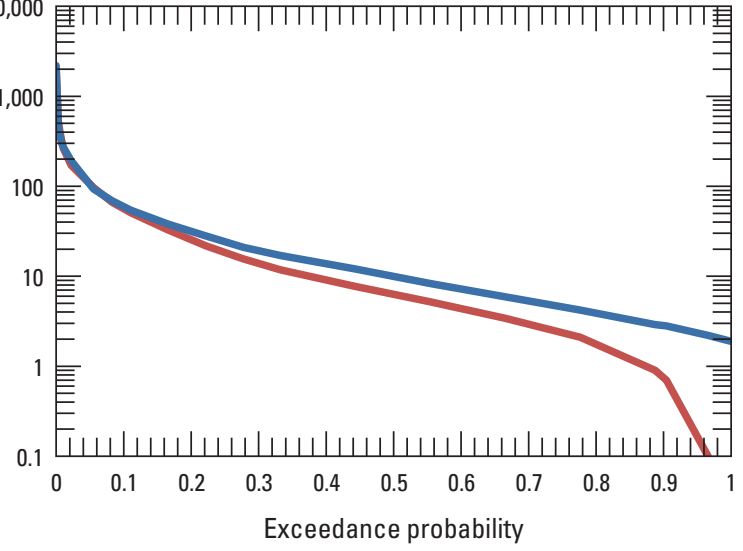




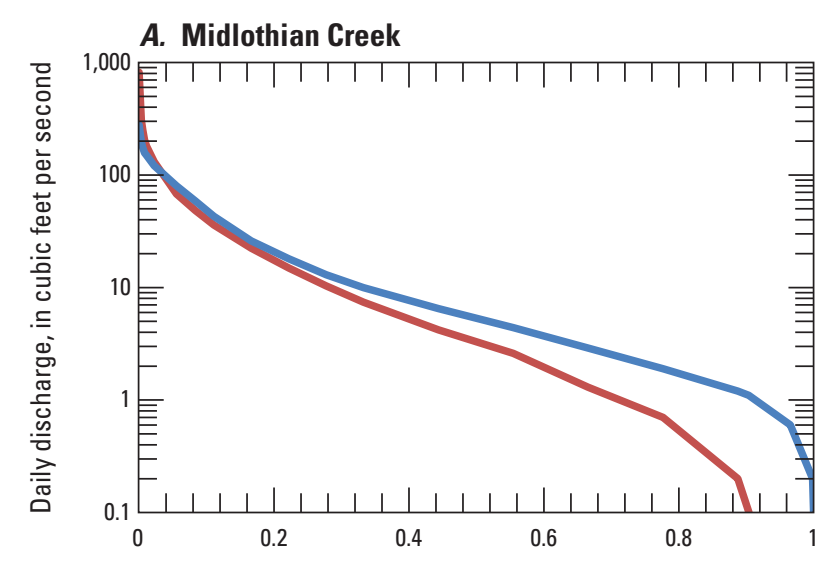

B. Tinley Creek

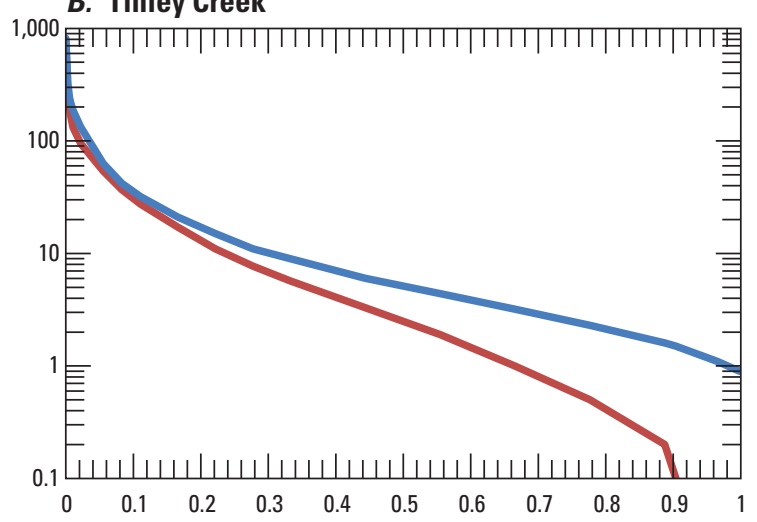

D. Skokie River

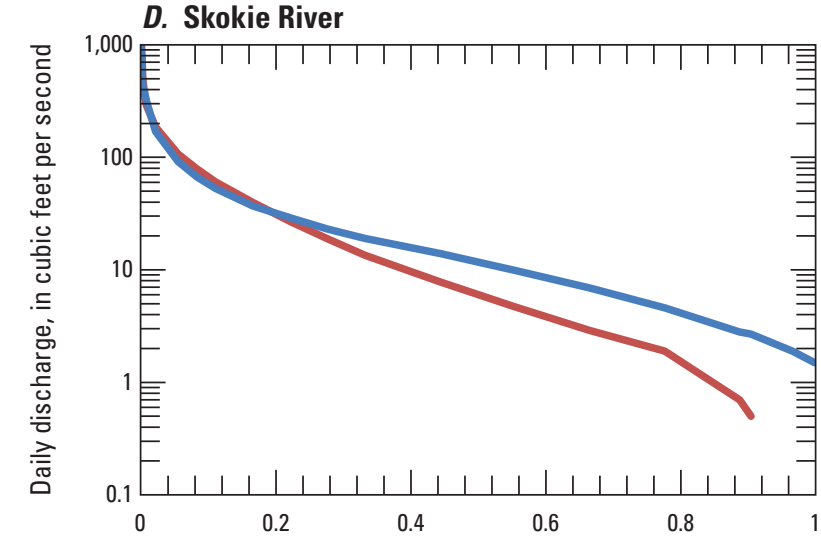

G. Hart Ditch at Munster
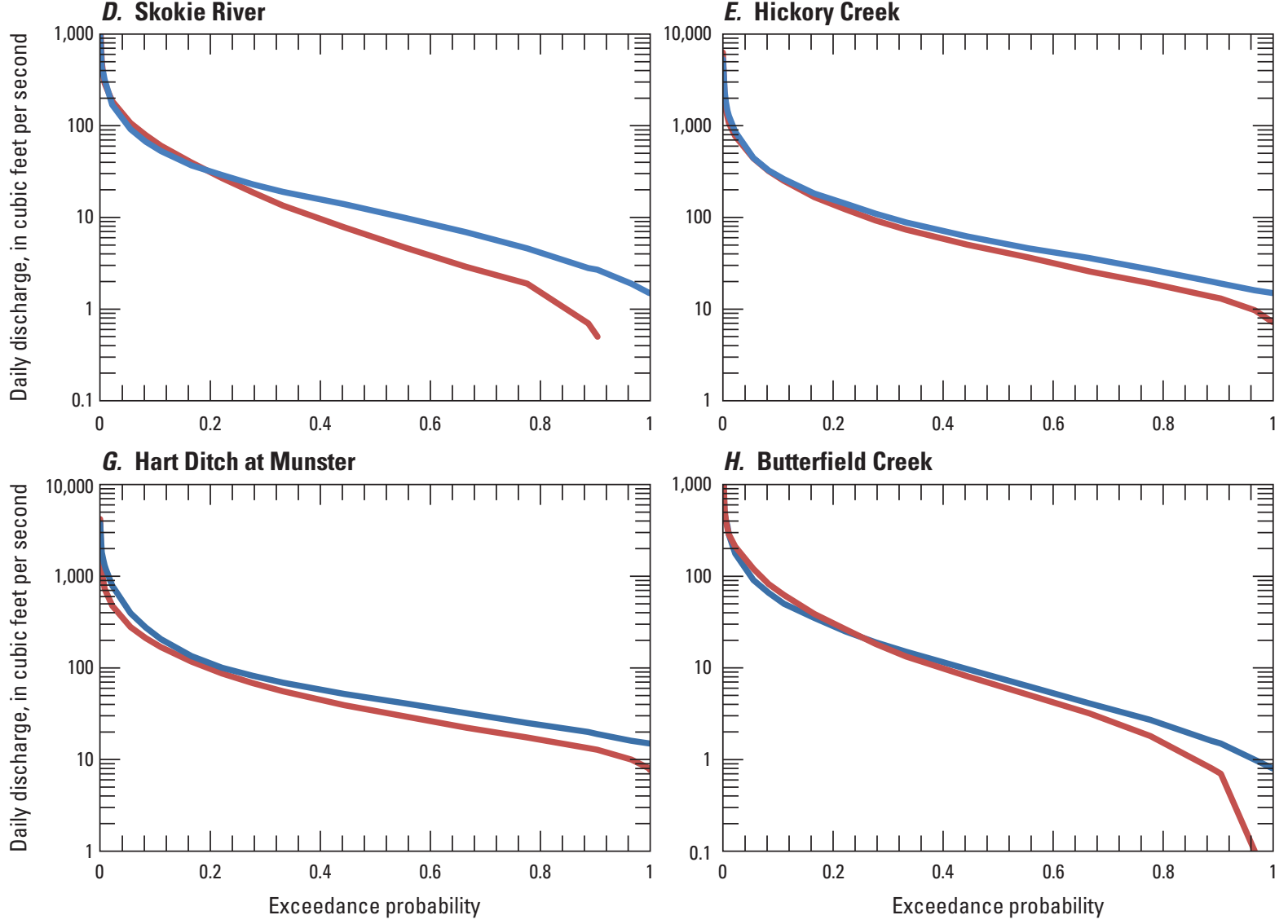

H. Butterfield Creek

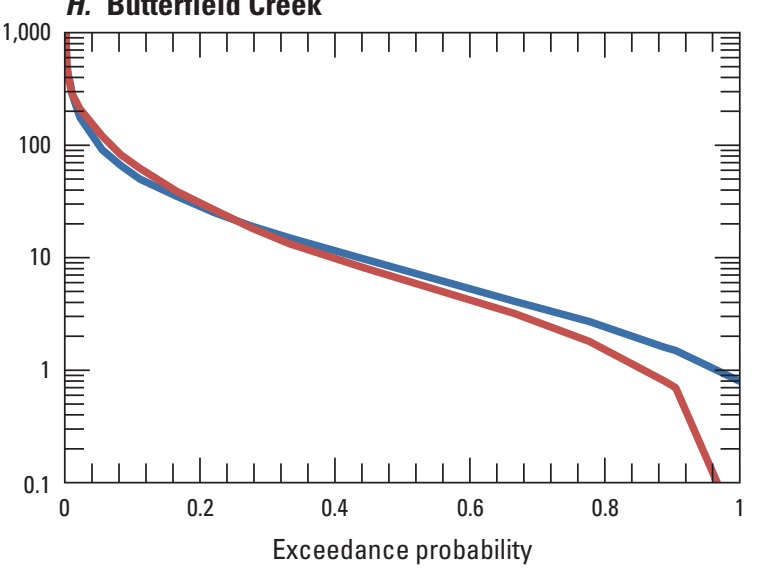

Figure 11. Flow-duration curves of observed streamflow and simulated runoff volume for the nine study watersheds using the 1999 parameter set for the water years 1996 to 2011.
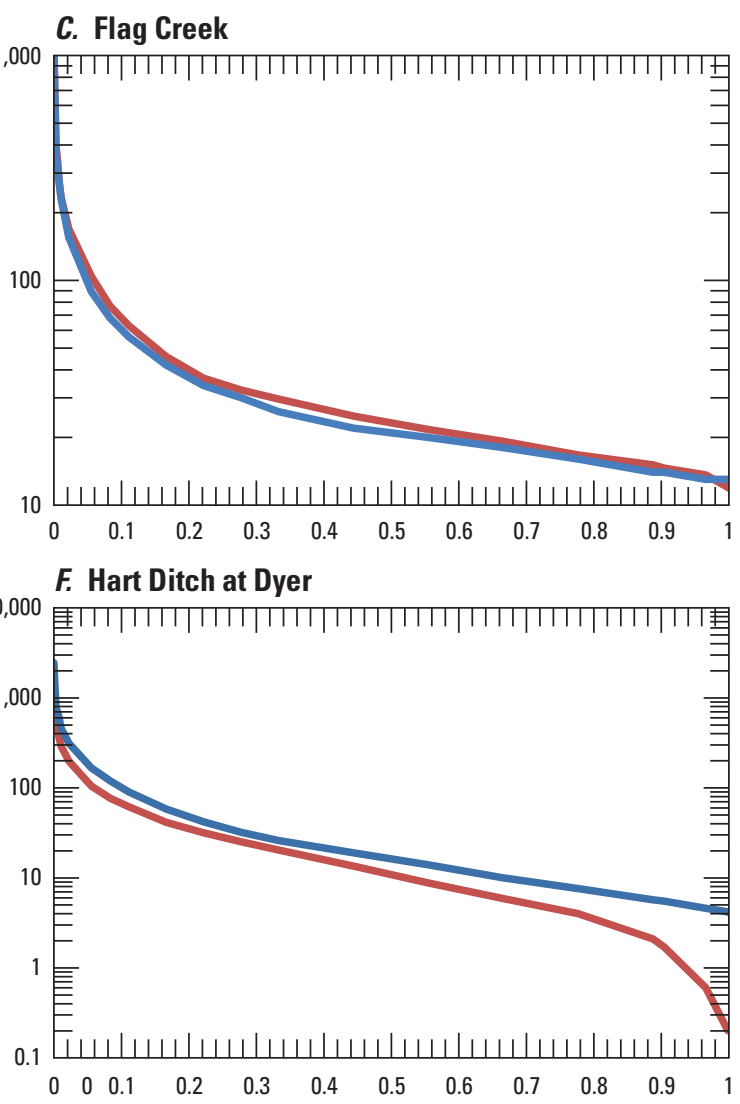

\section{Long Run}

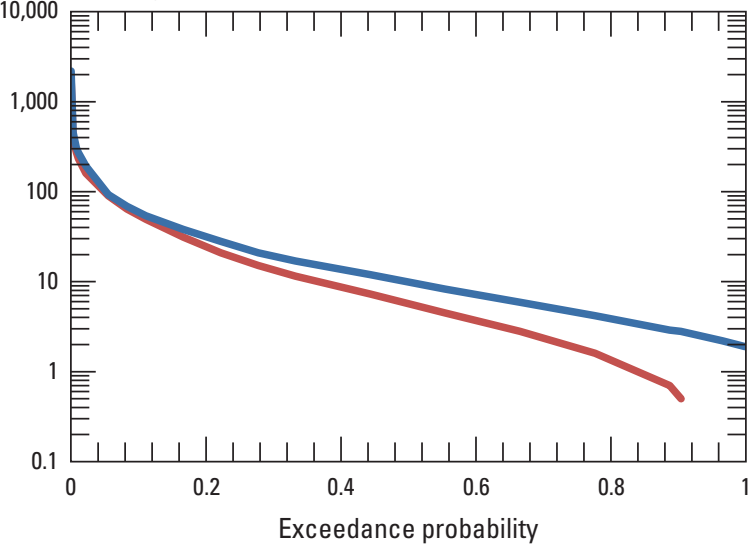

EXPLANATION 


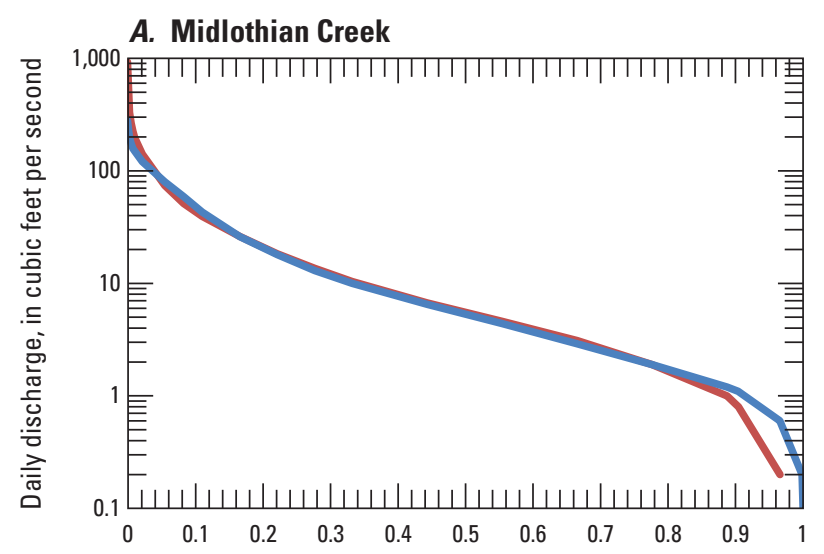

B. Tinley Creek

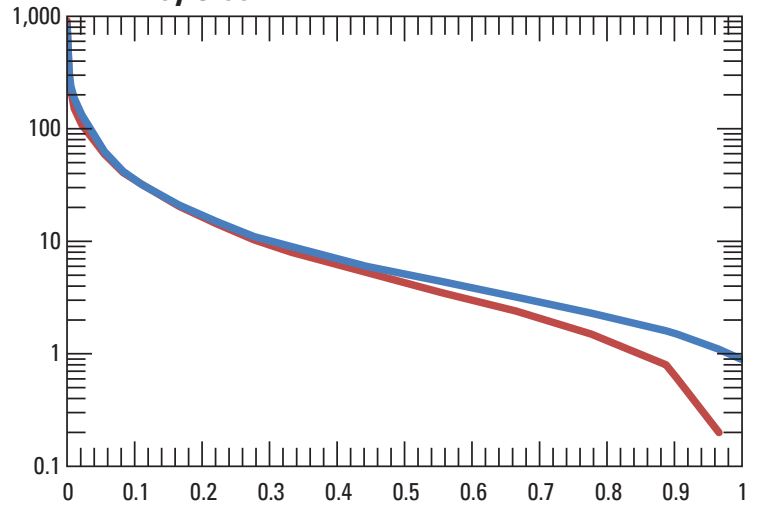

E. Hickory Creek

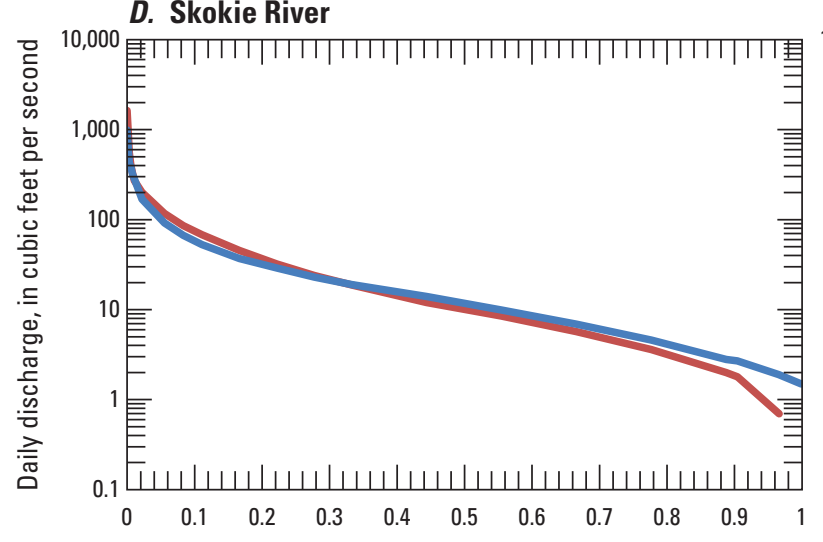

G. Hart Ditch at Munster

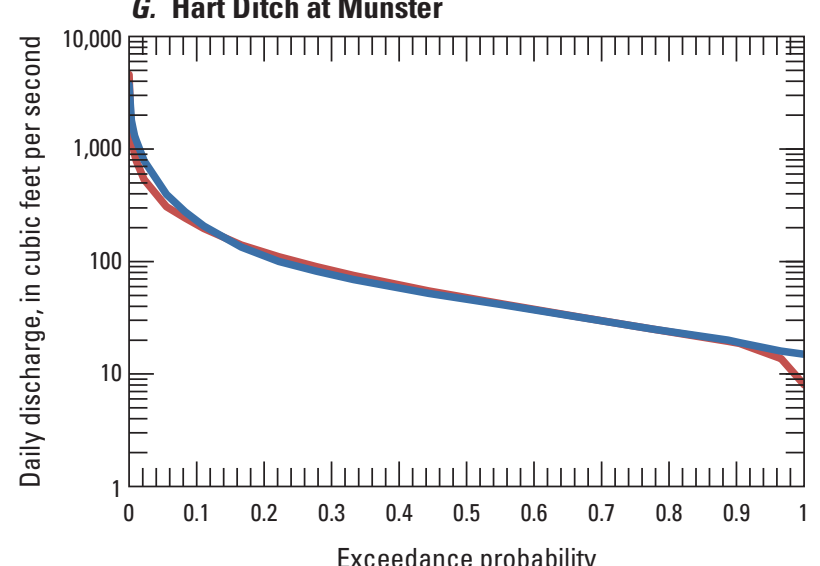

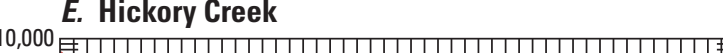

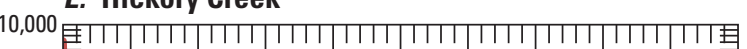

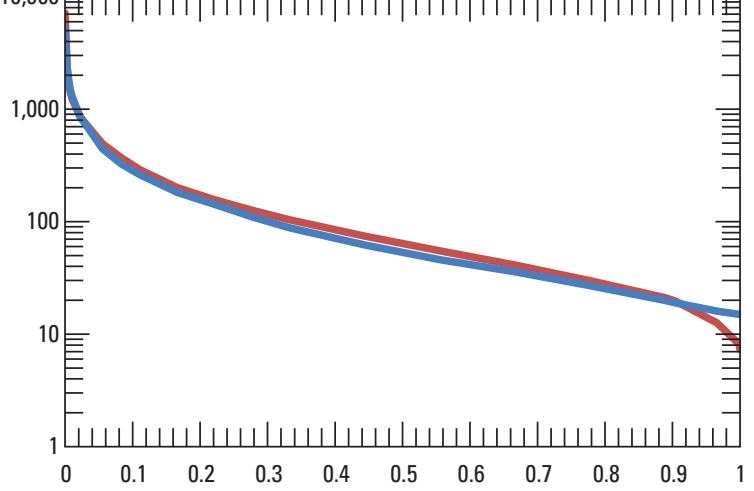

H. Butterfield Creek

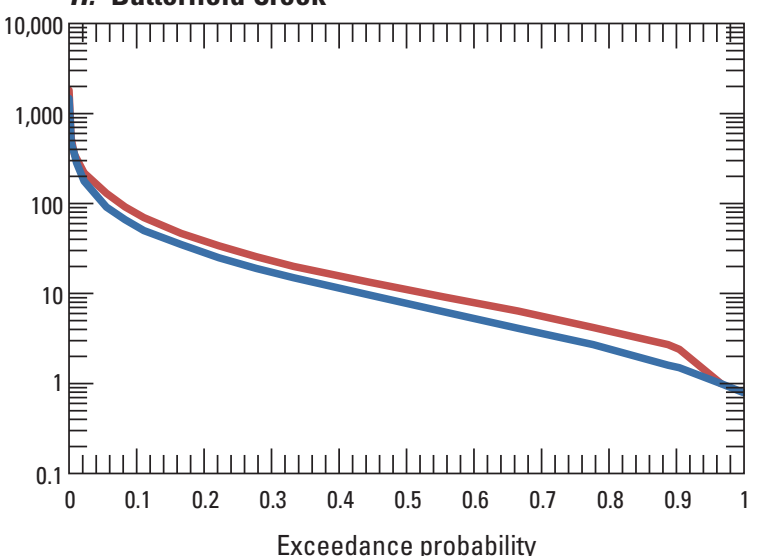

C. Flag Creek

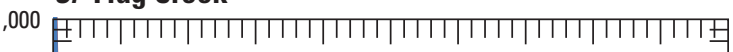

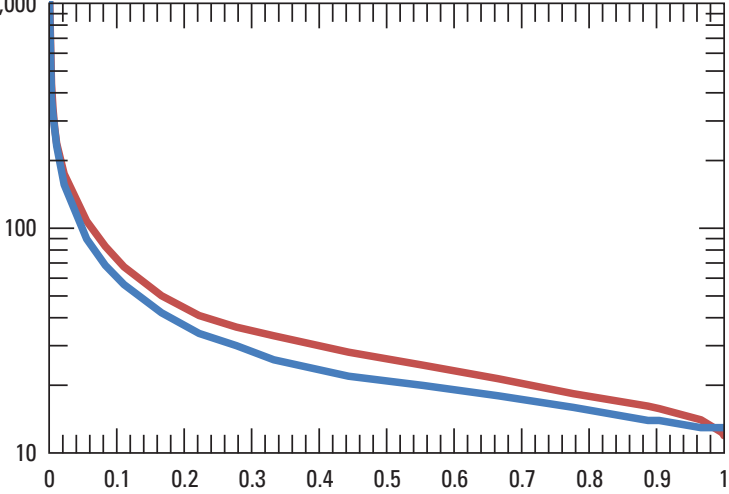

F. Hart Ditch at Dyer

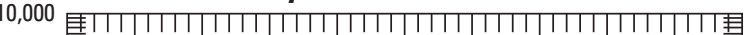

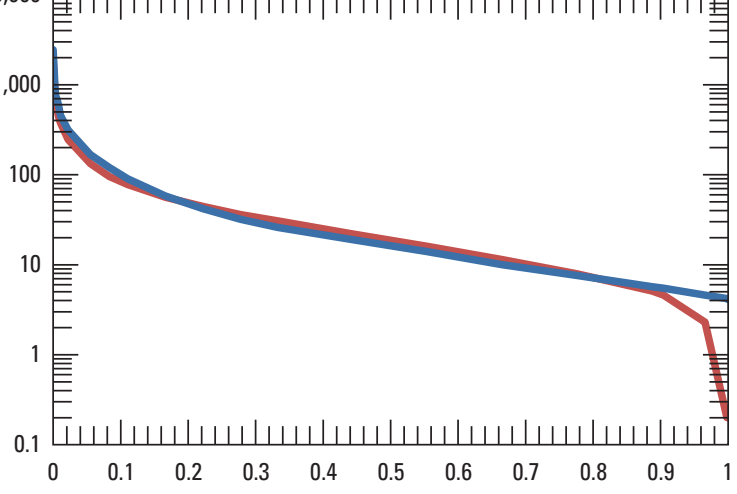

l. Long Run

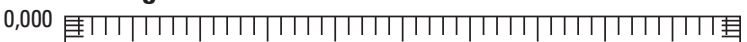

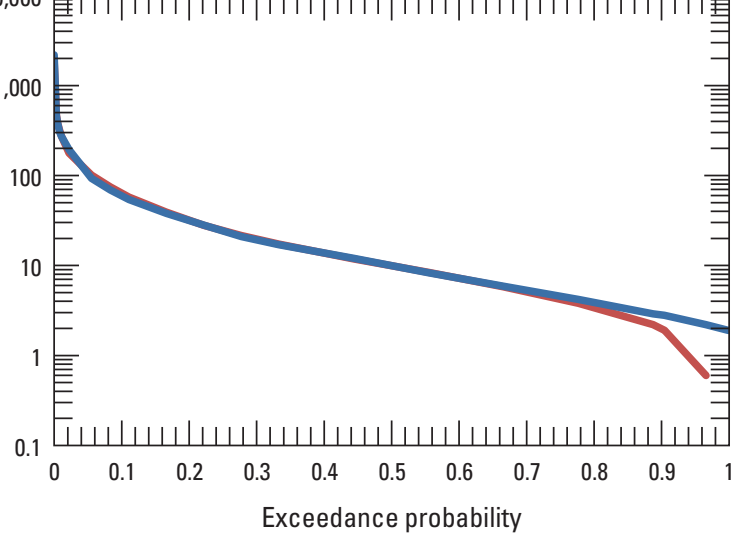

EXPLANATION

Figure 12. Flow-duration curves of observed streamflow and simulated runoff volume for the nine study watersheds Simulated Observed 
Visually well-fitted FDCs do not imply the S/R ratio is always closer to unity. For example, the observed and simulated FDCs for Flag Creek, Hickory Creek, and Hart Ditch at Munster fit well using the North Branch parameter set (fig. 10 ), but the corresponding overall $\mathrm{S} / \mathrm{R}$ ratios deviated by approximately 16,5 , and -17 percent, respectively (table 13 ). The FDC is useful in model calibration and the fit of FDCs is evaluated by specifying quantiles at exceedance probability intervals important to the watershed. For example, the exceedance probability corresponding to the mean magnitudes of measured daily streamflows (table 10) is approximately 22 percent for all of the study watersheds except for Flag Creek, Skokie River, Hickory Creek, and Long Run, which are approximately 25 percent. The exceedance probabilities for the mean magnitudes of simulated daily runoff were approximately between 21 and 25 percent. Therefore, the information content in the range of exceedance probability in this range needs be emphasized for volume computation when FDC is used as an objective function.

\section{Quantitative Statistics}

Statistics of PBIAS, NSE, and RSR based on simulated monthly runoff volumes by the six parameter sets are given in table 14. The performance of a parameter set on an individual watershed is evaluated by the statistics in the "very good" and "unsatisfactory" categories (table 12) and on nine watersheds by totaling the number of statistics in the "very good" and "unsatisfactory" categories. In table 14, results in the "very good" category are typed in bold and for those in the "unsatisfactory" category their cells are shaded.

Table 14. Statistics of the mean monthly runoff volume at nine study watersheds simulated by the existing parameter sets for the period from October 1, 1995, to September 30, 2011.

[PBIAS, percent bias; NSE, Nash-Sutcliffe model fit coefficient; RSR, ratio of the root mean square error to the standard deviation of measured data (Moriasi and others, 2007); NIPC, Northeastern Illinois Planning Commission; CTE, Consoer Townsend Envirodyne Engineers. Results in the "very good" category are shown in bold, and those in the "unsatisfactory" category are shown in gray-shaded cells]

\begin{tabular}{|c|c|c|c|c|c|c|c|c|c|}
\hline \multirow[b]{2}{*}{ Statistic } & \multicolumn{9}{|c|}{ Watershed } \\
\hline & $\begin{array}{l}\text { Midlothian } \\
\text { Creek }\end{array}$ & $\begin{array}{l}\text { Tinley } \\
\text { Creek }\end{array}$ & $\begin{array}{l}\text { Flag } \\
\text { Creek }\end{array}$ & $\begin{array}{c}\text { Skokie } \\
\text { Creek }\end{array}$ & $\begin{array}{c}\text { Hickory } \\
\text { Creek }\end{array}$ & $\begin{array}{c}\text { Hart Ditch } \\
\text { at Dyer }\end{array}$ & $\begin{array}{l}\text { Hart Ditch } \\
\text { at Munster }\end{array}$ & $\begin{array}{c}\text { Butterfield } \\
\text { Creek }\end{array}$ & $\begin{array}{c}\text { Long } \\
\text { Run }\end{array}$ \\
\hline PBIAS & 0.00 & -0.14 & 0.16 & 0.13 & 0.05 & -0.20 & -0.17 & 0.29 & -0.04 \\
\hline NSE & 0.87 & 0.77 & 0.77 & 0.57 & 0.82 & 0.70 & 0.68 & 0.79 & 0.81 \\
\hline PBIAS & -0.02 & -0.15 & 0.15 & 0.11 & 0.03 & -0.22 & -0.18 & 0.27 & -0.05 \\
\hline NSE & 0.87 & 0.77 & 0.80 & 0.62 & 0.84 & 0.70 & 0.67 & 0.83 & 0.82 \\
\hline \multirow[t]{2}{*}{ RSR } & 0.35 & 0.48 & 0.45 & 0.61 & 0.40 & 0.55 & 0.58 & 0.41 & 0.43 \\
\hline & \multicolumn{9}{|c|}{ NIPC parameter set } \\
\hline RSR & \multicolumn{9}{|c|}{1999 parameter set } \\
\hline PBIAS & -0.07 & -0.19 & 0.11 & 0.04 & -0.05 & -0.29 & -0.24 & 0.17 & -0.13 \\
\hline NSE & 0.86 & 0.74 & 0.84 & 0.65 & 0.82 & 0.64 & 0.63 & 0.87 & 0.79 \\
\hline \multirow[t]{2}{*}{ RSR } & 0.38 & 0.51 & 0.40 & 0.59 & 0.42 & 0.60 & 0.61 & 0.36 & 0.46 \\
\hline & \multicolumn{9}{|c|}{ CTE parameter set } \\
\hline PBIAS & 0.08 & -0.01 & 0.19 & 0.23 & 0.16 & -0.03 & -0.07 & 0.40 & 0.09 \\
\hline NSE & 0.85 & 0.82 & 0.73 & 0.51 & 0.79 & 0.75 & 0.72 & 0.71 & 0.8 \\
\hline \multirow[t]{2}{*}{ RSR } & 0.39 & 0.43 & 0.52 & 0.70 & 0.45 & 0.50 & 0.53 & 0.54 & 0.44 \\
\hline & \multicolumn{9}{|c|}{2008 parameter set } \\
\hline
\end{tabular}




\section{Lake Michigan Diversion Accounting Land Cover Change Estimation}

All six parameter sets produced "very good" statistics for Midlothian Creek. Long Run had the next best statistics with two "good" results in PBIAS from NIPC and 1999 parameter sets, followed by Hickory Creek with two "satisfactory" results in PBIAS from CTE and 2008 parameter sets. The NIPC and 1999 parameter sets lowered the PBIAS by approximately 10 percent except for Tinley Creek, Hart Ditch at Dyer, and Hart Ditch at Munster, which have higher forestland percentages, and for Flag Creek, which has a greater percentage of hydraulically connected impervious land percentage. The 1999 parameter set also resulted in lower NSE and higher RSR in general. By modifying the grassland parameters (and further reducing RETSC in impervious parameters) from the 1999 parameters, the CTE parameter set resulted in higher runoffs and thus increased the PBIAS for the period evaluated. Among the study watersheds, Flag Creek, Midlothian Creek, Skokie River, and Butterfield Creek have the highest impervious land percentages. The CTE and 2008 parameter sets yield the same PBIAS value; however, the 2008 parameter set had slightly lower NSE and higher RSR values than the CTE parameter set in several watersheds.

\section{Case for Recalibration}

Applying the previously calibrated LMDA regional parameter sets to the nine watershed models updated with better meteorological and land-cover data and to a time period different from their calibration timeframe has yielded results in the "very good" or "good" categories but there are also some in the "unsatisfactory" category. No individual parameter set produced "very good" or "good" results for all nine watersheds in the 16-year study period. The accuracy in simulated runoff volume could be affected by many factors, including the representativeness of the land cover (types and acreages), quality of measured data, parameterization, and the comprehensiveness of the model in representing the critical physical processes of a watershed. No potential errors were found in the acreages of the three land covers determined from the 2006 NCLD dataset or in measured precipitation and streamflow data. The trends in precipitation to streamflow responses were generally consistent in each of the nine watersheds, and the flood control reservoirs or stormwater management ordinances have not altered the streamflow patterns; therefore, it is reasonable to focus on parameter values for the simulation accuracy. Which HSPF parameters have improved or weakened the simulations accuracy could not be identified by inspecting the study results alone, but there are indications that the magnitude of simulation discrepancies and the proportions of grassland and forestland in the watersheds are related. Therefore, an attempt to recalibrate the PERLND parameters with the updated input data to improve the simulation accuracy of the HSPF watershed models was warranted.
The method by which a regional parameter set was determined from the original calibrations could not be determined (T.Y. Su, USACE-Chicago, oral commun., September 2014). Checking the performance of individually calibrated parameter sets is an acceptable approach. Evidence of improved regional performance has been visually observed through the DMC and FDC plots for the nine watersheds among the parameter sets tested; however, the Midlothian Creek, Hickory Creek, and Long Run watersheds showed tendency to respond to parameter sets in a similar pattern (that is, their responses in $\mathrm{S} / \mathrm{R}$ ratios, DMCs, FDCs, and quantitative statistics moved in parallel). This watershed response group (that is, Midlothian Creek, Hickory Creek, and Long Run) was best with the North Branch parameter set. Similarly, the Tinley Creek and Hart Ditch at Munster watersheds can be grouped together and were best predicted with the 2008 parameter set. The Skokie River and to some extent the Flag Creek watersheds are the other group and were best represented by the 1999 parameter set. None of the parameter sets evaluated had dramatically improved results in watersheds across the watershed response groups. Judging by the quantitative statistics (table 14), the North Branch and Hickory Creek parameter sets have produced the most "satisfactory" results in the nine watersheds for the study period followed by the CTE and 2008 parameter sets. The CTE and 2008 parameter sets improved the simulation accuracy from the 1999 and NIPC parameter sets and achieved similar "satisfactory" results as the North Branch parameter set but with an "unsatisfactory" result for Butterfield Creek. In general, the NSE and RSR of CTE and 2008 parameter set simulations were slightly inferior to those simulated by the North Branch parameter set.

Among the nine watersheds, Flag Creek, Butterfield Creek, and Hart Ditch at Dyer watersheds likely are not ideal for recalibration purposes. Effluent discharges exist in the Flag Creek, Hart Ditch at Dyer, Hart Ditch at Munster, and Hickory Creek watersheds. Although the effluent magnitudes retrieved from the governmental database are reasonable, approximating their hourly time series from monthly values is an appreciable simplification. Water withdrawals in the Flag Creek watershed have been determined to be minimal; however, the water withdrawal amounts in the Butterfield Creek watershed are difficult to estimate. Furthermore, the Butterfield Creek watershed seemed to have complex inflow and infiltration conditions. In the Hart Ditch at Dyer watershed, there may be other land use or drainage disruptions because the piecewise slope changes in the measured DMC did not match the simulated DMCs.

The Tinley Creek and Long Run watersheds were selected as the base watersheds for recalibrating the regional parameters because they represent two primary watershed response groups discussed above. These watersheds have no known effluent discharges and have more balanced distributions of forestland, grassland, and impervious land. The Tinley Creek and Long Run watersheds also have better raingage network coverage than the alternative watersheds. 


\section{Recalibration of PERLND Parameters}

The study applied both manual and automatic calibration techniques. In applications, the manual technique calibrated the Tinley Creek and Long Run watershed models separately, but the automatic technique calibrated the two watershed models separately as well as together. The purpose of the calibration was to compare the derived grassland and forestland parameter sets for their regional performance in simulating runoff volumes. The calibration period was from October 1, 2000, to September 30, 2009, and the validation periods were from WYs 1997 to 2000 and from WYs 2010 to 2011. The regional performance is evaluated based on the quantitative statistics at the nine study watersheds for calibration and validation periods, and $\mathrm{S} / \mathrm{R}$ ratios and DMCs for the entire study period. Note that the parameter values for the IMPLND segment were those specified in the CTE parameter set.

The goal for manual calibration was to continue the 2008 calibration work to include the grassland parameters. An automatic calibration has not previously been used in the LMDA system. The automatic calibration is anticipated to be robust in deriving an optimal parameter set but it is necessary to explore factors that constrain the automatic search such as the number of adjustable parameters, parameter bounds, formulation of objective functions, and weights. Through the automatic calibrations, there are opportunities to examine relevant topics applicable to LMDA watersheds such as: (1) parameter sensitivity, (2) applicable parameter bounds, (3) the importance of FOREST, PETMAX, and PETMIN, and (4) gaining insight on the parameter transferability for the LMDA system.

The PERLND module generally contains different landcover segments (grassland and forestland in the study); an order between them can be expected for a parameter of the same name (parameter order). The parameter order should follow an acceptable physical reasoning in addition to model calibration; for example, CEPSC for forestland would have higher values than for grassland. Kelliber and others (1993) determined that on a daily basis, the evaporation rate of a coniferous forest is appreciably lower than that of grassland. By studying soil moisture and ET of five land-cover types in the Loess Plateau of China during the growing season of 2011, Wang and others (2012) determined that the daily ET trends of the forests and shrub sites were similar and more stable than grass, subshrub, and crops (that is, corn). Incorporating the parameter order is a necessary part of model calibration but has not previously been investigated. In the existing parameter sets, a few parameters did not seem to have reasonable parameter orders.

\section{Manual Calibration}

The manual calibration was conducted with the aid of an expert system, HSPEXP (Lumb and others, 1994). HSPEXP integrates expertise of experienced watershed modelers into an artificial intelligence structure to guide the model calibration through identifying the parameter(s) to be adjusted according to the most discrepancies in a predefined composite objective function by using a set of hierarchical rules. Users can tailor the acceptance criteria for each group of the composite objective function to meet the purpose of their study. During the calibration, a sequential calibration that focused a subset of parameters during each step was used. For calibrating lumped watershed models like HSPF, Lumb and others (1994) and Donigian (2002) recommended a strategic sequence that targets water balance, low flows, seasonal distribution, and storm hydrographs.

When calibrating the Tinley Creek or Long Run watershed models, the FOREST parameter was revised to 0.1 and 0.2 for grassland and forestland because these values were judged to be more representative for the LMDA system. The values for parameters PETMAX and PETMIN were kept the same as those used in the LMDA parameter sets $\left(50^{\circ} \mathrm{F}\right.$ and $45^{\circ} \mathrm{F}$ for PETMAX and PETMIN, respectively) because there was no available information to justify a change in the existing values. By targeting minimizing the differences between observed and simulated runoff volumes as the main objective, parameters LZSN, INFILT, and LZETP seemed to be most frequently adjusted. The INFILT value tested was within the bounds appropriate for SCS hydrologic soil groups $\mathrm{C}$ and $\mathrm{C} / \mathrm{D}$, as described in the BASINS Technical Note No. 6 (U.S. Environmental Protection Agency, 2000), of the study watersheds. Adjusting INFILT affects the lower zone soil moisture storage (LZSN) and ET from lower zone (LZETP), which also affects water available for base flow from the active groundwater storage zone. Base flow is determined primarily by AGWRC, but also can be affected by KVARY, BASETP, and DEEPFR. Quick flow contributes a little more of the runoff volumes than base flow. UZSN controls the amount of water retained in the upper zone that becomes available for ET. UZSN has larger effects on the amount of quick flow in non-winter seasons. Because monthly variations were not simulated, it was necessary to identify effective annual representation for UZSN. Hydrograph shape is affected by the relative magnitudes of the surface runoff and interflow; therefore, the values of INTFW, IRC, and CEPSC were adjusted; INTFW and IRC control the amount and timing of interflow. Dominant parameters other than those described above may be present in other watersheds depending on the characteristics of the watersheds (Price, 1996). The manual calibration also incorporated the parameter order in adjusting parameter values for the grassland or forestland segments. Parameter order was enforced by the modeler; it is not expressed in HSPEXP. The convergent statistics of HSPEXP may not indicate the effectiveness of such adjustments and has added complexity in manual calibrations.

Calibrated parameter values and calibration results for the Tinley Creek and Long Run watersheds are listed in table 15. The errors in total volume had been minimized and each calibration obtained a good fit on the flow duration curves at most streamflow magnitudes except for Long Run at low flow. 
Table 15. Parameter values and calibration results for the manual calibration of Tinley Creek and Long Run watershed models.

\begin{tabular}{|c|c|c|c|c|}
\hline \multirow{3}{*}{$\begin{array}{l}\text { Parameter } \\
\text { name }\end{array}$} & \multicolumn{4}{|c|}{ Parameter values } \\
\hline & \multicolumn{2}{|c|}{ Tinley Creek } & \multicolumn{2}{|c|}{ Long Run } \\
\hline & Grass & Forest & Grass & Forest \\
\hline FOREST & 0.1 & 0.2 & 0.1 & 0.2 \\
\hline LZSN & 7 & 7 & 8.5 & 8.5 \\
\hline INFILT & 0.03 & 0.045 & 0.035 & 0.05 \\
\hline LSUR & 50 & 200 & 50 & 200 \\
\hline SLSUR & 0.01 & 0.01 & 0.01 & 0.01 \\
\hline KVARY & 1.8 & 1.8 & 1.5 & 1.5 \\
\hline AGWRC & 0.99 & 0.995 & 0.97 & 0.98 \\
\hline PETMAX & 50 & 50 & 50 & 50 \\
\hline PETMIN & 45 & 45 & 45 & 45 \\
\hline INFEXP & 2 & 2 & 2 & 2 \\
\hline INFILD & 2 & 2 & 2 & 2 \\
\hline DEEPFR & 0.05 & 0.05 & 0.05 & 0.05 \\
\hline BASETP & 0 & 0 & 0 & 0 \\
\hline AGWETP & 0.05 & 0.05 & 0.02 & 0.05 \\
\hline CEPSC & 0.1 & 0.2 & 0.1 & 0.2 \\
\hline UZSN & 0.35 & 0.7 & 0.8 & 1.5 \\
\hline NSUR & 0.2 & 0.25 & 0.2 & 0.25 \\
\hline INTFW & 3 & 3 & 10 & 5 \\
\hline IRC & 0.6 & 0.6 & 0.65 & 0.65 \\
\hline LZETP & 0.31 & 0.31 & 0.38 & 0.6 \\
\hline
\end{tabular}
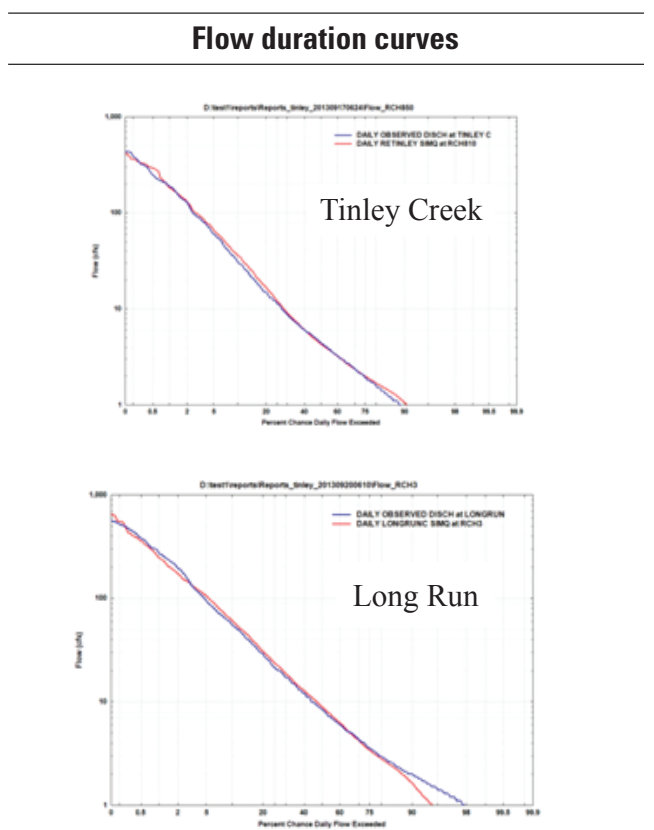

\begin{tabular}{lccc}
\hline \multicolumn{4}{c}{ Convergence criteria } \\
\hline Observations to minimize & $\begin{array}{c}\text { Criteria } \\
\text { (percent) }\end{array}$ & $\begin{array}{c}\text { Tinley } \\
\text { Creek } \\
\text { (percent) }\end{array}$ & $\begin{array}{c}\text { Long Run } \\
\text { (percent) }\end{array}$ \\
\hline Error in total volume & 10 & 0 & 0.3 \\
Error in low flow recession & 0.03 & -0.07 & -0.02 \\
Error in 50-percent lowest flow & 10 & -0.4 & -18.1 \\
Error in 10-percent highest flow & 15 & -4.2 & 1.7 \\
Error in storm peaks & 20 & -19.6 & -7.7 \\
Seasonal volume error & 20 & 18.8 & 39.9 \\
Summer storm volume error & 50 & -38.6 & 13.9 \\
\hline
\end{tabular}


Because the FOREST parameters used judgment values in the manual calibration, their sensitivity was investigated by setting the values back to 0.2 and 0.3 for grassland and forestland, respectively, after the calibration. Such a test resulted in minor reductions in simulated total runoff volume but did not cause violations in the convergence criteria, which is reasonable because the FOREST parameter affects SNOW melt portion in the water balance; however, if the PETMIN and PETMAX values were set to $35^{\circ} \mathrm{F}$ for PETMIN and $45^{\circ} \mathrm{F}$ for PETMAX in grassland and forestland, the resulting convergence criteria were altered enough to require continued calibration. Further evaluation of the FOREST, PETMAX, and PETMIN parameters will be discussed in the "Automatic Calibration" section.

\section{Automatic Calibration}

The automatic calibration was conducted by using the model-independent parameter estimation and uncertainty analysis program PEST (http://www.pesthomepage.org/). Examples concerning the applications of PEST to HSPF calibration includes Barber and others (2002) and Doherty and Johnston (2003). Reports that focused on PEST's solution techniques with HSPF applications include Cocca and others, 2003; Kim and others, 2006; Iskra and Droste, 2007; and Marce and others, 2008. The PEST user's manual (Doherty, 2005) and addendum (Doherty, 2013) provide detailed explanations of the theories, optimization techniques, and strategies for conducting parameter calibration.

The nine existing regional parameter sets provide a sample of local expert information about the adjustable parameters, initial values, and parameter bounds. The flow and watershed characteristics described in the "Preparation of Model and Input Data" section can provide auxiliary information for justifying the reasonableness of parameter bounds and for settling the objective function. In addition, experience from manual calibration can provide insight on adjustment increments for selective parameters. Such prior knowledge is useful in building the automatic calibration to meet regional expectations. When "expert" local information is not available or inadequate; on the other hand, users will find the initial values and "Typical" or "Possible" parameter ranges described in BASINS Technical Notes No. 6 (U.S. Environmental Protection Agency, 2000) useful. The composite objective function provided in HSPEXP is comprehensive and is ideal for building the objective function for PEST, especially when the results from the two calibrations are compared (Kim and others, 2006); however, a different set of objective functions was used in the PEST analysis and is discussed later in the "Objective Function" section.

\section{Design of PEST Calibration}

Using its search capabilities, it is best to program PEST to start the optimization with as many adjustable parameters and the widest bounds as possible under properly formulated calibration data sets (objective function). Knowing that some of the existing parameter sets had resulted in "very good" ranking in the accuracy assessment, the search to determine the number of adjustable parameters, parameter bounds, objective function, and weights for observation group needs to address the appropriateness of information extracted from existing parameter sets, and from conducting the broad search. Therefore, the PEST calibration was completed in two stages: an initial calibration and refinement. The initial calibration was to determine the suitable number of adjustable parameters and their proper bounds for the three PEST models (Tinley Creek, Long Run, and the Tinley Creek and Long Run, which hereafter referred as PEST Tinley Creek watershed, PEST Long Run watershed, and PEST two-watershed models) to conduct the search for a regional parameter set. In the refinement stage, the three PEST models subject to these constraints were then optimized by investigating parameter sensitivity, correlation, and the use of local expert knowledge. The initial calibration was completed by using a three-tier analysis as follows. The design of the three-tier analysis is based on the information embedded in existing LMDA parameter sets.

- In Tier 1, only the grassland parameters were calibrated. Parameter values for forestland were the same as those in the 2008 parameter set. Adjustable parameters were those that had been modified from the original calibration through CTE and 2008 parameter sets. The 14 parameters included CEPSC, UZSN, LZSN, LZETP, AGWETP, INFILT, DEEPFR, INTFW, LSUR, SLSUR, NSUR, IRC, KVARY, and AGWRC. The bounds for these parameters follow those established in the "typical range" defined in BASINS Technical Note No. 6 (U.S. Environmental Protection Agency, 2000) except for those mentioned above. Initial parameter values for grassland parameters are based on the CTE parameter set.

- In Tier 2, adjustable parameters for grassland and forestland were the same 14 parameters as in Tier 1, but the forestland parameter was specified as a constant proportion of the counterpart grassland parameter value. The grassland parameters and corresponding parameter ratios were optimized. Initial parameter values for the grassland segment were the same as those in the 2008 parameter set. Two parameter bounds were tested:

a. The bounds determined in the "original" calibration set, and

b. The "typical range" defined in BASINS Technical Note No. 6 (U.S. Environmental Protection Agency, 2000). 
- In Tier-3, 17 grassland and forestland parameters were calibrated. The initial values were the same as those of the 2008 parameter set, parameter ratios were applied, and the parameter bounds started with the "possible ranges" defined in BASINS Technical Note No. 6 (U.S. Environmental Protection Agency, 2000). The 17 parameters were FOREST, LZSN, INFILT, LSUR, SLSUR, KVARY, AGWRC, PETMAX, PETMIN, DEEPFR, AGWETP, CEPSC, UZSN, NSUR, INTFW, IRC, and LZETP.

During the PEST calibration, initial values for FOREST were 0.3 for forestland and 0.2 for grassland; PETMAX was $50^{\circ} \mathrm{F}$ and PETMIN was $45^{\circ} \mathrm{F}$, respectively, for grassland and forestland. Because parameter ordering was explicitly investigated (explained in a later "Parameter Ratios" section), a wind correction factor $(0.76)$ specified to the forestland segment in the existing models was set to 1 (no correction). Additionally, the upper and lower bounds for INFILT were revised to 0.01 to 0.1 inch per hour, representing soil types $\mathrm{C}$ to $\mathrm{D}$, and for SLSUR were revised to vary from 0.007 to 0.02 foot per foot.

\section{Objective Function}

The objective function of PEST, phi, is the sum of squared weighted residuals between models and observations for each of the observation groups considered. PEST adjusts parameters while attempting to minimize the objective function to obtain an optimum calibration. Suitable observation groups for forming the objective function were determined first and the same observation groups were kept throughout the calibration. The objective function used in the study consisted of the following observation groups:

- Selected storm hydrographs,

- Daily streamflow,

- Daily quick flow derived from daily streamflow,

- Daily base flow derived from daily streamflow,

- Monthly runoff volume,

- Annual runoff volume,

- Total runoff volume of the calibration period, and

- Flow duration curve (FDC).

Note that this composite objective function, although comprehensive, is not the same as those used in HSPEXP. The objective function and PEST control file were set up with the aid of a general time-series processor to assist in model calibration and result summarization (TSPROC) program (Westenbroek and others, 2012). The storm hydrographs, quick flow and base flow time series, and flow volumes were determined using functions described in the TSPROC program. For specifying storm hydrographs, a threshold peak magnitude is needed for each watershed. The magnitude and duration of storm hydrographs were determined from the measured discharge hydrographs with a threshold peak flow discharge of $300 \mathrm{ft}^{3} / \mathrm{s}$ and $342 \mathrm{ft}^{3} / \mathrm{s}$, respectively, for Tinley Creek and Long Run watersheds; and the storm duration was set to 7 days with 2 days before the peak. Fourteen quantiles were used in describing an FDC with emphasis given at two tails in the ranges of exceedance probabilities smaller than 25 percent and larger than 60 percent.

\section{Parameter Ratios}

Allowing all grassland and forestland parameters to search some parameters independently may result in unreasonable values (for example, a parameter that should have similar values for grassland and forestland with values that were greatly different) or the problem becoming ill-posed; therefore, it enforces the need for parameter ordering. The parameter ordering was established by setting the forestland parameter equal to a ratio of the corresponding adjustable grassland parameter. Instead of optimizing the forestland parameters, the adjustable grassland parameters and the corresponding ratios were optimized by the PEST; therefore, the ranges for grassland parameters are evaluated and the ranges for forestland parameters are specified through the ratios. The initial range for each parameter ratio was estimated based on factors that affect the parameter values or based on the relations in the existing LMDA parameter sets. The grassland parameters were directly calibrated because the acreages for grassland are generally larger than those for forestland in the nine watersheds. The parameter ratios used in the study are as follows:

- IRC and INTFW have equal or larger values in grassland than in forestland. The range for the INTFW ratio used was from 0.75 to 1.0 , and for a transformation form of IRC was $0.75-1.0$.

- INFILT, LSUR, AGWETP, CEPSC, and NSUR have equal or larger values in forestland than in grassland. The range for the INFILT ratio used was 1.00-1.05, for the LSUR ratio was 1.0-1.5, for the AGWETP ratio was $1.00-1.05$, for the CEPSC-ratio was $1.25-2.5$, and for the NUSR ratio was 1.0-1.25.

- UZSN and LZETP could have much larger values in forestland than in grassland. The range for the UZSN ratio used was 1.0-2.0, and for the LZETP ratio was 1.5-3.5.

- LZSN, SLSUR, AGWRC could have similar values in grassland and forestland. The range for the LZSN ratio used was $0.7-1.3$, for the SLSUR ratio was 0.9-1.1, and for a transformation form of the AGWRC ratio was $0.95-1.05$. 


\section{Weight for Observation Groups}

In PEST, the residuals between model and observations can be weighted, thereby allowing certain observations more importance than others in determining the optimization outcome to be made (Doherty, 2005). Weights for elements within an observation group were estimated by the inverse magnitude method (Doherty, 2005), and weights for each observation group (intergroup weights) were set so that the "phi" for yearly volumes, total volumes, and FDCs were approximately two times higher than the rest of observation groups. Initial PEST runs indicated that this type of weighting resulted in an improved calibration (higher correlation coefficients and smaller residuals in total volumes), compared with using uniform intergroup weights.

\section{Initial Calibration}

In the initial calibration stage, the three PEST models (Tinley Creek, Long Run, and PEST two-watershed) were applied to the three-tier designs. At this stage, a calibration run was considered completed if the objective function reduction between two consecutive runs had reached a minimum; with the second run using the optimal parameter values obtained from the prior run. Also, Doherty (2005) suggested the following indicators that the problem is not ill-posed: the Marquardt Lambda value must be trending smaller; the condition number be within proper range (less than $10^{4}$, for example), and the order of composite parameter sensitivities within two orders of magnitudes. The PEST program generates detailed outputs for these considerations. From reviewing the recorded run outputs, a parameter that adhered to its upper or lower bound indicates that PEST was unable to determine its values based on the calibration datasets provided. In the initial calibration stage such parameter behaviors were not dealt with because the objective was to determine the number of adjustable parameters and their bounds combination. The tier to be used in the refinement analysis is the one that resulted in the most reduction in the objective function in the three PEST watershed models and the least residuals in the yearly runoff volume, total runoff volume, and FDC in the Tinley Creek and Long Run watersheds. Analysis of the results from the three tier designs are as follows.

1. For the FDC, Tier-1 yielded the least discrepancies (in underestimation), especially at low exceedance probabilities in two watersheds. Tier-3 had the second least discrepancies for Tinley Creek, but Tier-2b had the second least discrepancies for Long Run. Tier-2a produced the largest discrepancies (most underestimation) in most of the quantiles and large discrepancies in less frequent magnitudes.

2. For total runoff volumes, Tier-1 yielded the smallest discrepancy (underestimation, by -0.07 percent) followed by Tier-3 (-0.08 percent) and Tier-2b (-0.30 percent) for Tinley Creek. Tier-2b had the smallest discrepancy (overestimated by 0.11 percent) followed by Tier- 1 (-0.47 percent) and Tier-3 (-3.82 percent) for Long Run. Tier-3 had the second largest discrepancies for Long Run (-3.83 percent). Tier-2a had the largest discrepancies for both watersheds, approximately -14.05 percent for Tinley Creek and -8.98 percent for Long Run.

3. For annual runoff volumes, Tier-3 had the most number of years in minimum discrepancy for the 9-year period, whereas Tier-2a had the least number of years of minimum discrepancy in the two watersheds from all three PEST watershed models. In general, the yearly discrepancy by Tier-2a analysis differed from the remaining tiers most, whereas the results of remaining tiers were closely tied to each other. Note that when the two watershed models were calibrated simultaneously (PEST two-watershed model), the degrees of discrepancy in annual runoff volumes and FDC were lower than those determined from individual PEST watershed models.

These comparisons indicated that Tier-1 and Tier-3 performed better in the Tinley Creek watershed, whereas Tier$2 \mathrm{~b}$ and Tier-1 performed better in the Long Run watershed. Because the objective of the study was to develop a regional parameter set, and Tier-1 and Tier2b had limited adjustable parameters and narrower bounds than those applied to Tier-3, the Tier-3 design was selected for further refinement.

\section{Parameter Sensitivity}

The observation group to parameter sensitivity relations for the adjustable parameters in the Tier-3 analysis are listed in table 16 using results from the PEST Tinley Creek and PEST Long Run watershed models. The sensitivity relations at the initial level are shown in table 16. In the listing, level-1 sensitive parameters are those with the highest sensitivity, level-2 sensitive parameters are those differed by only one order of magnitude, and insensitive parameters are those of the lowest sensitivity.

The parameters AGWRC, FOREST, and IRC were insensitive to the calibration data formatted for each watershed (table 16), and currently (2015), there is no explanation for the different DEEPER sensitivity between the two watersheds.

\section{Refinement Calibration}

The focus in the refinement stage was to treat insensitive and highly correlated parameters in the three PEST models and incorporate expert knowledge to assist the determination of these parameters. Using additional observation groups to form the objective function may alleviate the insensitivity of some parameters and could be a worthwhile effort for future endeavors. Insensitive parameters cannot contribute to the lowering of objective function, and highly correlated parameters make it difficult for PEST to differentiate which parameter upgrade altered the objective function. Insensitive parameters 
Table 16. Observation group to parameter sensitivity relations obtained from the initial Tier-3 (17 parameter) analysis in PEST Tinley Creek and PEST Long Run watershed models.

[Two levels of sensitive parameters are listed. Level 1: most sensitive parameters, and Level 2: parameters where sensitivities differ from those of Level 1 by one order of magnitude. PEST, model-independent parameter estimation and uncertainty analysis program]

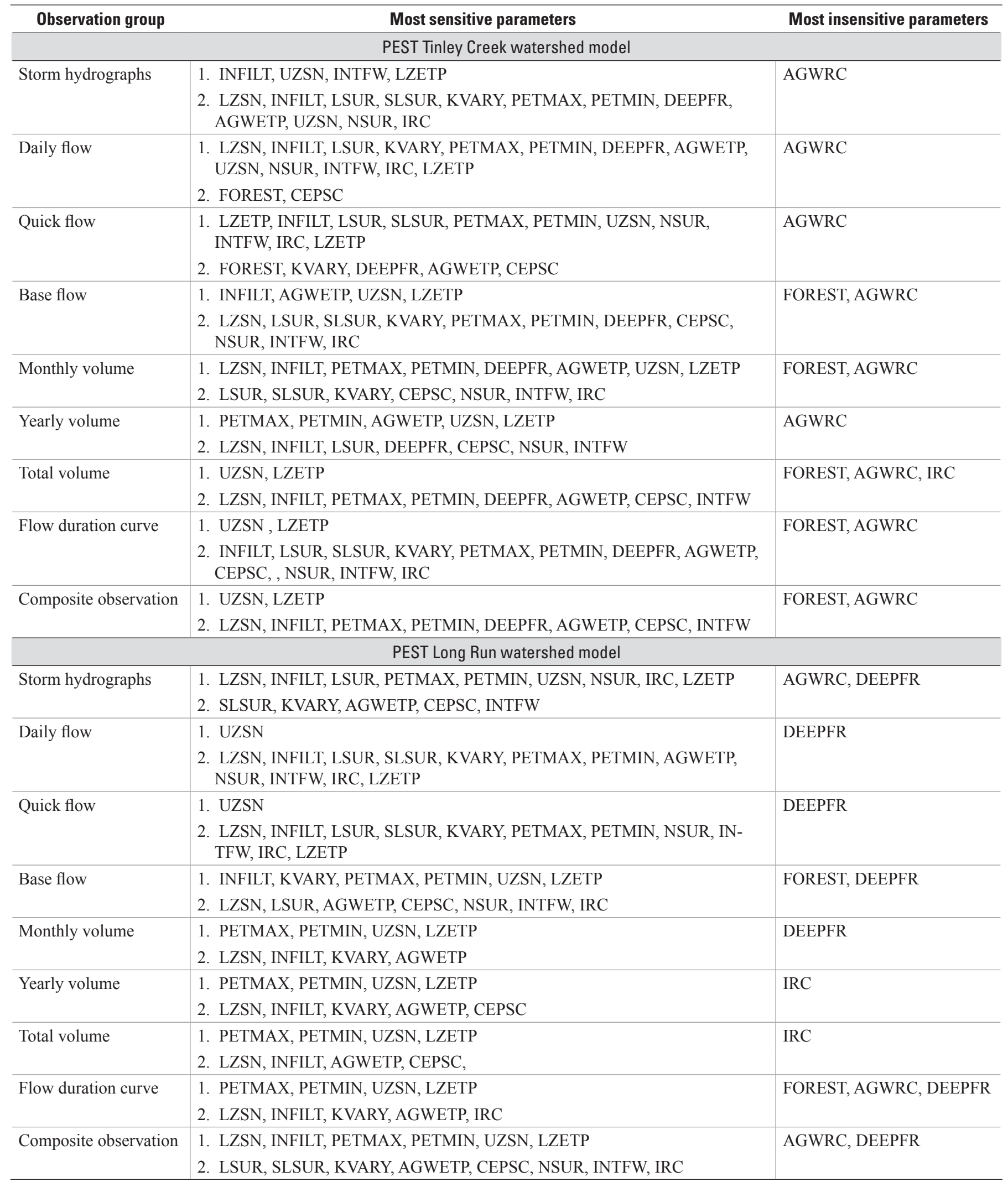


can be assigned with generally acknowledged values that will not affect PEST's optimization processes on other parameter values. Setting preferred values that fit the watershed characteristics as a fallback for some highly correlated parameters is an effective way to handle parameters with high correlations. Setting preferred values is done through the use of the "prior information" or "regularization" mode in PEST (Doherty, 2005). PEST has also insisted on lowering LZSN to its lower bound and raising UZSN to its upper bound without regularization (Doherty and Johnston, 2003). Although the parameters were still calibrated for the given objective function, the discrepancies on low flows were appreciable. This phenomenon was met in this study even with the objective function used. Enforcing the regularization in the optimization process became an essential part of the refinement process. For parameters whose preferred values are difficult to determine, the BASINS Technical Note No. 6 (U.S. Environmental Protection Agency, 2000) recommended assigning these parameters to general preferred values and revisiting them after all other parameter values have been estimated.

From the results of initial calibration, weak correlations between the parameter and its ratio were noticed for NSUR, DEEPFR, SLSUR, and LSUR in the Tinley Creek watershed model; and for LSUR, SLSUR, and NSUR in the Long Run watershed model. These weak relations met physical expectations; therefore, in the refinement calibrations these parameters were calibrated using their grassland and forestland parameters, not the parameter ratios. Insensitive parameters could be identified by examining the sensitivity output, like those shown in table 16. Examining the correlation matrix could determine parameters of high correlations. Parameter pairs that had high correlations were LZSN and DEEPFR, INFILT and INTFW, INFILT and LZETP, SLSUR and NSUR, AGWRC and AGWETP, and KVARY and AGWRC. These parameters generally adhered to their upper or lower bounds at the end of calibration.

Modifications made to the parameter bounds or the preferred values set in the refinement stage included the following:

1. Modify the bounds for AGWRC to approximate the range obtained in the recession analysis (between 10 and 50 days), modify the bounds for SLSUR to between 0.0085 and 0.0015 (mean watershed slope listed in table 5), modify the bounds for LSUR to between 200 and 500, and lower the upper bound of INTFW from 10 to 5 . The latter two modifications were based on flat terrain of the LMDA watersheds. The INFILT has been constrained to between 0.001 and 0.1 , reflecting the soil of the $\mathrm{C}$ and $\mathrm{D}$ types.

2. Remove parameter ordering for NSUR, DEEPFR, SLSUR, and LSUR, as described above. Because that grassland and forestland should represent different flow resistance, the bounds for NSUR grassland were reduced to between 0.15 and 0.25 .
3. Set preferred values for insensitive parameters: 0.7 for IRC because of flat terrain, 0.3 for FOREST as forestland, and 0.2 for FOREST as grassland.

4. Set preferred values for AGWETP to the fraction of wetlands (0.05) obtained from the land-use analysis (table 6) KVARY and DEEPFR to a near zero value (U.S. Environmental Protection Agency, 2000)

5. Set the preferred values for other grassland parameters (LZSN, INFILT, LSUR, SLSUR, KVARY, AGWRC, PETMAX, PETMIN, DEEPFR, AGWETP, CEPSC, UZSN, NSUR, INTFW, IRC, and LZETP) to those obtained from the two-watershed model under Tier-3 constraints in the initial calibration.

The refinement stage then proceeded to calibrate the watershed models using PEST. After the three watershed models were calibrated, the KVARY, DEEPFR, and AGWETP mostly stayed at the values assigned. In the final step, these three parameters were calibrated with ET-related parameter sets to the best values that were available. At this final stage, non-ET-related parameters FOREST, LSUR, SLSUR, AGWRC, PETMAX, PETMIN, NSUR, INTFW, and LZETP were fixed at their optimal values.

\section{Analysis of Calibrated Parameter Sets}

Parameter values obtained from the HSPEXP and PEST automatic calibrations are listed in table 17. Parameters LZSN, INFILT, AGWETP, CEPSC, UZSN, and LZETP were the most sensitive in the three PEST models; these parameters and their combinations form the explanatory variables of regression equations for those adjustable parameters (Doherty, 2005). Each of the PEST watershed models estimated LZSN for grassland and forestland to be the same, raised SLUR to its upper bound, and lowered SLSUR to its lower bound. The PETMAX was lowered to $45^{\circ} \mathrm{F}$ and PETMIN to a range between $30^{\circ} \mathrm{F}$ and $35^{\circ} \mathrm{F}$. Physical representations of these values could be reasonable but information for justifying their correctness is not currently available.

The simulated runoffs were first checked for the basic flow statistics (like those presented in table 10) and the fraction of base flow volume in total flow volume over the calibration period (table 18); however, keep in mind that the routing functions in these watershed models were preliminary approximation only (derived through BASINS) therefore matches in the maximum and minimum discharges are not as indicative of a better fit as matches in the mean discharge, reduction in variances, and the fraction of base flow in total flow volumes. For the Tinley Creek watershed, the PEST Tinley Creek watershed model performed best, followed by the PEST two-watershed model; for the Long Run watershed, the HSPEXP Long Run watershed model performed best, followed by PEST Long Run watershed model and PEST two-watershed model (table 18). 
Table 17. Grassland and forestland parameters obtained from HSPEXP and PEST calibrations.

[PEST, model-independent parameter estimation and uncertainty analysis program. Note that when applying these parameter values, the wind correction factor for forestland should not be used.]

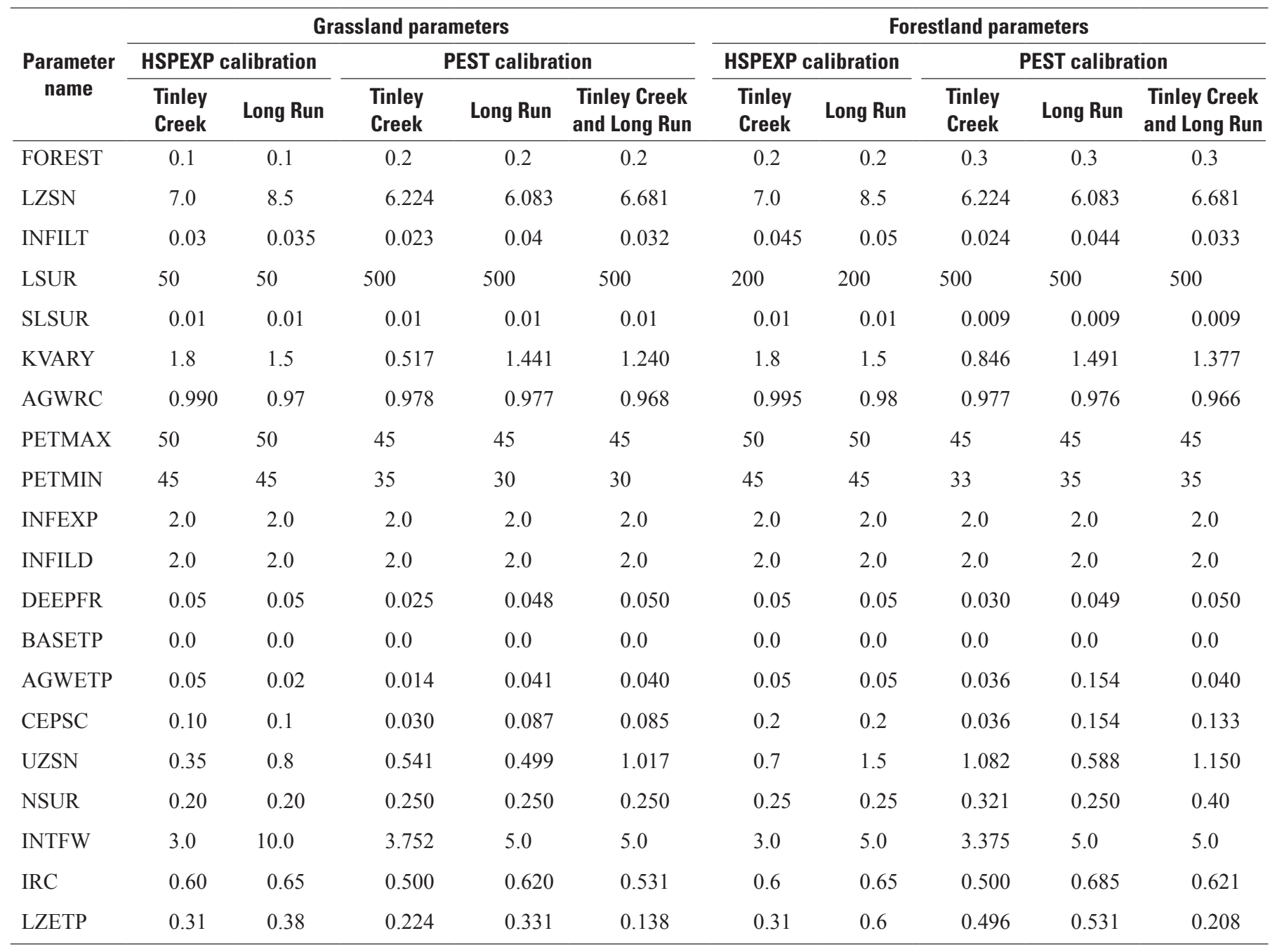


Table 18. Comparison of basic flow statistics and fraction of base flow volume derived from measured daily flows and simulated daily runoff time series derived with the HSPEXP and PEST calibration parameters for the calibration period between 0ctober 1, 2000, and September 30, 2009.

$\left[\mathrm{ft}^{3} / \mathrm{s}\right.$, cubic feet per second. PEST, model-independent parameter estimation and uncertainty analysis program. Note: the minimum simulated runoff is a very small number (less than 0.01 cubic feet per second) and is represented as 0$]$

\begin{tabular}{lccccc}
\hline \multicolumn{1}{c}{ Parameter name } & $\begin{array}{c}\text { Maximum } \\
\text { discharge } \\
\left(\mathbf{f t}^{3} / \mathbf{s}\right)\end{array}$ & $\begin{array}{c}\text { Minimum } \\
\text { discharge } \\
\left(\mathbf{f t}^{3} / \mathbf{s}\right)\end{array}$ & $\begin{array}{c}\text { Mean } \\
\text { discharge } \\
\left(\mathbf{f t}^{3} / \mathbf{s}\right)\end{array}$ & $\begin{array}{c}\text { Standard } \\
\text { deviation }\end{array}$ & $\begin{array}{c}\text { Base flow } \\
\text { fraction }\end{array}$ \\
\hline Measured & \multicolumn{2}{c}{ Tinley Creek watershed } & & & 0.480 \\
HSPEXP Tinley Creek watershed model & 628 & 0 & 14.5 & 38.1 & 0.456 \\
HSPEXP Long Run watershed model & 942 & 0 & 15.2 & 42.3 & 0.487 \\
PEST Tinley Creek watershed model & 859 & 0 & 13.3 & 33.3 & 0.456 \\
PEST Long Run watershed model & 895 & 0 & 14.4 & 39.8 & 0.472 \\
PEST two-watershed model & 874 & 0 & 13.5 & 35.1 & 0.482 \\
\hline & 864 & 0 & 14.3 & 36.8 & \\
\hline Measured & \multicolumn{2}{c}{ Long Run watershed } & & & 0.564 \\
HSPEXP Tinley Creek watershed model & 843 & 0.2 & 24.9 & 55.1 & 0.475 \\
HSPEXP Long Run watershed model & 1,430 & 0 & 28.1 & 75.4 & 0.519 \\
PEST Tinley Creek watershed model & 1,310 & 0 & 24.3 & 56.2 & 0.480 \\
PEST Long Run watershed model & 1,380 & 0.1 & 26.8 & 70.6 & 0.505 \\
PEST two-watershed model & 1,340 & 0 & 24.5 & 60.0 & 0.506 \\
\hline
\end{tabular}

The quantitative statistics computed for the calibration and verification periods are listed in table 19, with "very good" results shown in bold and "unsatisfactory" results shown as shaded. Using the number of "very good" ratings on PBIAS, NSE, and RSR as the basis for evaluation, the PEST twowatershed and PEST Long Run watershed models performed best followed by the manual Long Run model in the calibration period. Apparently, the watershed selected for calibrating the regional parameter set is a factor; however, none of the parameter sets performed well for the Skokie River watershed. In verification period one (WYs 1997 to 2000), the performances of all parameter set dropped. The PEST two-watershed model performed better than the PEST-Long Run watershed model, followed by the HSPEXP Long Run watershed model.
The performances of all watershed models further declined in validation period two (WYs 2010 and 2011), although the PEST two-watershed model and PEST-Long Run watershed model were the better performers.

The calibrated parameters were checked for their regional performance with the annual and overall S/R ratios and DMCs based on results from the entire period WYs 1996 to 2011. Judging from the number of watersheds that have $S / R$ ratios close to unity (table 20) and the matches of observed and simulated DMC plots (figs. 13 to 17), the parameter sets obtained from the PEST two-watershed model and the PEST Long Run watershed model perform better than other parameter sets in the regional applications. 
Table 19. Quantitative statistics of PBIAS, NSE, and RSR for the calibration and verification periods for parameters obtained from HSPEXP and PEST calibrations.

[Calibration period: water years 2001-09; Validation period 1: water years 1997-2000; Validation period 2: water years 2000-01; PBIAS, percent bias, NSE, Nash-Sutcliffe efficiency; RSR, root-mean-square error to the standard deviation of measured data (Moriasi and others, 2007); PEST, model-independent parameter estimation and uncertainty analysis program. Results in the "very good" category are shown in bold, and those in the "unsatisfactory" category are shown in gray-shaded cells.]

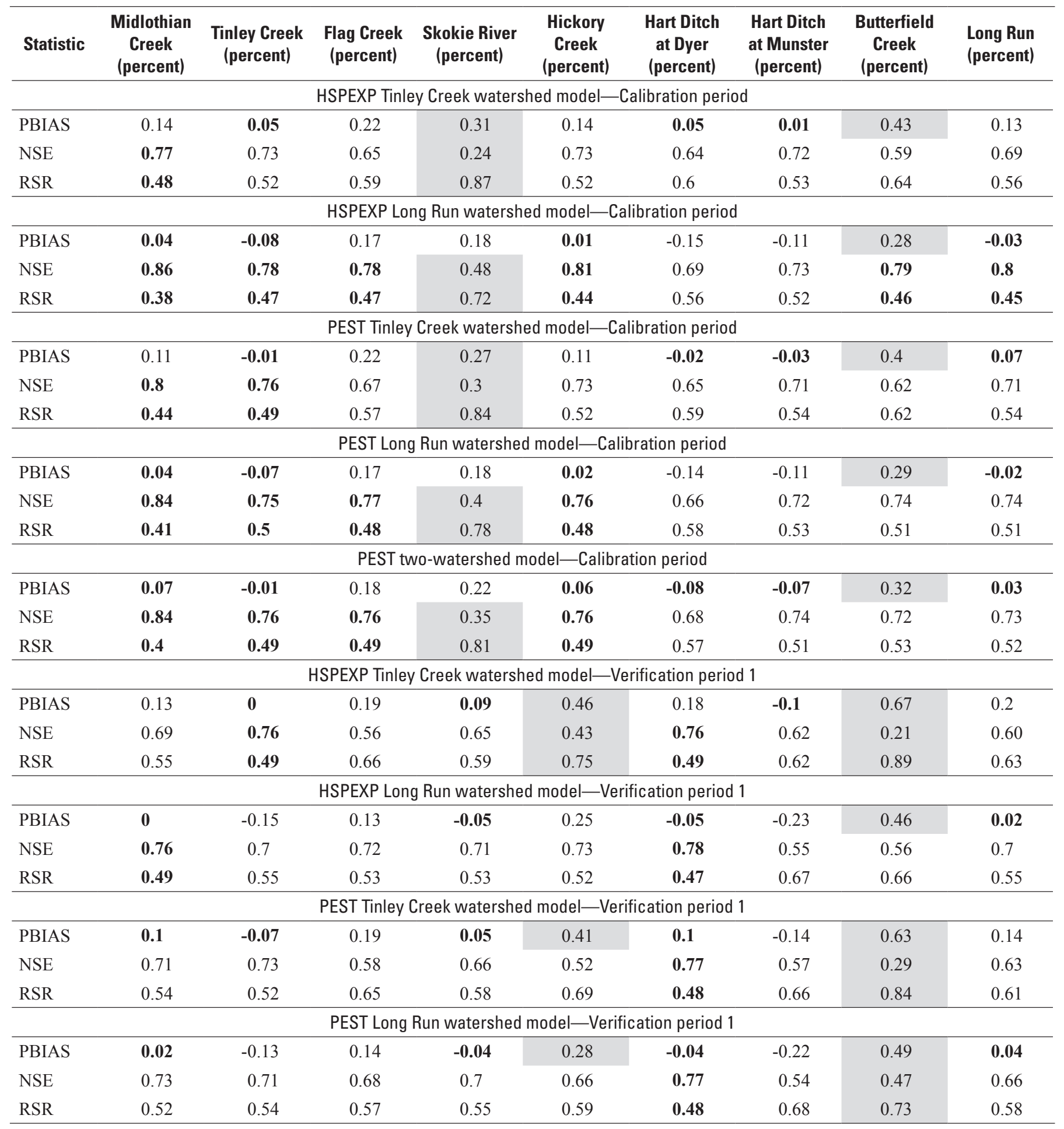


Table 19. Quantitative statistics of PBIAS, NSE, and RSR for the calibration and verification periods for parameters obtained from HSPEXP and PEST calibrations.-Continued

[Calibration period: water years 2001-09; Validation period 1: water years 1997-2000; Validation period 2: water years 2000-01; PBIAS, percent bias, NSE, Nash-Sutcliffe efficiency; RSR, root-mean-square error to the standard deviation of measured data (Moriasi and others, 2007); PEST, model-independent parameter estimation and uncertainty analysis program. Results in the "very good" category are shown in bold, and those in the "unsatisfactory" category are shown in gray-shaded cells.]

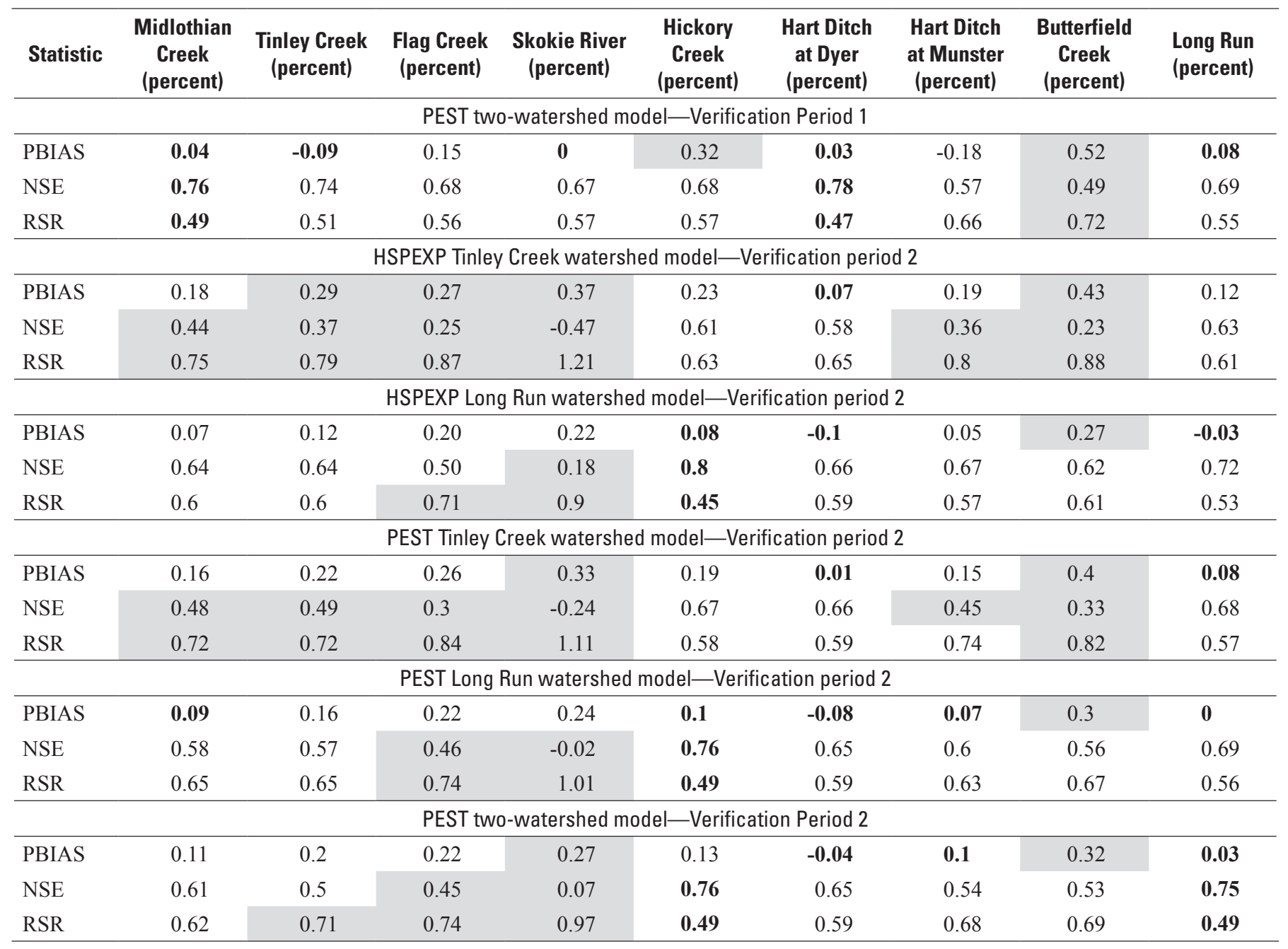


Table 20. Ratio of simulated annual runoff volume to recorded annual streamflow volume (S/R ratio) determined from HSPEXP and PEST calibrations at the nine study watersheds for water years 1996 to 2011. [S, simulated runoff volume; R, recorded streamflow volume; PEST, model-independent parameter estimation and uncertainty analysis program

\begin{tabular}{|c|c|c|c|c|c|c|c|c|c|c|c|c|c|c|c|c|c|c|}
\hline & 1996 & 1997 & 1998 & 1999 & 2000 & 2001 & 2002 & 2003 & 2004 & 2005 & 2006 & 2007 & 2008 & 2009 & 2010 & 2011 & Overall & Range \\
\hline \multicolumn{19}{|c|}{ Midlothian Creek } \\
\hline HSPEXP Tinley watershed model & 1.18 & 1.14 & 1.11 & 1.18 & 1.12 & 1.12 & 1.01 & 1.00 & 1.18 & 1.14 & 1.31 & 1.26 & 1.10 & 1.13 & 1.29 & 1.08 & 1.15 & $(1.00-1.31)$ \\
\hline HSPEXP Long Run watershed model & 1.06 & 1.06 & 0.99 & 1.06 & 0.96 & 1.01 & 0.92 & 0.89 & 1.04 & 1.05 & 1.17 & 1.17 & 0.99 & 1.07 & 1.17 & 0.97 & 1.04 & $(0.88-1.17)$ \\
\hline PEST Tinley watershed model & 1.16 & 1.13 & 1.07 & 1.14 & 1.11 & 1.08 & 0.97 & 0.99 & 1.14 & 1.12 & 1.28 & 1.22 & 1.08 & 1.11 & 1.26 & 1.06 & 1.12 & $(0.97-1.28)$ \\
\hline PEST Long Run watershed model & 1.11 & 1.06 & 1.01 & 1.08 & 0.99 & 1.02 & 0.94 & 0.89 & 1.07 & 1.05 & 1.20 & 1.18 & 1.00 & 1.08 & 1.19 & 0.99 & 1.06 & $(0.89-1.2)$ \\
\hline PEST two-watershed model & 1.11 & 1.06 & 1.00 & 1.06 & 1.02 & 1.00 & 0.91 & 0.88 & 1.07 & 1.03 & 1.20 & 1.16 & 1.01 & 1.06 & 1.20 & 0.99 & 1.05 & $(0.88-1.2)$ \\
\hline \multicolumn{19}{|c|}{ Tinley Creek } \\
\hline HSPEXP Tinley watershed model & 1.01 & 1.12 & 1.07 & 0.95 & 0.98 & 1.02 & 0.90 & 0.90 & 0.95 & 1.07 & 1.05 & 1.08 & 1.20 & 1.22 & 1.42 & 1.16 & 1.08 & $(0.90-1.42)$ \\
\hline HSPEXP Long Run watershed model & 0.89 & 1.01 & 0.92 & 0.83 & 0.80 & 0.89 & 0.78 & 0.76 & 0.81 & 0.94 & 0.87 & 0.96 & 1.03 & 1.13 & 1.25 & 1.00 & 0.94 & $(0.76-1.25)$ \\
\hline PEST Tinley watershed model & 0.99 & 1.07 & 1.00 & 0.88 & 0.93 & 0.95 & 0.82 & 0.86 & 0.89 & 1.01 & 0.99 & 1.01 & 1.14 & 1.17 & 1.35 & 1.09 & 1.02 & $(0.82-1.35)$ \\
\hline PEST Long Run watershed model & 0.95 & 1.00 & 0.94 & 0.84 & 0.82 & 0.89 & 0.80 & 0.76 & 0.83 & 0.94 & 0.90 & 0.98 & 1.06 & 1.14 & 1.27 & 1.03 & 0.96 & $(0.76-1.27)$ \\
\hline PEST two-watershed model & 0.95 & 1.00 & 0.93 & 0.82 & 0.85 & 0.88 & 0.77 & 0.76 & 0.83 & 0.93 & 0.92 & 0.97 & 1.08 & 1.12 & 1.29 & 1.03 & 0.96 & $(0.76-1.29)$ \\
\hline \multicolumn{19}{|c|}{ Flag Creek } \\
\hline HSPEXP Tinley watershed model & 1.23 & 1.27 & 1.33 & 1.11 & 1.15 & 1.21 & 1.17 & 1.20 & 1.26 & 1.21 & 1.26 & 1.18 & 1.28 & 1.22 & 1.20 & 1.35 & 1.23 & $(1.11-1.35)$ \\
\hline HSPEXP Long Run watershed model & 1.16 & 1.23 & 1.24 & 1.07 & 1.08 & 1.15 & 1.11 & 1.15 & 1.19 & 1.17 & 1.20 & 1.13 & 1.22 & 1.18 & 1.14 & 1.27 & 1.17 & $(1.07-1.27)$ \\
\hline PEST Tinley watershed model & 1.23 & 1.28 & 1.32 & 1.10 & 1.16 & 1.20 & 1.16 & 1.20 & 1.25 & 1.21 & 1.26 & 1.17 & 1.28 & 1.22 & 1.20 & 1.34 & 1.22 & $(1.1-1.34)$ \\
\hline PEST Long Run watershed model & 1.20 & 1.22 & 1.27 & 1.07 & 1.09 & 1.16 & 1.13 & 1.15 & 1.20 & 1.17 & 1.21 & 1.14 & 1.23 & 1.19 & 1.16 & 1.29 & 1.18 & $(1.07-1.29)$ \\
\hline $\begin{array}{l}\text { PEST two-watershed model } \\
\end{array}$ & 1.20 & 1.23 & 1.26 & 1.06 & 1.10 & 1.15 & 1.11 & 1.14 & 1.19 & 1.16 & 1.20 & 1.13 & 1.23 & 1.18 & 1.15 & 1.28 & 1.17 & $(1.06-1.28)$ \\
\hline \multicolumn{19}{|c|}{ Skokie River } \\
\hline $\begin{array}{l}\text { HSPEXP Tinley watershed model } \\
\end{array}$ & 1.47 & 1.93 & 1.06 & 1.09 & 1.14 & 1.16 & 1.28 & 1.11 & 1.30 & 1.48 & 1.10 & 1.42 & 1.56 & 1.25 & 1.15 & 1.60 & 1.31 & $(1.06-1.93)$ \\
\hline HSPEXP Long Run watershed model & 1.31 & 1.75 & 0.95 & 0.96 & 0.95 & 1.04 & 1.13 & 0.99 & 1.15 & 1.32 & 0.98 & 1.30 & 1.41 & 1.16 & 1.03 & 1.42 & 1.17 & $(0.95-1.75)$ \\
\hline PEST Tinley watershed model & 1.45 & 1.88 & 1.01 & 1.05 & 1.10 & 1.11 & 1.21 & 1.06 & 1.27 & 1.44 & 1.09 & 1.38 & 1.52 & 1.22 & 1.12 & 1.56 & 1.27 & $(1.01-1.88)$ \\
\hline PEST Long Run watershed model & 1.39 & 1.77 & 0.96 & 0.97 & 0.98 & 1.06 & 1.16 & 1.00 & 1.18 & 1.32 & 0.99 & 1.32 & 1.44 & 1.19 & 1.05 & 1.45 & 1.20 & $(0.96-1.77)$ \\
\hline PEST two-watershed model & 1.39 & 1.75 & 0.93 & 0.97 & 1.00 & 1.04 & 1.14 & 0.94 & 1.17 & 1.31 & 0.98 & 1.32 & 1.44 & 1.16 & 1.05 & 1.46 & 1.19 & $(0.93-1.75)$ \\
\hline \multicolumn{19}{|c|}{ Hickory Creek } \\
\hline $\begin{array}{l}\text { HSPEXP Tinley watershed model } \\
\end{array}$ & 1.58 & 1.67 & 1.40 & 1.43 & 1.62 & 1.46 & 0.82 & 1.08 & 1.16 & 1.18 & 1.42 & 1.05 & 1.20 & 1.15 & 1.29 & 1.17 & 1.26 & $\begin{array}{ll}(0.82-1.67) \\
\end{array}$ \\
\hline HSPEXP Long Run watershed model & 1.39 & 1.51 & 1.19 & 1.26 & 1.33 & 1.28 & 0.71 & 0.94 & 0.99 & 1.05 & 1.21 & 0.95 & 1.05 & 1.05 & 1.13 & 1.01 & 1.10 & $(0.71-1.51)$ \\
\hline PEST Tinley watershed model & 1.54 & 1.64 & 1.33 & 1.38 & 1.59 & 1.41 & 0.77 & 1.11 & 1.11 & 1.15 & 1.38 & 1.02 & 1.18 & 1.11 & 1.25 & 1.13 & 1.22 & $(0.77-1.64)$ \\
\hline PEST Long Run watershed model & 1.49 & 1.50 & 1.23 & 1.29 & 1.38 & 1.29 & 0.74 & 0.92 & 1.02 & 1.04 & 1.26 & 0.97 & 1.07 & 1.08 & 1.16 & 1.05 & 1.13 & $(0.74-1.5)$ \\
\hline PEST two-watershed model & 1.47 & 1.51 & 1.22 & 1.26 & 1.41 & 1.27 & 0.71 & 0.93 & 1.02 & 1.04 & 1.26 & 0.95 & 1.09 & 1.05 & 1.16 & 1.04 & 1.12 & $(0.71-1.51)$ \\
\hline \multicolumn{19}{|c|}{ Hart Ditch at Dyer } \\
\hline $\begin{array}{l}\text { HSPEXP Tinley watershed model } \\
\end{array}$ & 1.13 & 1.19 & 1.22 & 1.02 & 1.38 & 1.62 & 0.97 & 1.36 & 1.52 & 1.13 & 1.28 & 0.90 & 0.72 & 0.90 & 1.06 & 1.09 & 1.09 & $(0.72-1.62)$ \\
\hline HSPEXP Long Run watershed model & 0.94 & 1.02 & 1.01 & 0.86 & 0.95 & 1.34 & 0.81 & 1.01 & 1.16 & 0.89 & 1.00 & 0.78 & 0.56 & 0.77 & 0.88 & 0.91 & 0.89 & $(0.55-1.34)$ \\
\hline PEST Tinley watershed model & 1.10 & 1.12 & 1.14 & 0.94 & 1.31 & 1.52 & 0.89 & 1.28 & 1.38 & 1.07 & 1.17 & 0.84 & 0.69 & 0.84 & 1.01 & 1.02 & 1.02 & $(0.69-1.52)$ \\
\hline PEST Long Run watershed model & 1.03 & 1.04 & 1.05 & 0.87 & 1.01 & 1.36 & 0.85 & 1.03 & 1.20 & 0.91 & 1.08 & 0.79 & 0.58 & 0.80 & 0.91 & 0.95 & 0.92 & $(0.58-1.36)$ \\
\hline PEST two-watershed model & 1.03 & 1.03 & 1.03 & 0.83 & 1.02 & 1.32 & 0.79 & 1.01 & 1.18 & 0.92 & 1.05 & 0.77 & 0.60 & 0.76 & 0.91 & 0.94 & 0.91 & $(0.60-1.32)$ \\
\hline \multicolumn{19}{|c|}{ Hart Ditch at Munster } \\
\hline $\begin{array}{l}\text { HSPEXP Tinley watershed model } \\
\end{array}$ & 0.94 & 1.02 & 0.85 & 0.76 & 1.31 & 1.35 & 0.91 & 0.99 & 1.20 & 0.70 & 1.32 & 1.04 & 0.97 & 0.98 & 1.19 & 1.20 & 1.01 & $(0.70-1.35)$ \\
\hline HSPEXP Long Run watershed model & 0.83 & 0.90 & 0.73 & 0.67 & 1.05 & 1.18 & 0.81 & 0.83 & 1.02 & 0.60 & 1.13 & 0.94 & 0.84 & 0.89 & 1.05 & 1.06 & 0.88 & $(0.60-1.17)$ \\
\hline PEST Tinley watershed model & 0.93 & 0.98 & 0.81 & 0.73 & 1.28 & 1.29 & 0.87 & 0.96 & 1.13 & 0.68 & 1.25 & 1.00 & 0.95 & 0.95 & 1.16 & 1.15 & 0.97 & $(0.68-1.29)$ \\
\hline PEST Long Run watershed model & 0.89 & 0.91 & 0.75 & 0.68 & 1.09 & 1.19 & 0.84 & 0.84 & 1.04 & 0.61 & 1.18 & 0.95 & 0.85 & 0.91 & 1.07 & 1.09 & 0.90 & $(0.61-1.19)$ \\
\hline PEST two-watershed model & 0.89 & 0.91 & 0.74 & 0.66 & 1.11 & 1.16 & 0.80 & 0.83 & 1.02 & 0.61 & 1.17 & 0.93 & 0.87 & 0.88 & 1.07 & 1.08 & 0.90 & $(0.61-1.17)$ \\
\hline \multicolumn{19}{|c|}{ Butterfield Creek } \\
\hline $\begin{array}{l}\text { HSPEXP Tinley watershed model } \\
\end{array}$ & 1.56 & 1.80 & 1.62 & 1.54 & 2.01 & 1.70 & 1.33 & 1.76 & 1.70 & 1.52 & 1.55 & 1.17 & 1.35 & 1.32 & 1.49 & 1.38 & 1.50 & $(1.17-2.01)$ \\
\hline HSPEXP Long Run watershed model & 1.39 & 1.65 & 1.42 & 1.40 & 1.68 & 1.52 & 1.18 & 1.53 & 1.47 & 1.36 & 1.37 & 1.07 & 1.21 & 1.22 & 1.32 & 1.22 & 1.34 & $(1.067-1.68)$ \\
\hline PEST Tinley watershed model & 1.54 & 1.78 & 1.57 & 1.51 & 2.01 & 1.67 & 1.27 & 1.77 & 1.64 & 1.50 & 1.50 & 1.13 & 1.34 & 1.28 & 1.46 & 1.35 & 1.47 & $(1.13-2.01)$ \\
\hline PEST Long Run watershed model & 1.47 & 1.66 & 1.46 & 1.42 & 1.71 & 1.55 & 1.22 & 1.53 & 1.52 & 1.36 & 1.43 & 1.08 & 1.22 & 1.24 & 1.36 & 1.26 & 1.37 & $(1.08-1.71)$ \\
\hline PEST two-watershed model & 1.46 & 1.64 & 1.45 & 1.38 & 1.75 & 1.51 & 1.17 & 1.53 & 1.51 & 1.36 & 1.41 & 1.05 & 1.24 & 1.21 & 1.36 & 1.25 & 1.35 & $(1.05-1.75)$ \\
\hline \multicolumn{19}{|c|}{ Long Run } \\
\hline HSPEXP Tinley watershed model & 1.45 & 1.67 & 1.36 & 1.14 & 1.11 & 1.37 & 1.11 & 1.46 & 1.25 & 1.14 & 1.41 & 0.90 & 1.09 & 0.98 & 1.19 & 1.05 & 1.19 & $(0.90-1.67)$ \\
\hline HSPEXP Long Run watershed model & 1.26 & 1.51 & 1.15 & 1.00 & 0.90 & 1.17 & 0.96 & 1.19 & 1.06 & 1.01 & 1.14 & 0.80 & 0.94 & 0.90 & 1.04 & 0.91 & 1.03 & $(0.80-1.51)$ \\
\hline PEST Tinley watershed model & 1.41 & 1.62 & 1.27 & 1.09 & 1.07 & 1.30 & 1.03 & 1.41 & 1.17 & 1.08 & 1.36 & 0.86 & 1.06 & 0.95 & 1.15 & 1.01 & 1.14 & $(0.86-1.62)$ \\
\hline PEST Long Run watershed model & 1.35 & 1.51 & 1.19 & 1.01 & 0.93 & 1.18 & 1.00 & 1.22 & 1.10 & 1.01 & 1.19 & 0.81 & 0.96 & 0.92 & 1.06 & 0.93 & 1.05 & $(0.81-1.51)$ \\
\hline PEST two-watershed model & 1.35 & 1.51 & 1.18 & 0.99 & 0.95 & 1.17 & 0.95 & 1.22 & 1.08 & 0.98 & 1.20 & 0.80 & 0.98 & 0.89 & 1.07 & 0.93 & 1.05 & $(0.80-1.51)$ \\
\hline
\end{tabular}


A. Midlothian Creek

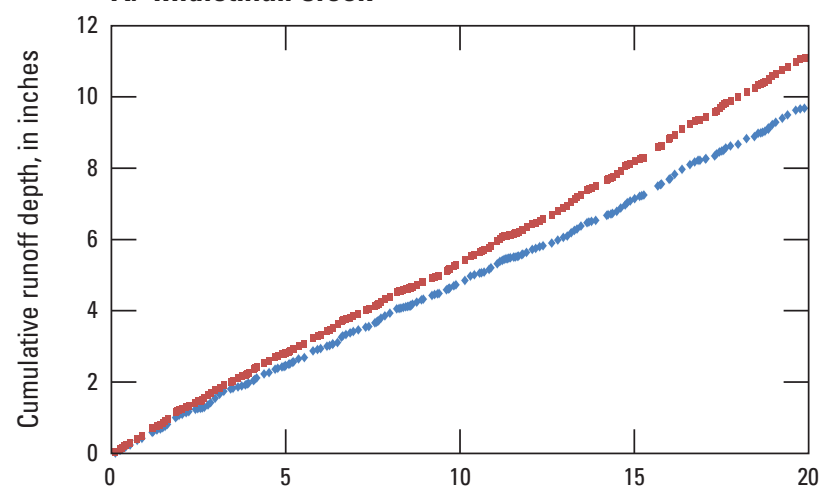

D. Skokie River

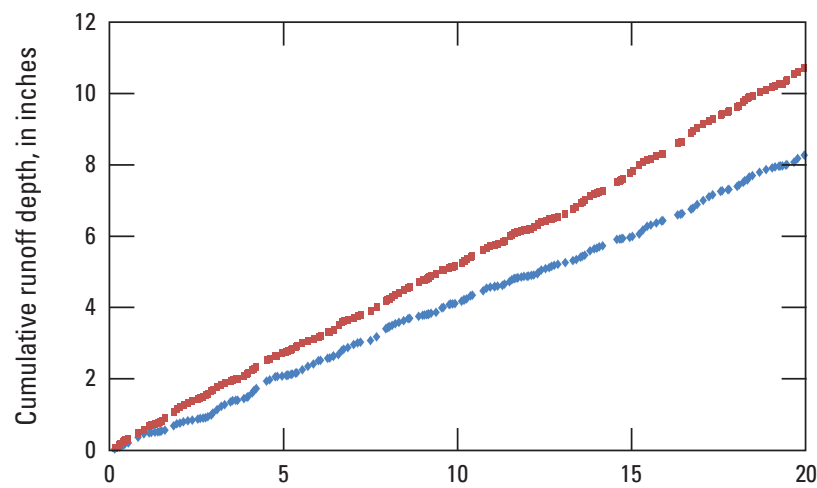

G. Hart Ditch at Munster

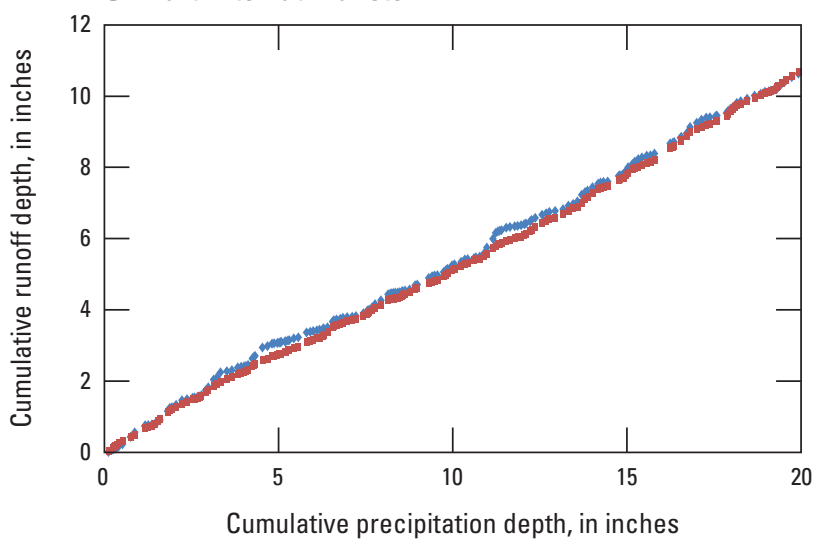

Cumulative precipitation depth, in inches
B. Tinley Creek

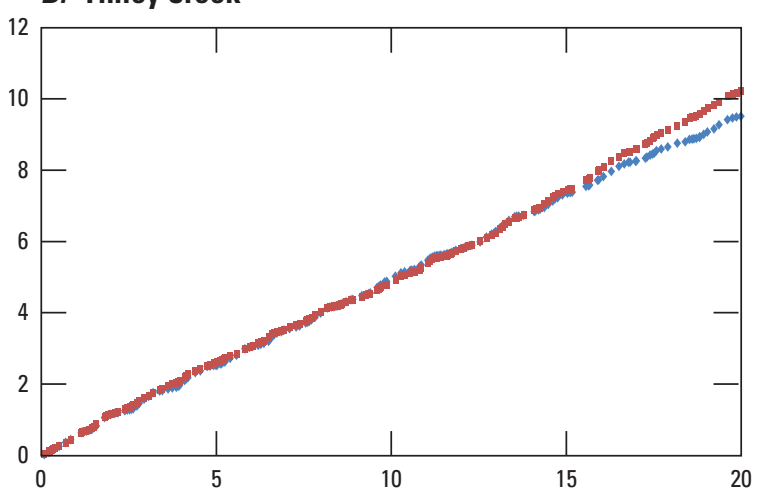

E. Hickory Creek

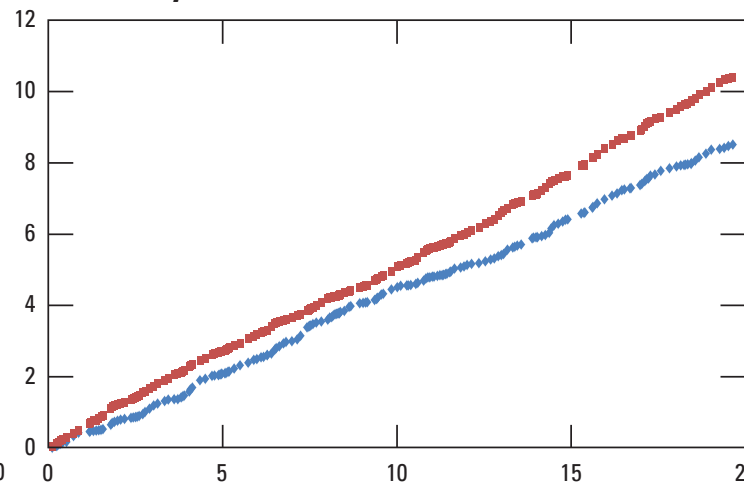

H. Butterfield Creek

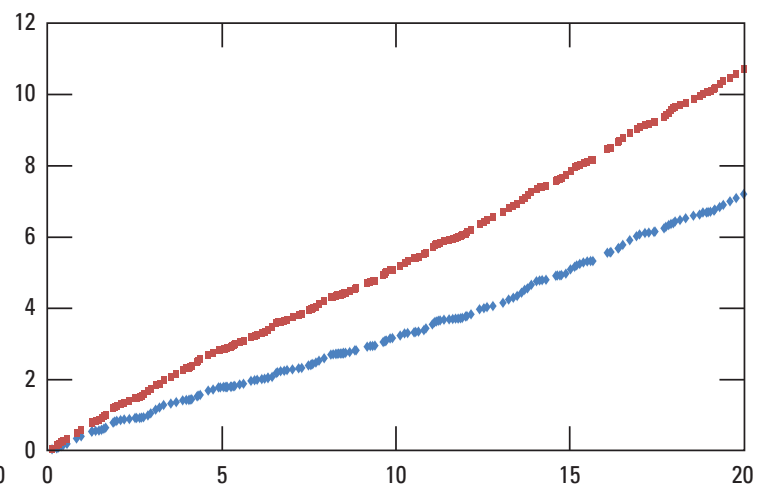

Cumulative precipitation depth, in inches

\section{Flag Creek}

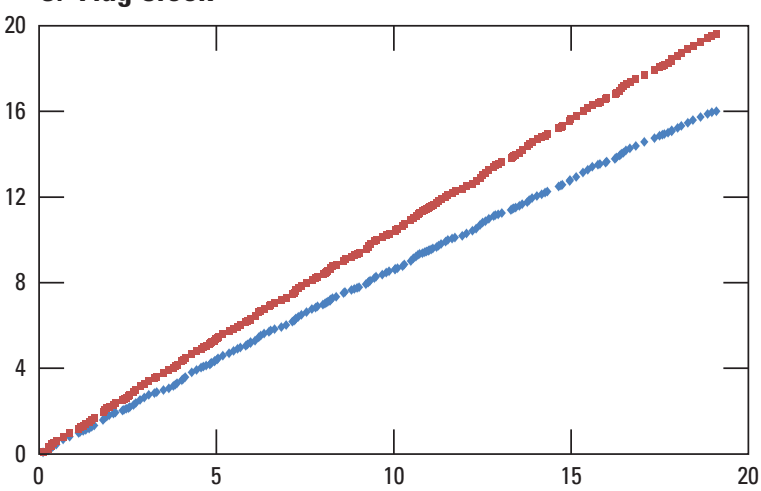

F. Hart Ditch at Dyer

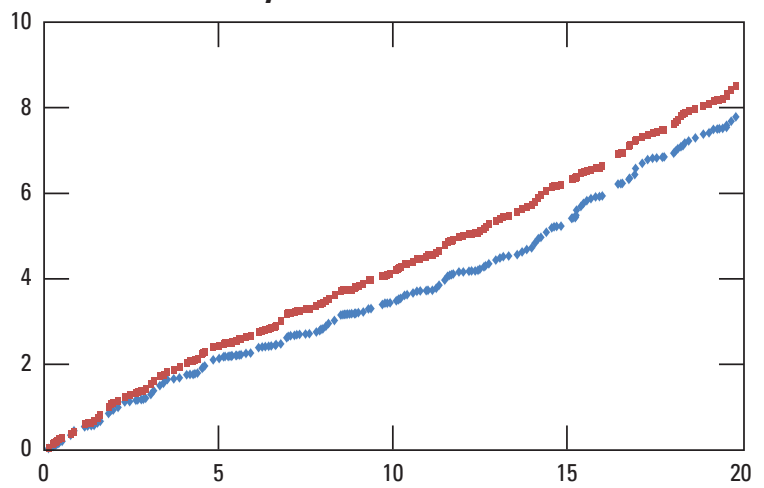

I. Long Run

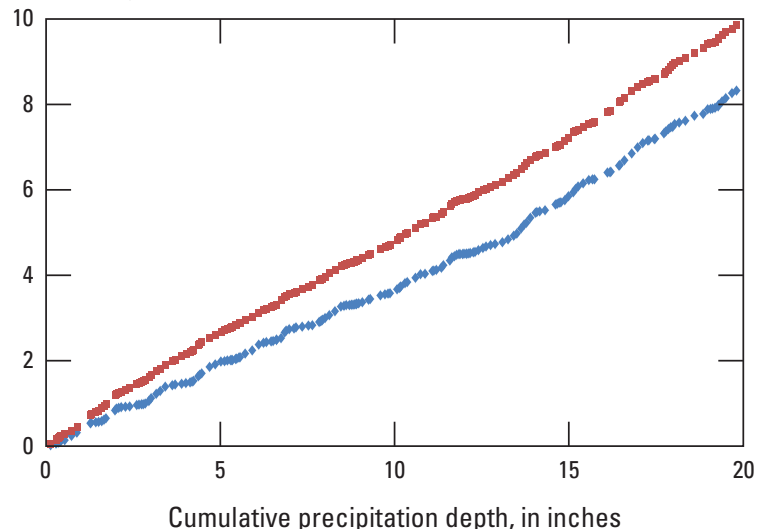

EXPLANATION

- Observed flow

Simulated total runoff (SIMO)

Figure 13. Double-mass curves of observed streamflow and simulated runoff volumes for the nine study watersheds using calibrated parameter set obtained from the HSPEXP Tinley Creek watershed model for water years 1996 to 2011. 

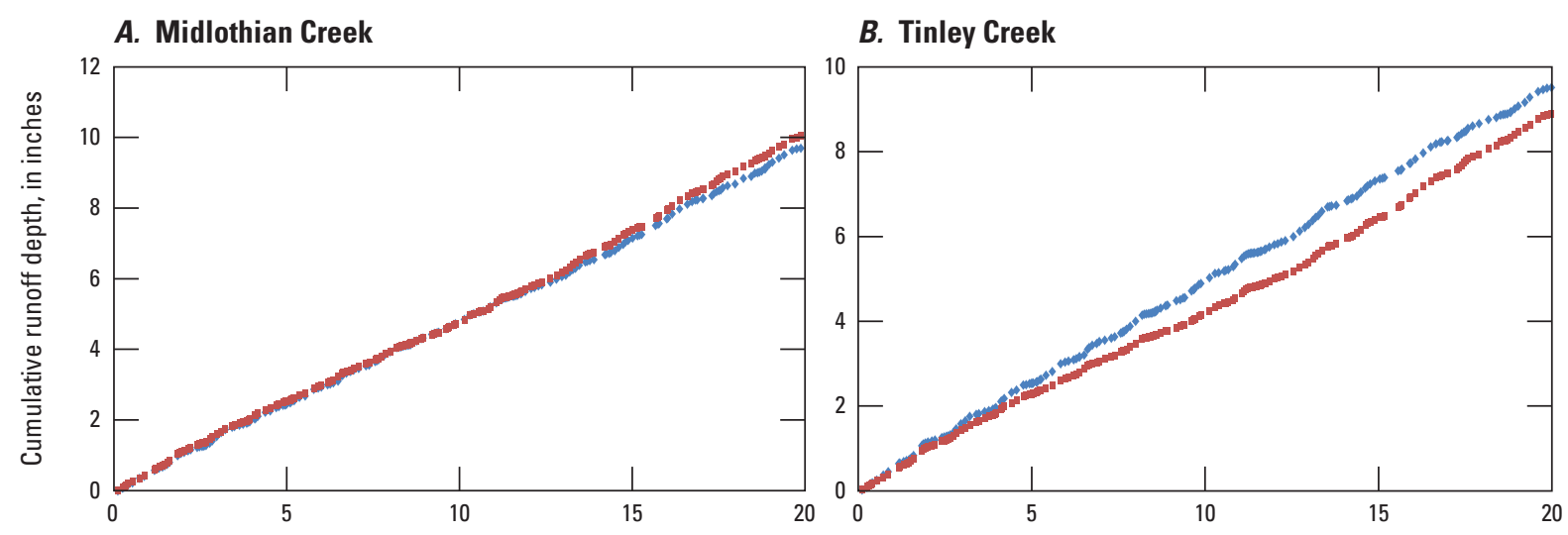

\section{Flag Creek}
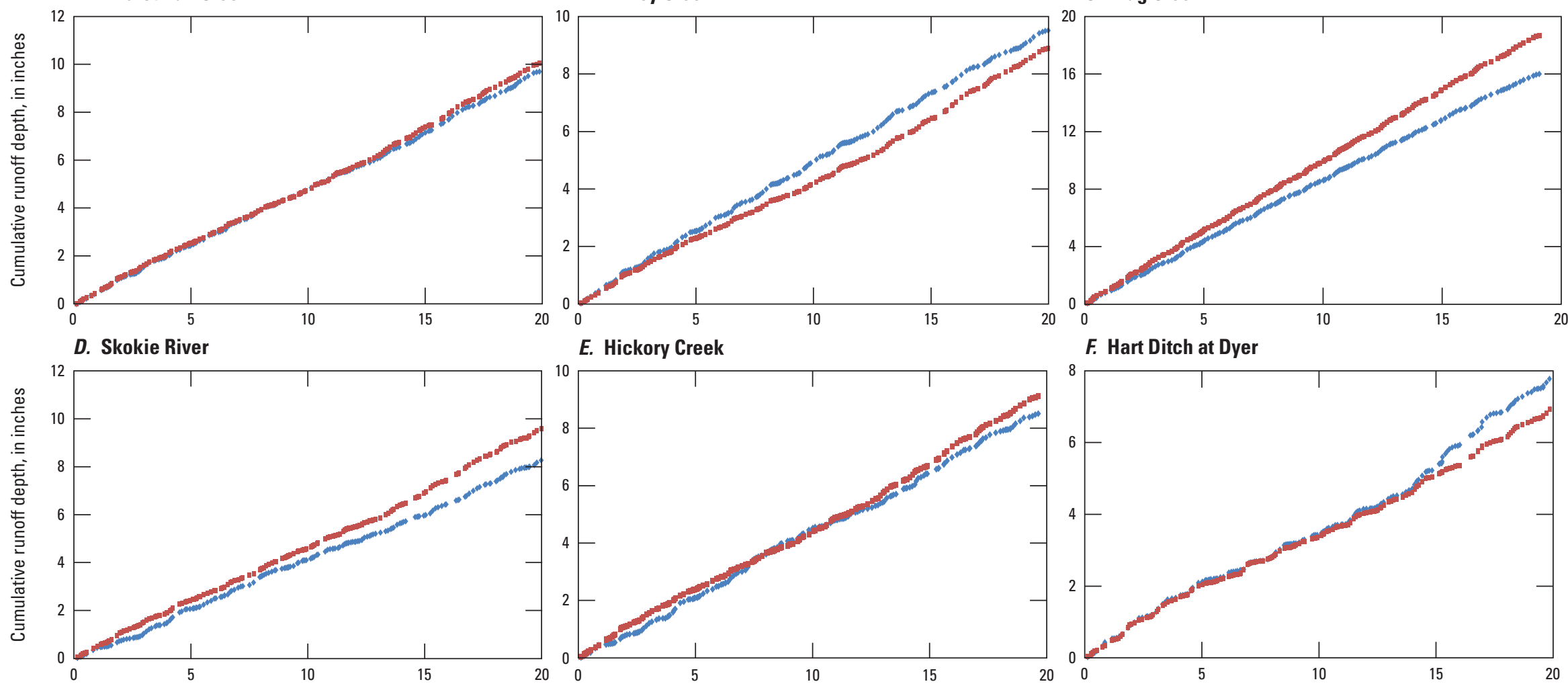

E. Hickory Creek

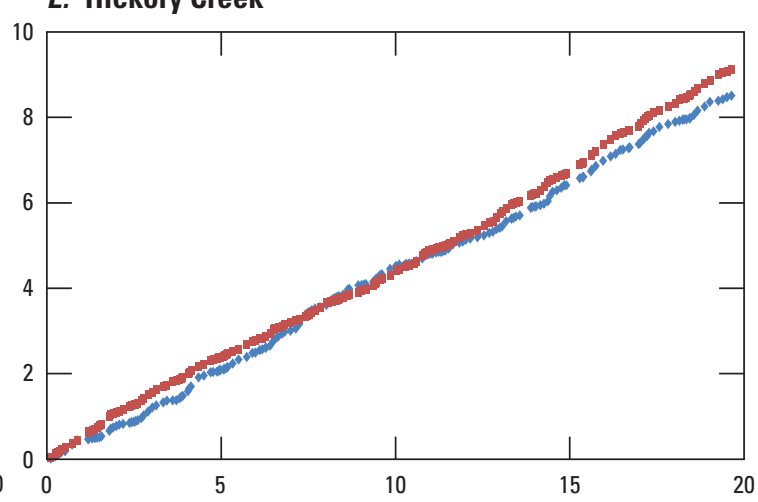

H. Butterfield Creek
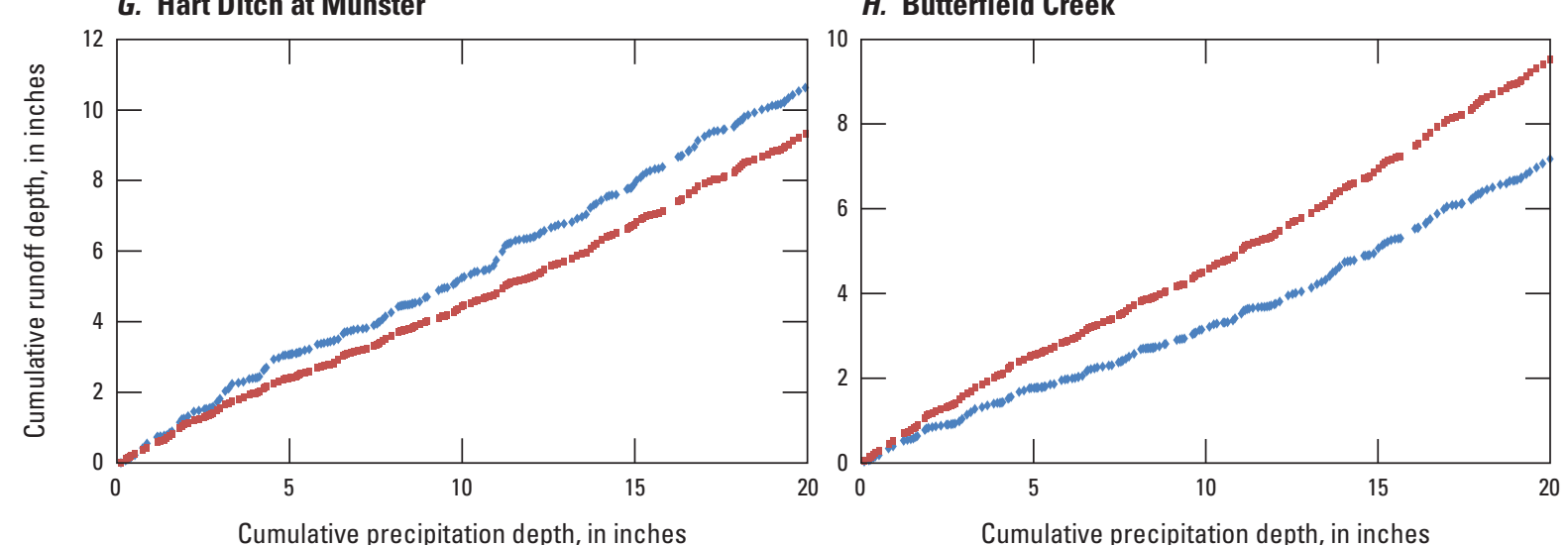

Cumulative precipitation depth, in inches

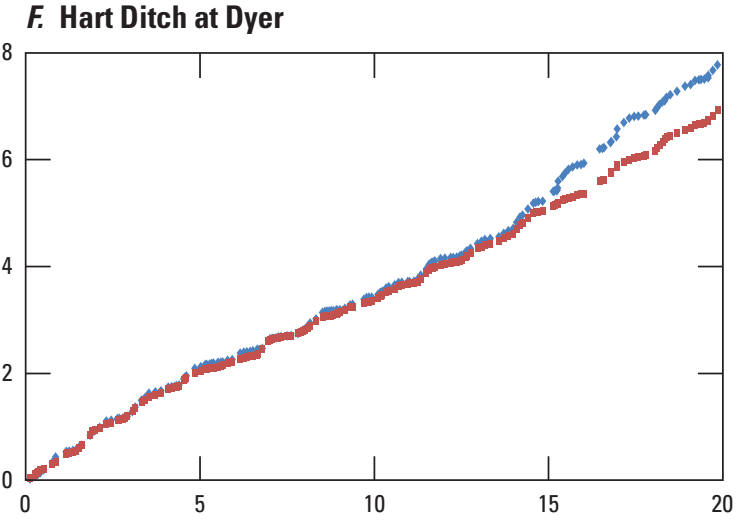

\section{l. Long Run}

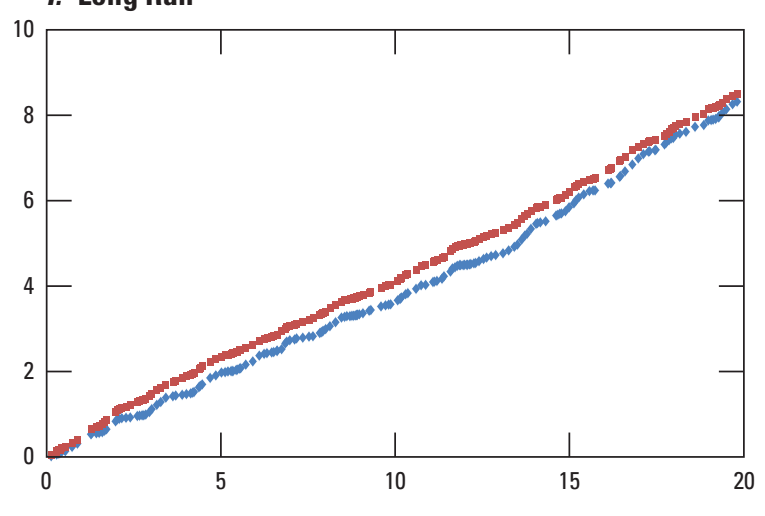

Cumulative precipitation depth, in inches

EXPLANATION

Figure 14. Double-mass curves of observed streamflow and simulated runoff volumes for the nine study watersheds using calibrated

- Observed flow

parameter set obtained from the HSPEXP Long Run watershed model for water years 1996 to 2011.

- Simulated total runoff (SIMO) 
A. Midlothian Creek

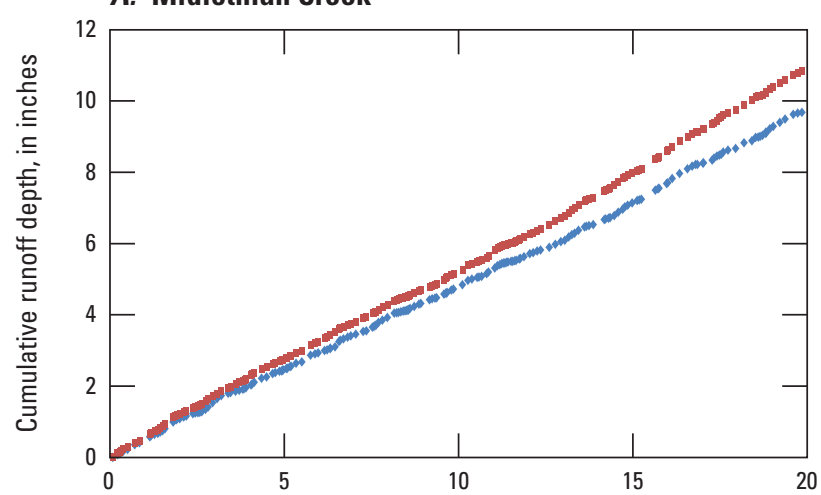

D. Skokie River

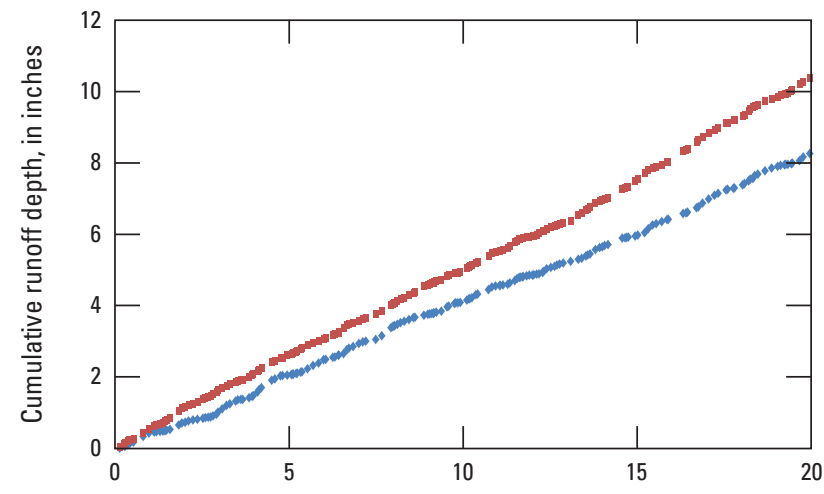

G. Hart Ditch at Munster

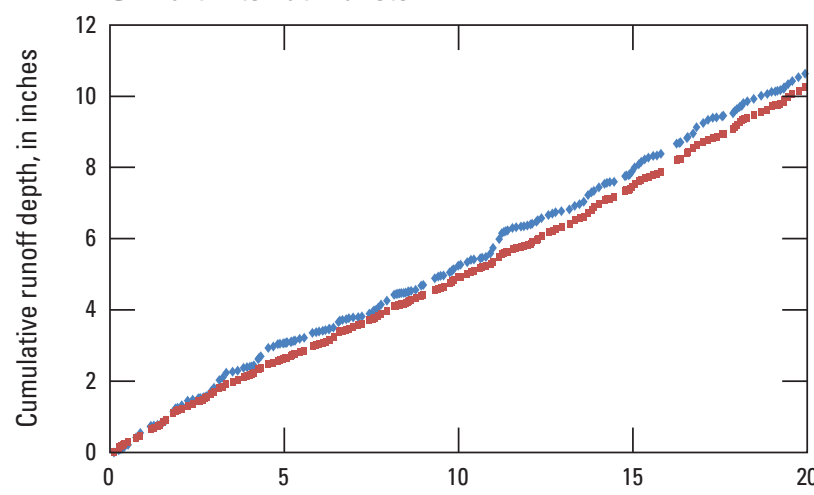

Cumulative precipitation depth, in inches
B. Tinley Creek

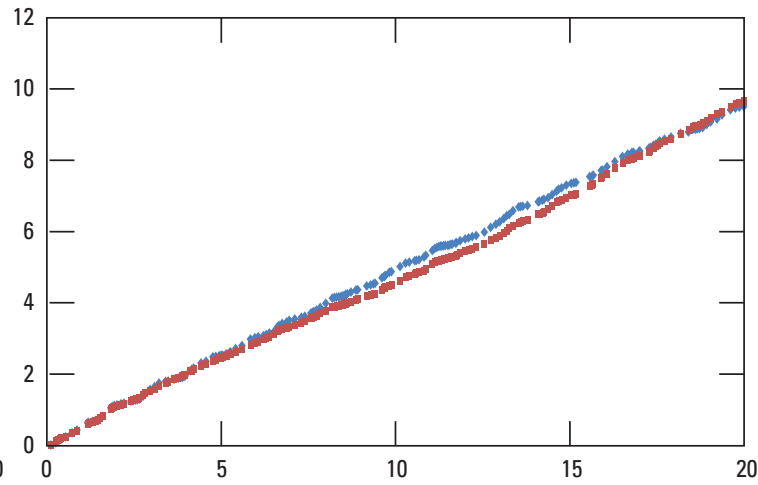

E. Hickory Creek

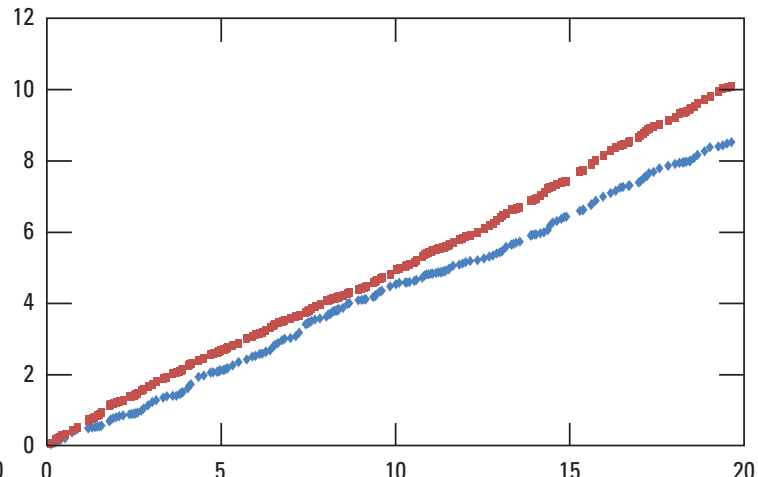

H. Butterfield Creek

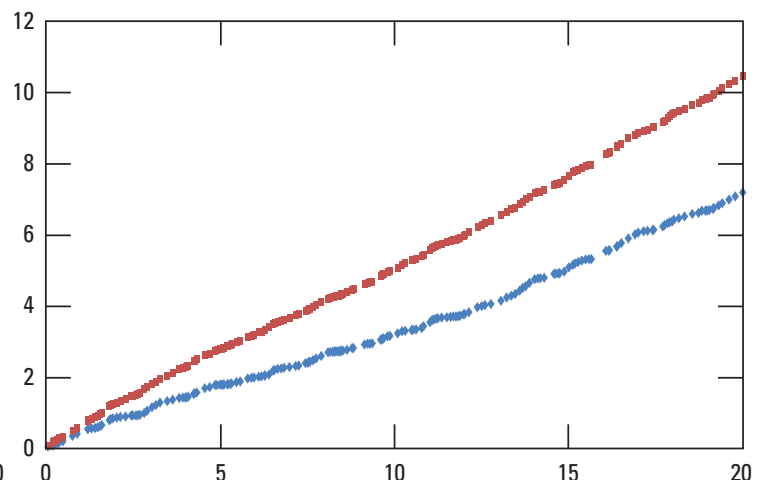

Cumulative precipitation depth, in inches
C. Flag Creek

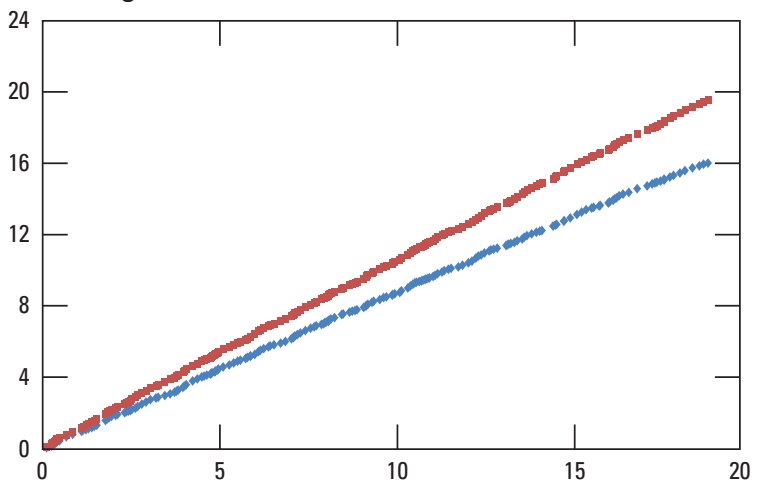

F. Hart Ditch at Dyer

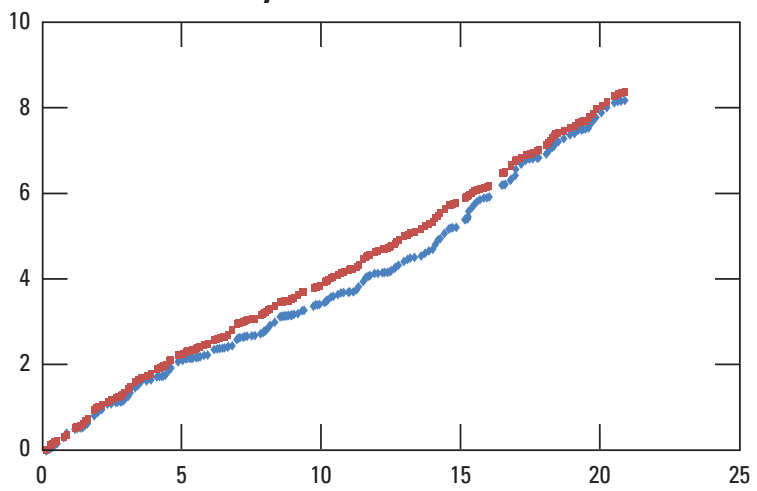

I. Long Run

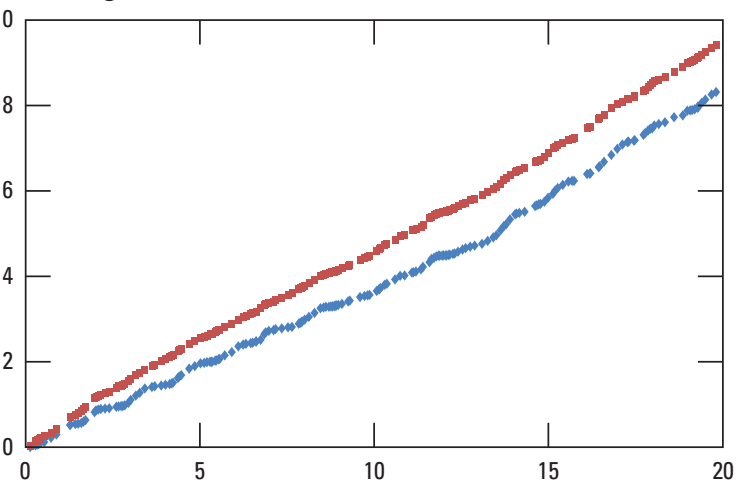

Cumulative precipitation depth, in inches

EXPLANATION

- Observed flow

- Simulated total runoff (SIMO)

Figure 15. Double-mass curves of observed streamflow and simulated runoff volumes for the nine study watersheds using calibrated parameter set obtained from the PEST Tinley Creek watershed model for water years 1996 to 2011. 


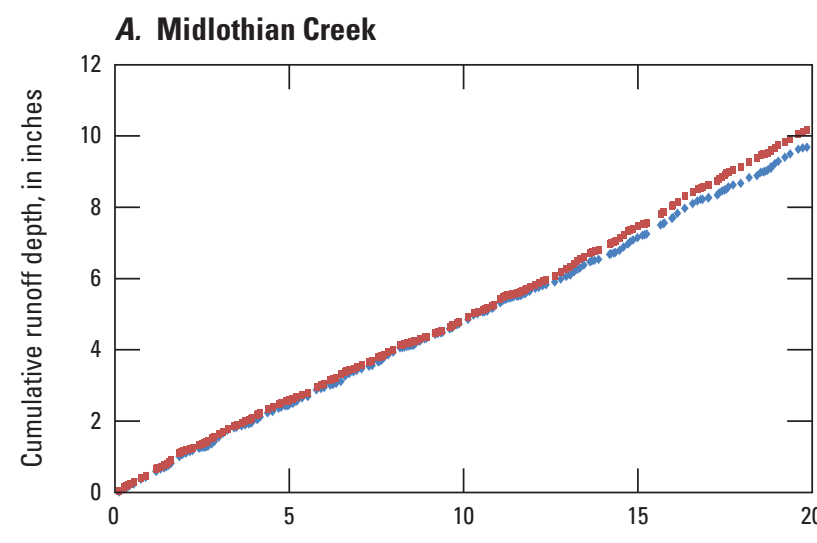

\section{B. Tinley Creek}

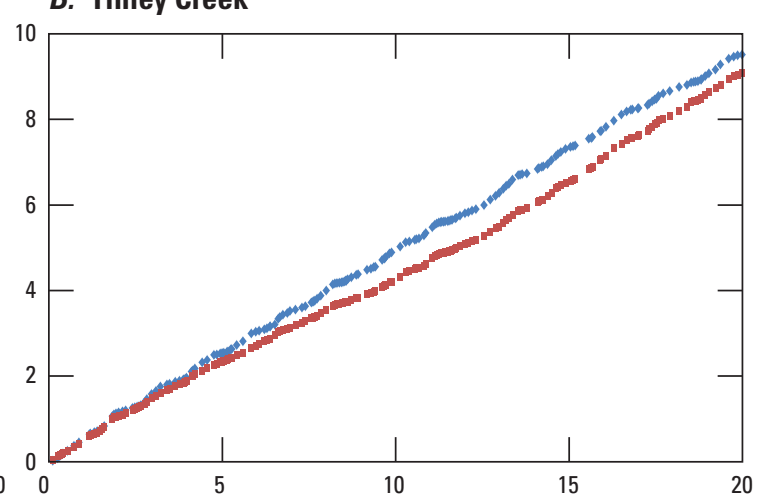

D. Skokie River
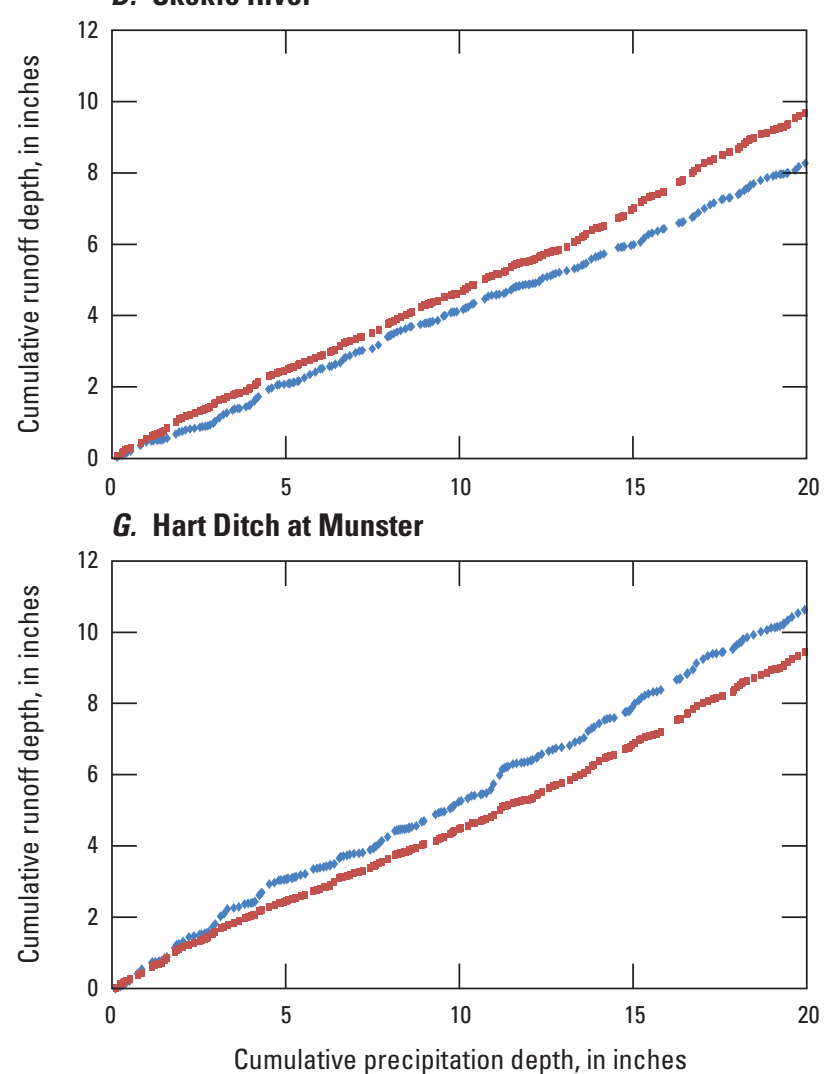

Cumulative precipitation depth, in inches

\section{E. Hickory Creek}

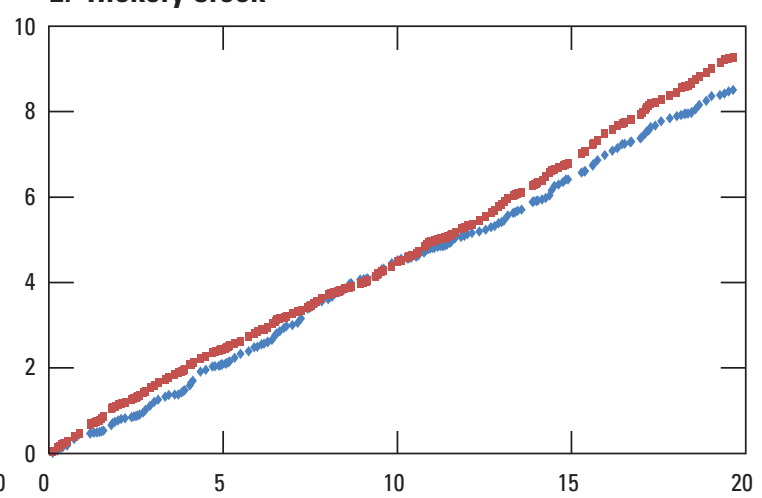

H. Butterfield Creek

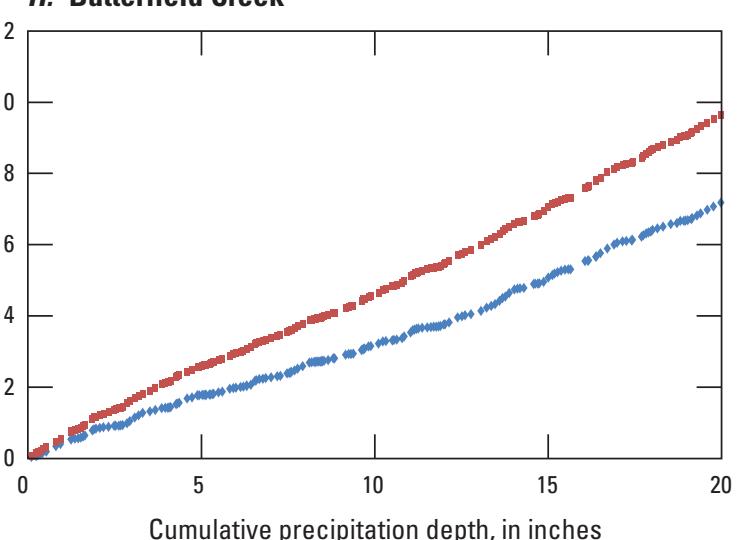

Cumulative precipitation depth, in inches

\section{Flag Creek}

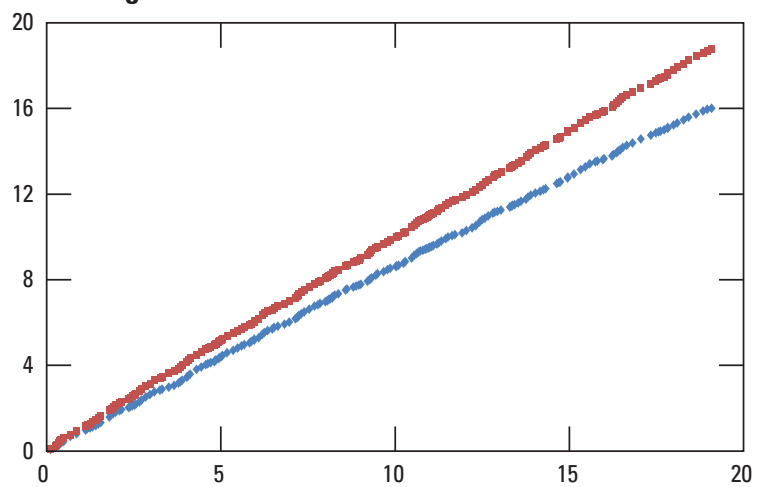

F. Hart Ditch at Dyer

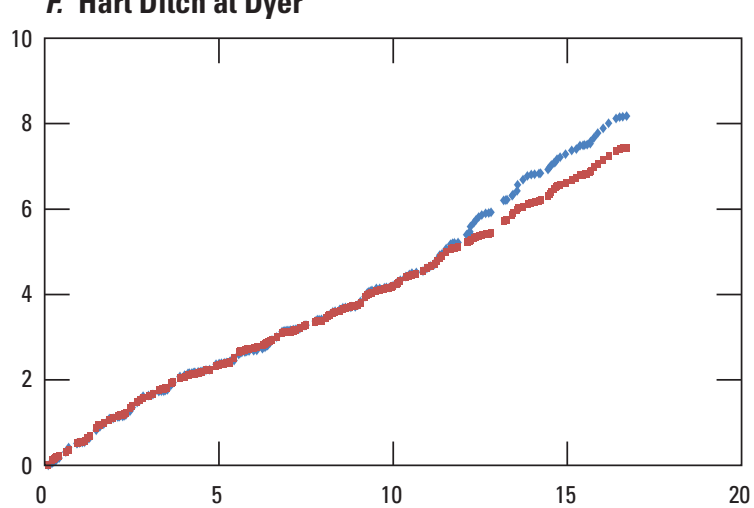

I. Long Run

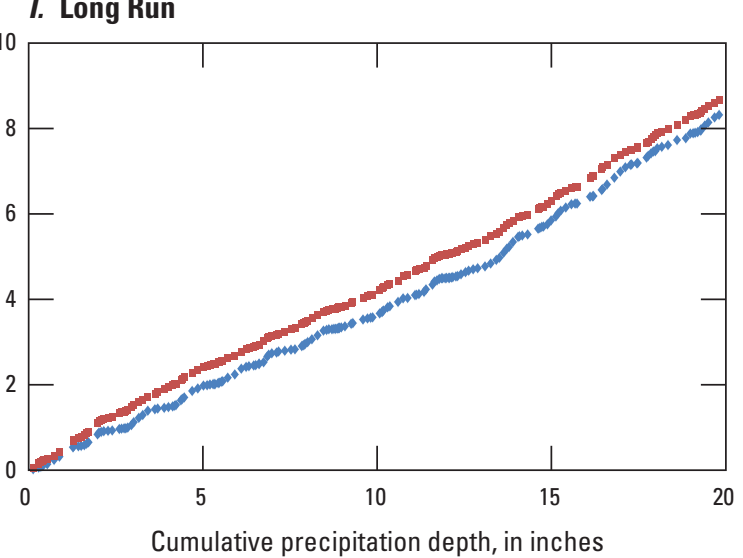

Figure 16. Double-mass curves of observed streamflow and simulated runoff volumes for the nine study watersheds using

EXPLANATION

calibrated parameter set obtained from the PEST Long Run watershed model for water years 1996 to 2011.

- Observed flow

- Simulated total runoff (SIMO) 


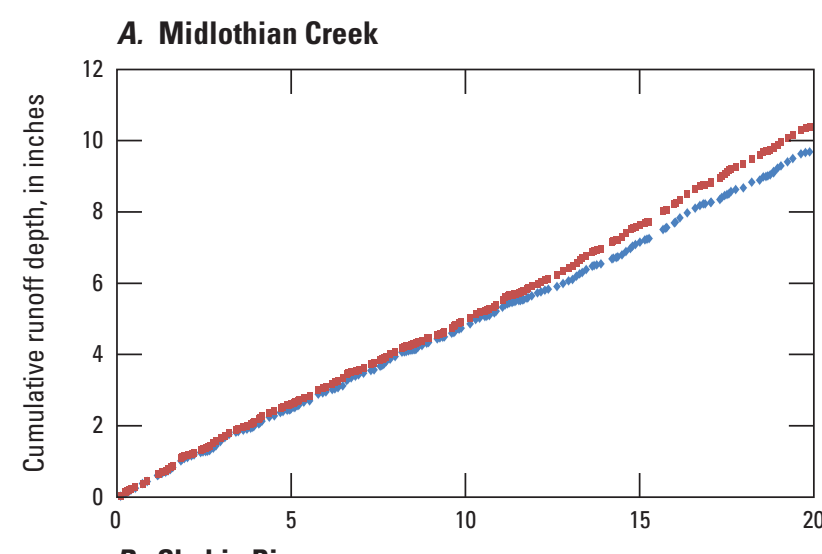

\section{B. Tinley Creek}

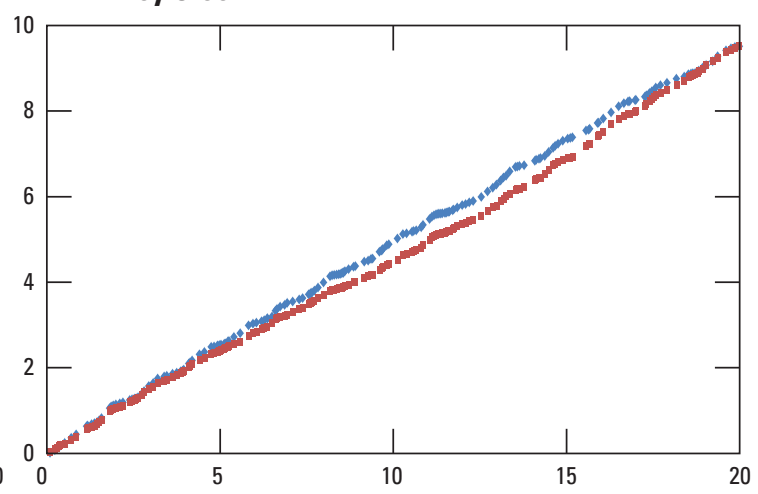

E. Hickory Creek

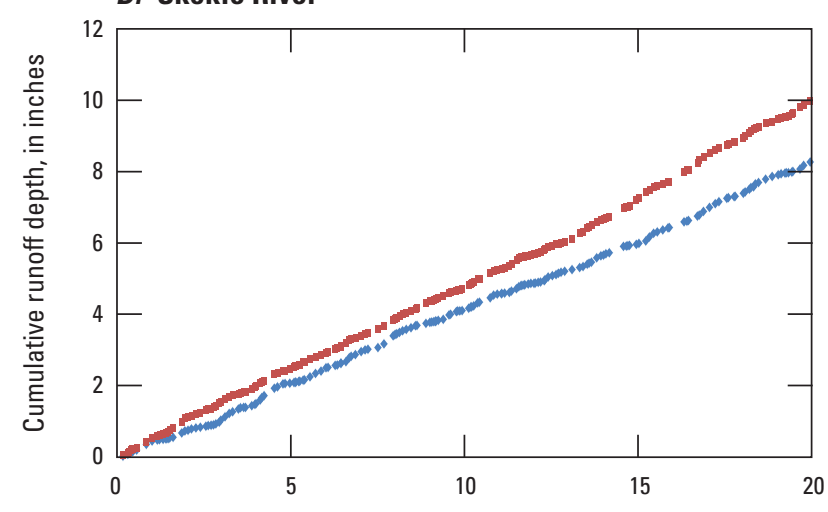

G. Hart Ditch at Munster

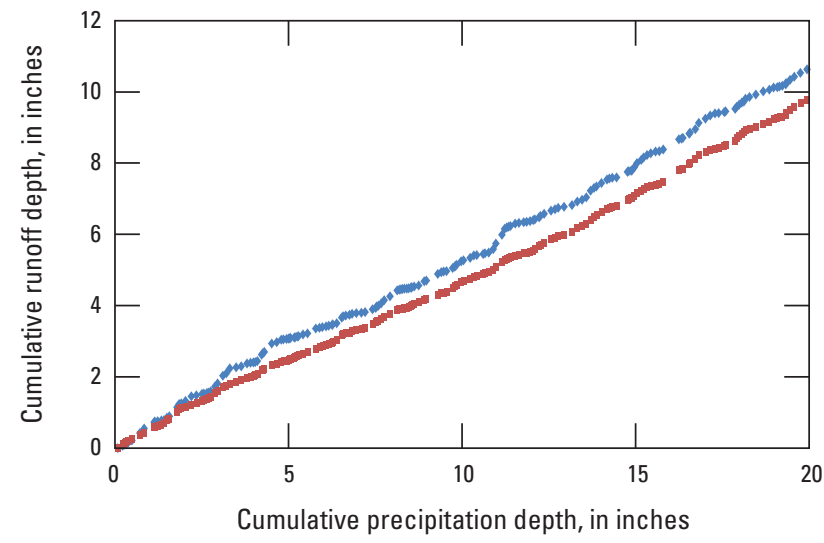

0

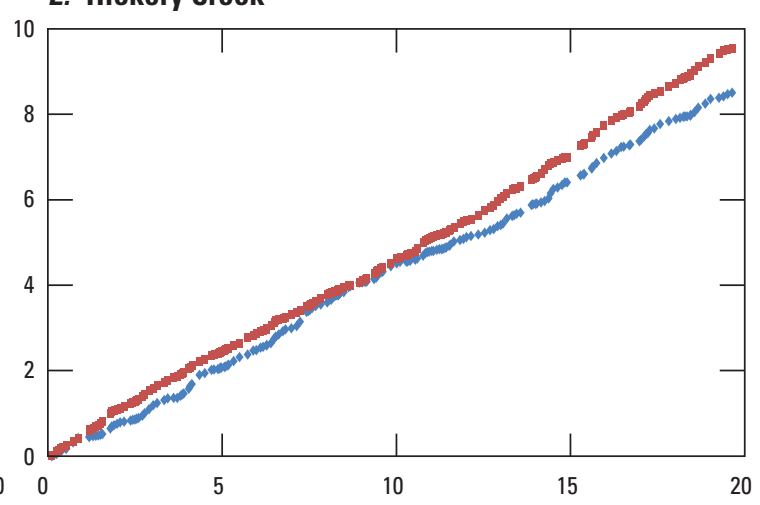

H. Butterfield Creek

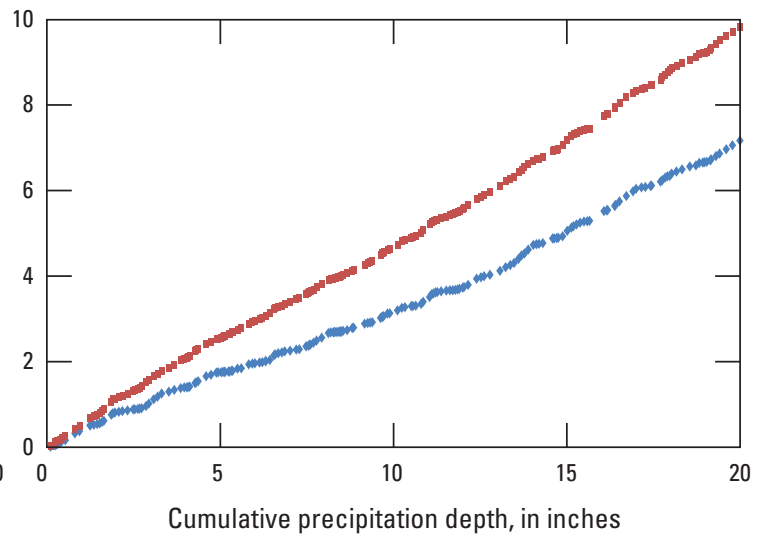

Cumulative precipitation depth, in inches

\section{Flag Creek}

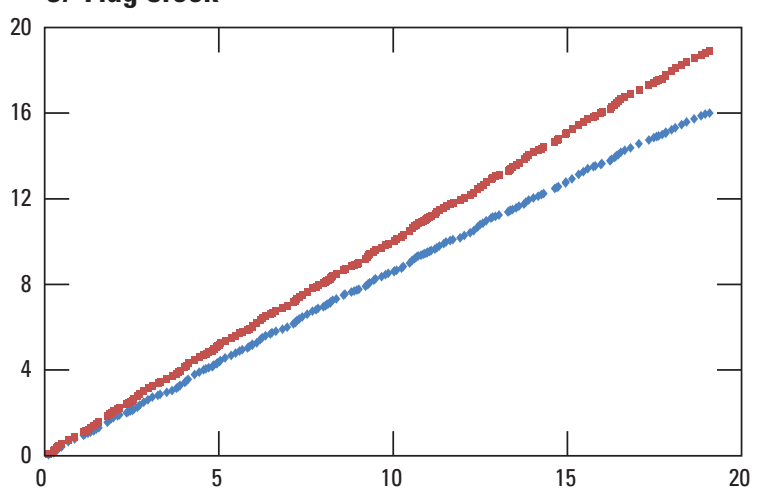

F. Hart Ditch at Dyer

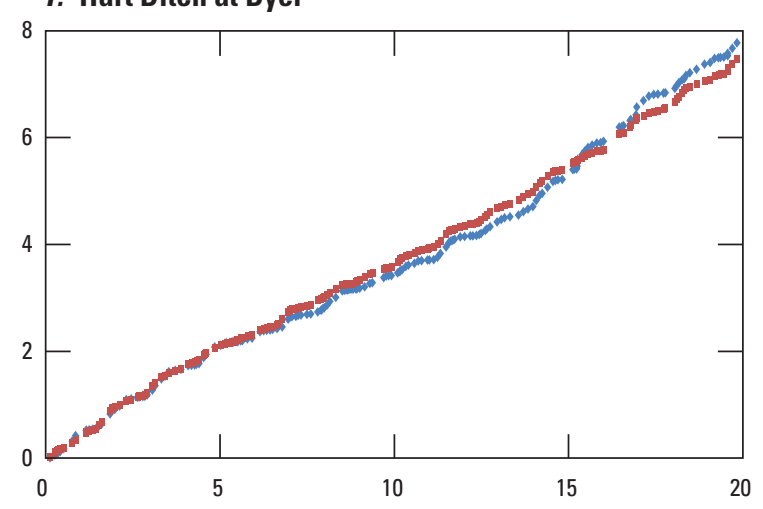

I. Long Run

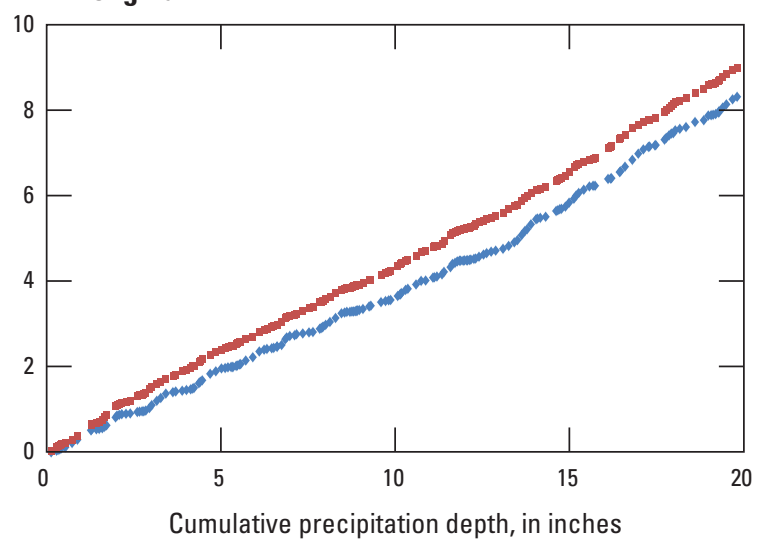

EXPLANATION

- Observed flow

- Simulated total runoff (SIMO) 


\section{Lake Michigan Diversion Accounting Land Cover Change Estimation}

Another criterion used to evaluate the regional performance of the parameter sets was whether a parameter set could break through the "watershed response group" boundaries. Earlier in the "Case for Recalibration" section, the "watershed response group" concept that subgroups of the nine study watersheds responded alike to certain parameter sets was discussed. Improved parameters obtained from the single watershed model did not indicate such breakthrough. For example, the parameter set obtained from the HSPEXP Tinley Creek model generated better $\mathrm{S} / \mathrm{R}$ ratios, quantitative statistics, and DMC's than those generated using the 2008 parameter set for Tinley Creek and Hart Ditch at Munster; however, improvements in these criteria in other watersheds were not as obvious. Conversely, the parameter set obtained from the PEST two-watershed model generated "very good" and "good" results in multiple watersheds that cross the boundary of watershed response groups. As a final check, the quantitative statistics pertaining to the PEST two-watershed model was compared to those of the North Branch parameter set (the best parameter set among the existing parameter sets), for the study period. As shown in table 21, the PEST two-watershed model parameter set resulted in a "very good" rating in PBIAS in five watersheds and the North Branch parameter set has the "very good" rating in three watersheds. But the performance in NSE and RSR by the PEST two-watershed model is not as good as that by the North Branch parameter set. Possible causes of the less ideal performance in NSE and RSR may come from the observation groups used to form the objective function or the approach, that parameters have the same values across watersheds, used in the present PEST two-watershed model. The candidate watersheds selected for use in the simultaneous calibration can also be an important factor for the performance of the resulting parameter values. These factors are not examined further in this study.

The parameter set obtained from the PEST two-watershed model was selected to represent the regional parameter set for the nine watersheds. The grassland and forestland values of these parameters and how they were obtained are listed in table 22 . Note that unless specifically specified, the bounds and sources used were those "possible ranges" specified in BASINS Technical Note No. 6 (U.S. Environmental Protection Agency, 2000). The FOREST parameters affect the HSPF snowmelt process. They remain unchanged in this analysis because SNOW parameters were not included in the calibration. Allowing some adjustable parameters to vary among the watersheds selected in the simultaneous multiple watershed model calibration can help gain insight for the parameter transferability topic. The adjustable parameters that should vary or not vary across watersheds depend on individual watershed characteristics and regional physical settings. Parameter sets like the North Branch or Hickory Creek that performed well in multiple watersheds during the evaluation analysis can be good candidates to include in the multiple-watershed model for regional parameter development.

Table 21. Quantitative statistics of PBIAS, NSE, RSR for the study periods, water years 1996 to 2011, for the North Branch parameter set and PEST two-watershed parameter set.

[PBIAS, percent bias; NSE, Nash-Sutcliffe efficiency; RSR, root-mean-square error to the standard deviation of measured data, Moriasi and others (2007); PEST, model-independent parameter estimation and uncertainty analysis program. Results in the "very good" category are shown in bold and those in the "unsatisfactory" category are shown in gray-shaded cells.]

\begin{tabular}{|c|c|c|c|c|c|c|c|c|c|}
\hline \multirow[b]{2}{*}{ Statistic } & \multicolumn{9}{|c|}{ Watershed } \\
\hline & $\begin{array}{c}\text { Midlothian } \\
\text { Creek } \\
\text { (percent) }\end{array}$ & $\begin{array}{c}\text { Tinley Creek } \\
\text { (percent) }\end{array}$ & $\begin{array}{c}\text { Flag Creek } \\
\text { (percent) }\end{array}$ & $\begin{array}{c}\text { Skokie River } \\
\text { (percent) }\end{array}$ & $\begin{array}{c}\text { Hickory } \\
\text { Creek } \\
\text { (percent) }\end{array}$ & $\begin{array}{l}\text { Hart Ditch } \\
\text { at Dyer } \\
\text { (percent) }\end{array}$ & $\begin{array}{l}\text { Hart Ditch } \\
\text { at Munster } \\
\text { (percent) }\end{array}$ & $\begin{array}{c}\text { Butterfield } \\
\text { Creek } \\
\text { (percent) }\end{array}$ & $\begin{array}{l}\text { Long Run } \\
\text { (percent) }\end{array}$ \\
\hline & \multicolumn{9}{|c|}{ North Branch parameter set } \\
\hline PBIAS & 0.00 & -0.14 & 0.16 & 0.13 & 0.05 & -0.20 & -0.17 & 0.29 & -0.04 \\
\hline RSR & \multicolumn{9}{|c|}{ PEST two-watershed parameter set } \\
\hline PBIAS & 0.07 & 0.00 & 0.18 & 0.22 & 0.15 & -0.04 & -0.07 & 0.37 & 0.08 \\
\hline NSE & 0.84 & 0.79 & 0.73 & 0.44 & 0.76 & 0.72 & 0.71 & 0.69 & 0.77 \\
\hline RSR & 0.40 & 0.46 & 0.52 & 0.75 & 0.49 & 0.53 & 0.54 & 0.55 & 0.48 \\
\hline
\end{tabular}


Table 22. Calibrated parameter values of grassland and forestland for the nine study watersheds with description of the sources for estimating the parameter values.

[LMDA, Lake Michigan Diversion Accounting; in/hr, inches per hour; ft/ft, foot per foot; 1/in, inverse of an inch; ET, evapotranspiration; \%, percent; NLCD, National Land Cover Database]

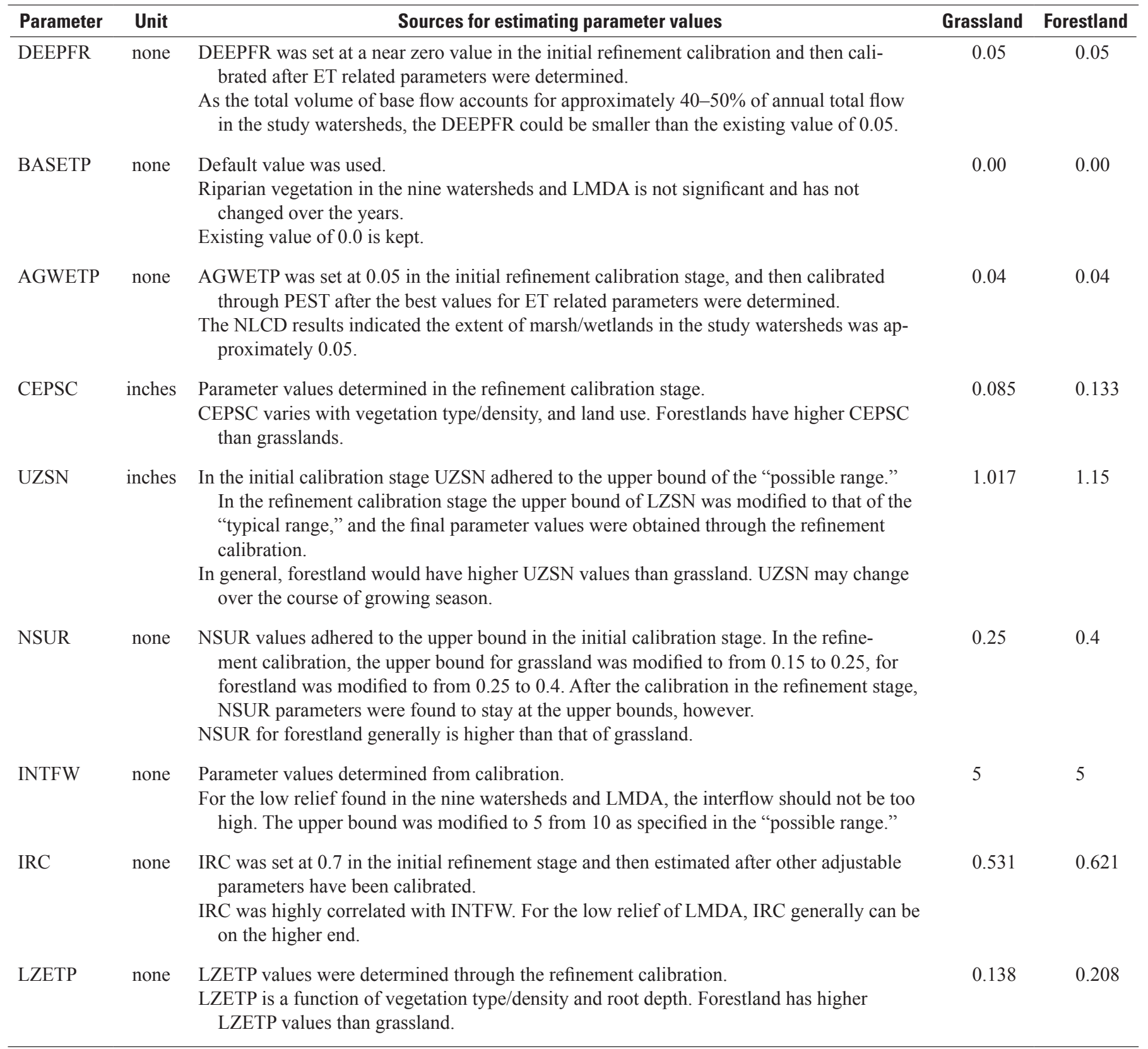




\section{Lake Michigan Diversion Accounting Land Cover Change Estimation}

\section{Summary}

In this study, the accuracy of six existing rainfall-runoff parameter sets for the Hydrological Simulation Program-FORTRAN (HSPF) were evaluated by using nine gaged watersheds in or adjacent to the diverted Lake Michigan watershed in northeast Illinois and northwest Indiana. The diverted Lake Michigan watershed is a 673-square-mile watershed that is comprised of the Chicago River and Calumet River watersheds. Flows of the two rivers originally drained into Lake Michigan now are diverted to the Mississippi River watershed via three canals constructed in the Chicago area in the early twentieth century. The U.S. Army Corps of Engineers, Chicago District has applied the HSPF to estimate the runoff from the ungaged portion, which is about 393 square miles, of the diverted Lake Michigan watershed. All HSPF watershed models in the system use the same parameter set to simulate their runoff; therefore, assessing and documenting the accuracy of this "regional parameter set" is an important element of the Lake Michigan Diversion Accounting (LMDA) system. The nine gaged watersheds comprised Flag Creek near Willow Spring, IL, Skokie River near Highland Park, IL, Butterfield Creek near Flossmoor, IL, Midlothian Creek at Oak Park, IL, Tinley Creek near Palos Park, IL, Long Run near Lemont, IL, Hickory Creek at Joliet, IL, Hart Ditch at Dyer, IN, and Hart Ditch at Munster, IN. Nine regional parameter sets have been developed and used in the past or currently are in use by the LMDA system. In this study, the HSPF models for the nine watersheds were established using the three land-cover types (grass, forest, and hydraulically connected imperviousness) that were determined using the 2006 National Land Cover Database, and driven by the latest meteorological and precipitation data consistent with the current (2014) LMDA system modeling framework. Each of the six parameter sets, comprising the North Branch, Hickory Creek, NIPC, 1999, CTE, and 2008, was applied to the nine watershed models to simulate runoff from water years 1996 to 2011.

The goal of the parameter set is to focus on the accuracy of modeled runoff volumes for water budget predictions, and a better parameter set is the one that can attain a better regional performance, that is, to have "very good" rating according to the criteria used in more watersheds. The evaluation criteria used included: on annual basis, the simulated runoff volume to recorded streamflow volume $(\mathrm{S} / \mathrm{R})$ ratio; on monthly time interval, the goodness-of-fit statistics percent of bias (PBIAS), Nash-Sutcliffe efficiency (NSE), and root mean square error to the standard deviation of measured data (RSR), and visual fit of simulated and observed double mass curve (DMC). Before evaluating the six existing parameter sets, an analysis of input data excluded possible errors in measured data and inaccuracy caused by effects from urban development in the nine watersheds; in particular it was determined that it is reasonable to use one set of land-cover descriptions in each watershed model for the 16 years of simulation. The following conclusions are drawn from the parameter evaluation.
1. The North Branch and Hickory Creek parameter sets that belong to the original calibration group attained an overall "satisfactory" rating in the simulated runoff volume based on three performance statistics, but none of the existing parameter sets produced "very good" or "good" results for all nine watersheds in the 16-year study period.

2. Judging from their performance in the nine watersheds, the six evaluated parameter sets were placed into three groups such that each parameter set group had better simulation results for a subgroup of the nine watersheds. The North Branch and Hickory Creek parameter sets comprise one parameter set group, and the runoff volumes of Midlothian Creek, Hickory Creek, and Long Run watersheds were best predicted by the North Branch parameter set. The CTE and 2008 comprise another parameter set group, and the runoff of Tinley Creek and Hart Ditch at Munster watersheds were best predicted by the 2008 parameter set. Lastly, the NIPC and 1999 parameter sets comprise the third parameter set group and the runoff of Skokie and Flag Creek watersheds were best predicted by the 1999 parameter set. Breaking the boundaries of these "watershed response groups" is a criterion for the regional performance evaluation.

3. After excluding the possible errors in input data and land-cover changes, the simulation errors are considered to be parameter related. Through the parameter accuracy evaluation, there is evidence of improvements in accuracy that occurred in different groups of the nine study watersheds by different parameter sets; therefore, it is feasible to recalibrate the parameters to attain a better performing regional parameter set.

Recalibration focused on parameters in the PERLND (pervious land) segment of HSPF, and used both a manual calibration method with the aid of the HSPEXP program (Lumb and others, 1994) and an automatic calibration method with the aid of the model-independent parameter estimation and uncertainty analysis program PEST program. The objective of the parameter recalibration was to develop a regional parameter set that can achieve more accurate runoff volume simulation for the nine study watersheds, and therefore for the ungaged Lake Michigan Diversion Accounting (LMDA) watershed area. The recalibration did not include parameters pertinent to the snow simulation, nor monthly variations for parameters that could have seasonal effects: that is, only annual values of parameters were considered.

The recalibration used Tinley Creek and Long Run as the representative watersheds for testing and developing the regional parameter set. The calibration period was from October 1, 2000, to September 30, 2009, and the validation periods were from WYs 1997 to 2000 and from WYs 2010 to 2011. HSPEXP was applied to calibrate the parameters in each watershed model individually, but PEST was applied to calibrate the parameters in watershed models individually 
and together, that is, a PEST Tinley Creek watershed model, a PEST Long Run watershed model, and a PEST two-watershed model were developed. Because the existing parameter sets may contain information valuable to the automatic calibration pertaining to the upper and lower bounds for adjustable parameters, what parameters can be considered as adjustable, and likely values for parameters relating to watershed characteristics; and because PEST has not been applied to the LMDA system before, the calibrations with PEST were carried out in two stages: the initial calibration and refinement calibration stages. The goal of the initial calibration was to determine the suitable number of adjustable parameters and their bounds for the three PEST watershed models. Besides those determined from the existing parameter sets, parameter bounds from the "typical range" and "possible range" specified in BASINS Technical Note No. 6 were also evaluated in the initial calibration, and the objective function for each PEST model consisted of multiple observation groups including: selected storm hydrographs, daily streamflow, daily quick flows and base flows, monthly, annual, and total runoff volumes, and flow duration curves. All three PEST watershed models started with initial parameter values specified as in the 2008 parameter set. A PEST watershed model calibration was considered completed if reduction in objective function between two consecutive runs reached a minimum and the model run remained stable. The calibration was the one that generated the most accurate predictions in all three PEST watershed models.

The initial PEST calibration results indicated that parameter bounds adapted from the historical parameter sets restricted PEST's ability to search for optimal parameter combinations. From the initial calibration the parameter set selected to move on to the refinement calibration, was the one that produced best matches in the flow duration curve, annual and total runoff volumes. The refinement calibration started with all regular adjustable parameters (17 parameters in grassland and in forestland) with their bounds set according to the "possible range" specified in BASINS Technical Note No. 6.

In the final step, calibrated parameter sets from the two HSPEXP and three PEST watershed models were compared for their accuracy and regional performance as follows.

- Flow statistics of simulated and observed mean and standard deviation of daily streamflows, and fraction of base flow to total flow volumes for the calibration period from WYs 2001 to 2009 were checked. For those computed for the Tinley Creek watershed, the PEST Tinley Creek watershed model performed best, followed by the PEST two-watershed model; for those computed for the Long Run watershed, the HSPEXP Long Run watershed model performed best, followed by the PEST Long Run watershed model and the PEST two-watershed model.
- Goodness-of-fit statistics in the calibration and two verification periods: For the calibration period, the PEST two-watershed and PEST Long Run watershed models performed best followed by HSPEXP Long Run model. The performance of all parameter sets declined in the two verification periods. For verification period one (WYs 1997 to 2000), the PEST two-watershed model performed better than the PEST Long Run model, followed by the HSPEXP Long Run model. For verification period two (WYs 2010 to 2011), the PEST two-watershed model and PEST Long Run model performed better than the other models.

- The regional performance with the annual and overall $\mathrm{S} / \mathrm{R}$ ratios and DMCs based on results from the entire period of WYs 1996 to 2011: Judging from the number of watersheds that have $\mathrm{S} / \mathrm{R}$ ratios close to unity and the matches of observed and simulated DMC plots, the parameter sets obtained from the PEST two-watershed model and the PEST Long Run model perform better than other parameter sets in regional application.

Another criterion used to evaluate the regional performance of the parameter sets was whether a parameter set could break through the "watershed response group" boundaries discussed in the "Case for Recalibration" section. Parameter values obtained from the PEST two-watershed model had the best overall performance among the recalibrated parameter sets determined; therefore, this parameter set was used to compare with the North Branch parameter set (the best parameter set among the existing parameter sets), using the quantitative statistics for the study period. The results showed that the PEST two-watershed model parameter set resulted in a "very good" rating in PBIAS in five watersheds (across the watershed response groups) and the North Branch parameter set had a "very good" rating in three watersheds. Parameter sets obtained from the PEST two-watershed model calibration produced the best results in this study.

For future studies, it is noted that the performance in NSE and RSR by the PEST two-watershed model is not as good as that by the North Branch parameter set. Possible causes may reside in the types of observation groups used to form the objective function or the assumption that parameters have the same values in the PEST two-watershed models. The candidate watersheds selected for use in the simultaneous calibration can also be an important factor for the performance of the resulting parameter values. These factors were not examined in this study. 


\section{References Cited}

Barber, M.C., Baca, R.M., Bird, S.L., Doherty, J., Exum, L.R., Johnston, J.M., Lassiter, R.R., Rashleigh, B., Cyterski, M.J., Colarullo, S., Loux, N.T., Prieto, L.M., and Wright, C.J., 2002, Regional assessment of fish health-A prototype methodology and case study for the Albemarle-Pamlico River Basin, North Carolina: U.S. Environmental Protection Agency, EPA/600/R-002/067, 178 p.

Bicknell, B.R., Imhoff, J.C., Kittle, J.L., Jr., Jobes, T.H., and Donigian, A.S., Jr., 2000, Hydrological simulation program, FORTRAN (HSPF) - User's manual for release 12: Athens, Ga., U.S. Environmental Protection Agency Research Laboratory [variously paged].

Chaille, B., and Yen, B.C., 2000, Evaluating watershed changes using double-mass analysis - History in the Boneyard Creek stream gage record: University of Illinois at Urbana-Champaign, Department of Civil and Environmental Engineering, Civil Engineering Studies, Hydraulic Engineering Series No. 67, 48 p.

Chow, V.T., 1972, Handbook of applied hydrology: McGraw Hill, New York [variously paged].

Cocca, P., Doherty, J., and Kittle, J.L., Jr., 2003, Hydrologic calibration strategies for the HSPF watershed model Identifying effective objective functions for use with the parameter estimation (PEST) program: World Water \& Environmental Resources Congress 2003: p. 1-10.

Doherty, J., 2005, PEST, model-independent parameter estimation user manual (5th ed.): Watermark Numerical Computing [variously paged], accessed November 2013 at http://www.pesthomepage.org/Home.php.

Doherty, J., 2013, Addendum to the PEST manual: Watermark Numerical Computing, 293 p., accessed November 2013 at http://www.pesthomepage.org/Home.php.

Doherty, J., and Johnston, J.M., 2003, Methodologies for calibration and predictive analysis of a watershed model: Journal of American Water Resources Association, v. 39, p. 251-265.

Donigian, A.S., Imhoff, J.C., Bicknell, B.R., and Kittle, J.L., Jr., 1984, Application guide for Hydrologic Simulation Program-FORTRAN (HSPF): Athens, Ga., U.S. Environmental Protection Agency-600/3-84-065, Environmental Research Laboratory, $177 \mathrm{p}$.

Donigian, A.S., 2002, Watershed model calibration and validation - The HSPF experience: Proceedings of the Water Environment Federation, National TMDL Science and Policy 2002, Water Environment Federation, V 30. p. 44-73
Duncker, J.J., and Melching, C.S., 1998, Regional rainfallrunoff relations for simulation of streamflow for watersheds in Du Page County, Illinois: U.S. Geological Survey WaterResources Investigations Report 98-4035, 80 p.

Fry, J., Xian, G., Jin, S., Dewitz, J., Homer, C., Yang, L., Barnes, C., Herold, N., and Wickham, J., 2011, Completion of the 2006 National Land Cover Database for the conterminous United States: Photogrammetric Engineering and Remote Sensing, v. 77, no. 9, p. 858-864.

Gutierrez-Magness, A.L., 2005, A strategy for calibrating the HSPF model: Ph.D. Thesis, University of Maryland, College Park, 296 p.

Hey, D.L., Dreher, D.L., and Trybus, T.W., 1980, NIPC Chicago Waterways model - Verification/recalibration: Northeastern Illinois Planning Commission, Chicago, Ill.

Hummel, P., Kittle, J.L., Jr., and Gray, M., 2001, WDMUtil, version 2.0 - A tool for managing watershed modeling timeseries data, User's manual: Decatur, Ga., AQUA TERRA Consultants, $157 \mathrm{p}$.

Hydrocomp, 1977a, Des Plaines River hydrologic calibration: Chicago, Ill., Report to the Northeastern Illinois Planning Commission, Area wide Clean Water Planning, Water Quality Evaluation, v. V, no. 2.

Hydrocomp, 1977b, Hickory Creek hydrologic calibration: Chicago, Ill., Report to the Northeastern Illinois Planning Commission, Area wide Clean Water Planning, Water Quality Evaluation, v. VII, no. 2.

Hydrocomp, 1977c, Little Calumet River hydrologic calibration, Chicago, Ill., Report to the Northeastern Illinois Planning Commission, Area wide Clean Water Planning, Water Quality Evaluation, v. 8, no. 2.

Hydrocomp, 1977d, North Branch Chicago River hydrologic calibration: Chicago, Ill., Report to the Northeastern Illinois Planning Commission, Area wide Clean Water Planning, Water Quality Evaluation, v. VI, no. 2.

Hydrocomp, 1979, Chicago sanitary and ship canal hydrologic calibration: Chicago Ill., Report to the Northeastern Illinois Planning Commission, Area wide Clean Water Planning, Water Quality Evaluation.

Kelliber, F.M., Leuning, R., and Schulze, E.D., 1993, Evaporation and canopy characteristics of coniferous forests and grasslands: Oecologia, v. 95, no. 2, p. 153-163.

Kim, S.M., Benham, B.L., Brannan, K.M., and Zeckoski, R.W., 2006, Automatic calibration of hydrologic parameters in HSPF using PEST: American Society of Agricultural and Biological Engineers paper number 062127, Portland, Oregon, $11 \mathrm{p}$. 
Iskra, I., and Droste, R., 2007, Application of non-linear automatic optimization techniques for calibration of HSPF: Water Environment Research, v. 79, no. 6, p. 647-659.

Lumb, A.M., McCammon, R.B., and Kittle, J.L., Jr., 1994, User's manual for an expert system (HSPEXP) for calibration of the Hydrological Simulation Program-FORTRAN: U.S. Geological Survey Water-Resources Investigations Report 94-4168, 102 p.

Marce, R., Ruiz, C.E., and Armengol, J., 2008, Using spatially distributed parameters and multi-response objective functions to solve parameterization of complex applications of semi-distributed hydrological models: Water Resources Research, v. 44, W02436, 18 p.

Moriasi, D.N., Arnold, J.G., Van Liew, M.W., Bingner, R.L., Harmel, R.D., and Veith, T.L., 2007, Model evaluation guidelines for systematic quantification of accuracy in watershed simulation: Transaction of American Society of Agricultural and Biological Engineers, v. 50, no. 3, p. $885-900$.

Natural Resources Conservation Service, 2007, Hydrologic soil groups, chap. 7 of Part 630 Hydrology, National Engineering Handbook: U.S. Department of Agriculture, accessed November, 2013 at http://directives.sc.egov.usda. gov/OpenNonWebContent.aspx? content=17757.wba.

Peppler, Randy A., 1991, Installation and operation of a dense raingage network to improve precipitation measurements for Lake Michigan diversion accounting-Water year 1990: Illinois State Water Survey, 87 p.

Price, T.H., 1996, Application guide for hydrologic modeling in DuPage County using Hydrological Simulation Program - FORTRAN (HSPF) - Model organization and use, data collection and processing, calibration: DuPage County, Ill., Prepared for Stormwater Management Division, Environmental Concerns, 44 p. plus appendices.

Resource Coordination Policy Committee, 1998, Our community and flooding - A report of the status of floodwater management in the Chicago Metropolitan Area: $72 \mathrm{p}$.

RUST Environment and Infrastructure, 1993a, Diversion accounting update for the new 25-Gage Precipitation Network: Prepared for the U.S. Army Corps of Engineers, Chicago District, $5 \mathrm{p}$ with six appendixes.

RUST Environment and Infrastructure, 1993b, Technical Memorandum on HSPF Parameter Assignments Used in the Lake Michigan Diversion Accounting Program, U.S. Army Corps of Engineers - Chicago District: Prepared for the U.S. Army Corps of Engineers, Chicago District, 7 p with one appendix.

Singh, V.P., editor, 1995, Computer models of watershed hydrology; Water Resources Publications, Colorado, USA, $1130 \mathrm{p}$.
U.S. Army Corps of Engineers, Chicago District, 2004, Lake Michigan diversion-Findings of the fifth technical committee for review of diversion flow measurements and accounting procedures: Final Report, $181 \mathrm{p}$.

U.S. Army Corps of Engineers, Chicago District, 2009, Lake Michigan diversion - Findings of the sixth technical committee for review of diversion flow measurements and accounting procedures: Final Report, 198 p.

U.S. Army Corps of Engineers, Chicago District, 2014, Lake Michigan diversion accounting water year 2011 annual report: U.S. Army Corps of Engineers, Chicago District.

U.S. Army Corps of Engineers, Chicago District, 2014, Lake Michigan diversion - Findings of the seventh technical committee for review of diversion flow measurements and accounting procedures: Final Report, $152 \mathrm{p}$.

U.S. Department of Agriculture, Natural Resources Conservation Service, 1994, State soil geographic (STATSGO) data base - Data use information, miscellaneous publication number 1492 (rev. ed.): Fort Worth, Texas, National Soil Survey Center [variously paged].

U.S. Environmental Protection Agency, 2000, EPA BASINS Technical Note No. 6-Estimating hydrology and hydraulic parameters for HSPF: EPA-823-R00-012, 34 p.

Van Liew, M.W., Veith, T.L., Bosch, D.D., and Arnold, J.G., 2007, Suitability of SWAT for the conservation effects assessment project - A comparison on USDA-ARS experimental watersheds: Journal of Hydrologic Engineering, v. 12, no. 2, p. 173-189.

Wang, S., Fu, B.J., Gao, G.Y., Yao, X.L., and Zhou, J., 2012, Soil moisture and evapotranspiration of different land cover types in the Loess Plateau, China: Hydrology and Earth System Sciences, v. 16, p. 2883-2892, accessed May 30, 2013, at http://www.hydrol-earth-syst-sci. net $/ 16 / 2883 / 2012 /$.

Westcott, N.E., 2006, Continued operation of a 25-raingage network for collection, reduction, and analysis of precipitation data for Lake Michigan diversion accounting-Water year 2005: Illinois State Water Survey Contract Report 2006-2, 67 p.

Westcott, N.E., 2013, Continued operation of a 25-raingage network for collection, reduction, and analysis of precipitation data for Lake Michigan diversion accounting - Water year 2012: Illinois State Water Survey Contract Report 2006-2, $67 \mathrm{p}$.

Westenbroek, S.M., Doherty, J., Walker, J.F., Kelson, V.A., Hunt, R.J., and Cera, T.B., 2012, Approaches in highly parameterized inversion-TSPROC, a general time-series processor to assist in model calibration and result summarization: U.S. Geological Survey Techniques and Methods, book 7, chap. C7, 79 p., three appendixes. 
Manuscript approved on April 1, 2015.

Edited by Stephanee Walker of the Rolla Publishing Service Center (PSC). Rolla, Missouri.

Final illustrations and tables by Suzanne Roberts of the Rolla PSC. Rolla, Missouri.

Layout and cover by Rosemary Stenback, USGS, Columbus PSC. Madison, Wisconsin. 



\section{$\frac{\mathbb{2}}{3}$}

